
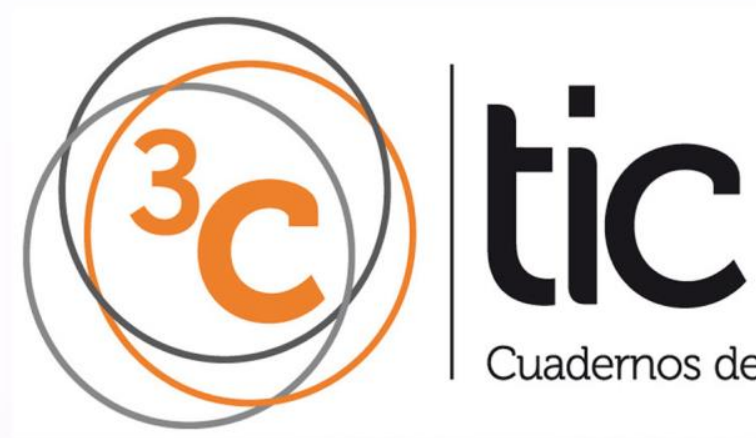

Cuadernos de desarrollo aplicados a las TIC

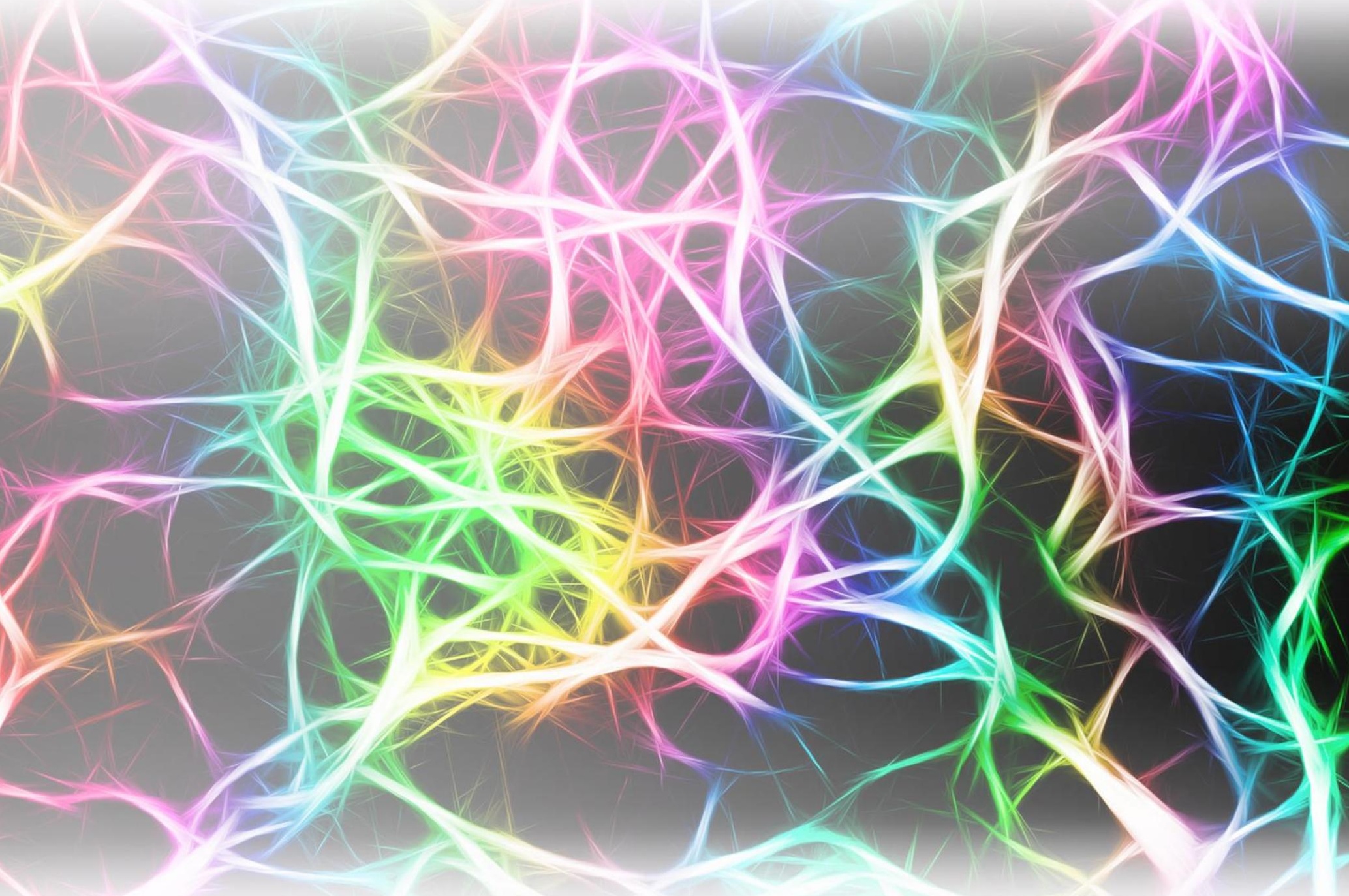

\title{
Edición 21
}

Vol. 6 № 2 (2017)

Junio - septiembre'17

ISSN: $2254-6529$

Publicación trimestral

Depósito legal: A299-2012 Área de Innovación y Desarrollo, S.L 


\section{3ciencias}

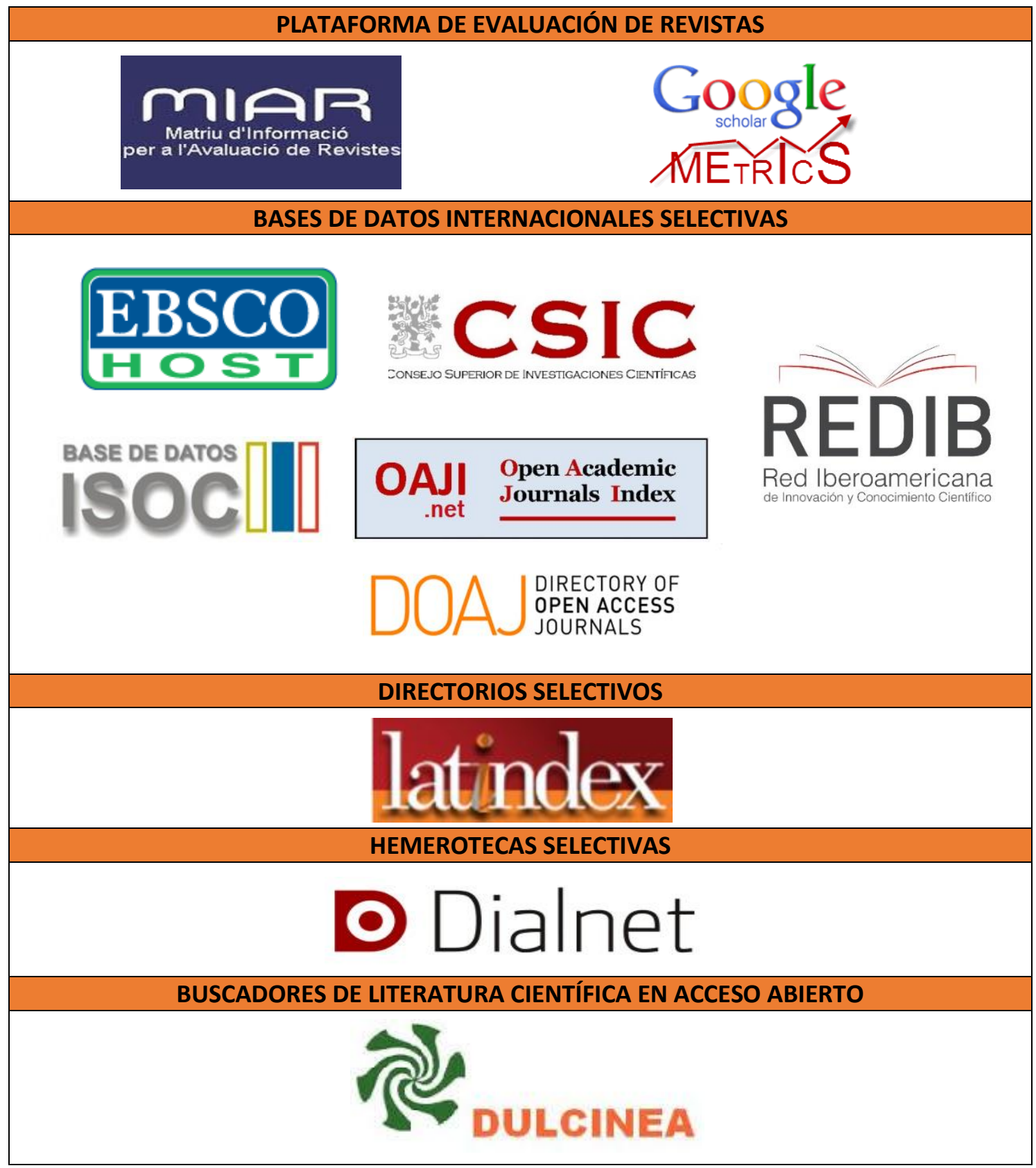




\section{OBJETIVO EDITORIAL}

La Editorial científica 3Ciencias pretende transmitir a la sociedad ideas y proyectos innovadores, plasmados, o bien en artículos originales sometidos a revisión por expertos, o bien en los libros publicados con la más alta calidad científica y técnica.

\section{NUESTRO PÚBLICO}

- Personal investigador.

- Doctorandos.

- Profesores de universidad.

- Oficinas de transferencia de resultados de investigación (OTRI).

- Empresas que desarrollan labor investigadora y quieran publicar alguno de sus estudios.

\section{COBERTURA TEMÁTICA}

La Revista 3 C TIC es una revista de carácter científico-social donde se difunden trabajos originales de investigación que abarcan diferentes temáticas relacionadas con las Tecnologías de la Información y la Comunicación, la docencia, Internet y las telecomunicaciones.

\section{INFORMACIÓN PARA AUTORES}

Toda la información sobre el envío de originales se puede encontrar en el siguiente enlace: http://www.3ciencias.com/normas-de-publicacion/instrucciones-para-el-envio-de-articulos/.

\begin{tabular}{|c|c|c|}
\hline & 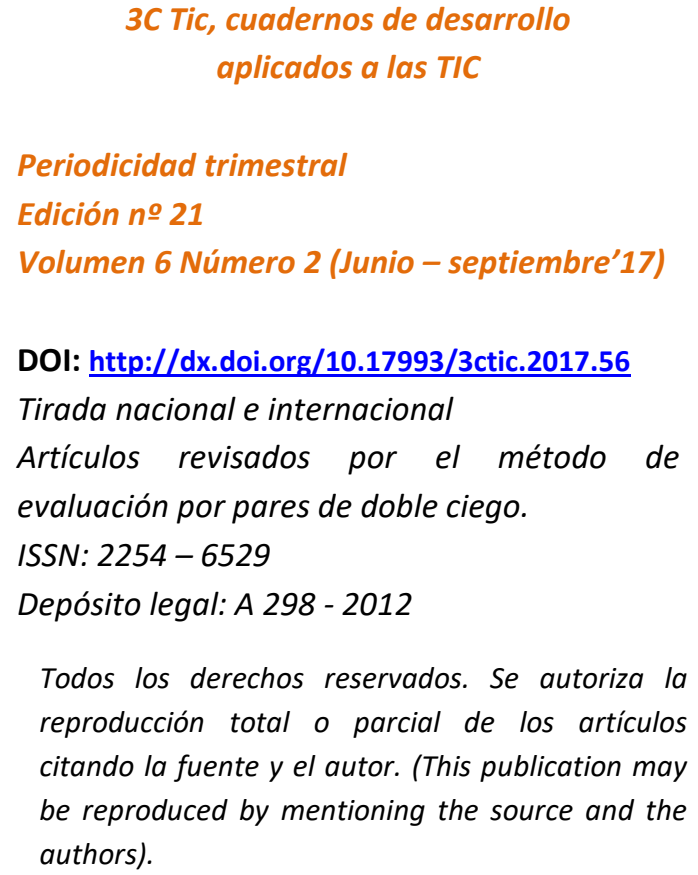 & $\begin{array}{l}\text { Editorial: Área de Innovación y Desarrollo, S.L. } \\
\text { Empresa de transferencia del conocimiento al } \\
\text { sector empresarial. } \\
\text { C/ Els Alzamora, no } 17 \\
\text { Alcoy, Alicante (España) } \\
\text { Tel: } 965030572 \\
\text { E-mail editor: info@3ciencias.com } \\
\text { Copyright @ Área de Innovación y } \\
\text { Desarrollo, S.L. }\end{array}$ \\
\hline
\end{tabular}




\section{PUBLISHING GOAL}

3Ciencias wants to transmit to society innovative projects and ideas. This goal is reached thought the publication of original articles which are subdue to peer review or thorough the publication of scientific books.

\section{OUR PUBLIC}

- Research staff.

- PhD students.

- Professors.

- Research Results Transfer Office.

- Companies that develop research and want to publish some of their works.

\section{TEMATIC COVERAGE}

3C TIC journal is a scientific-social journal, where original works are disseminated. These works cover different themes related to Information and Communication Technologies, Learning, Internet and Telecommunications.

\section{INFORMATION TO AUTHORS}

All information about sending originals can be found at the following link: http://www.3ciencias.com/normas-de-publicacion/instrucciones-para-el-envio-de-articulos/ 


\section{SUMARIO}

ALGORITMO DE BOOTH EN OPERACIONES DE EXPONENCIACIÓN MODULAR 1 BOOTH ALGORITHM IN MODULAR EXPONENTIATION OPERATIONS

Jesús Ayuso Pérez

DISEÑO E IMPLEMENTACIÓN DE UN SISTEMA DE INFORMACIÓN PARA EL SEGUIMIENTO DE PROYECTOS DE SENTENCIAS EN EL TRIBUNAL DE LO CONTENCIOSO ADMINISTRATIVO...................................................................... 13 DESIGN AND IMPLEMENTATION OF AN INFORMATION SYSTEM FOR THE FOLLOW-UP OF PROJECTS OF SENTENCES IN THE COURT OF ADMINISTRATIVE CONTENT

Juan Manuel Fernández Álvarez, Antonio Moreno Jauregui, Juan García Virgen y Reyes Benavides Delgado

SISTEMA DE GESTIÓN DE LA INFORMACIÓN EN LOS ALMACENES DE LA EMPRESA CONSTRUCTORA DE OBRAS DE ARQUITECTURA E INDUSTRIALES \#4 DE GRANMA 28 MANAGEMENT INFORMATION SYSTEM IN THE WAREHOUSES OF THE CONSTRUCTOR COMPANY OF ARCHITECTURE WORKS AND INDUSTRIAL \#4 OF GRANMA

Ángel Enrique Figueredo León, Agustín Alejandro Ortiz Díaz y Elena Martínez Pérez

SISTEMA INFORMÁTICO PARA EL DISEÑO Y GESTIÓN DE RECORRIDOS VIRTUALES PARA TOURDROID

THE COMPUTATIONAL THINKING ABOUT PROMOTING DEVELOPMENT OF SKILLS RELATED CREATIVE SOLVING PROBLEMS

Viana de la Cruz Leyva, Yoel Adrián Ortiz Pacheco y Noel Ernesto Enamorado Selema

LIENZO DE MODELO DE NEGOCIOS COMO HERRAMIENTA DE EMPRENDIMIENTO PARA PERSONAS CON CAPACIDADES ESPECIALES. UN ENFOQUE DESDE LA TECNOLOGÍA..

BUSINESS MODEL CANVAS AS A TOOL OF ENTREPRENEURS FOR DISABLED PEOPLE. AN APPROACH FROM TECHNOLOGY

Enrique Xavier Garcés, Galo Mauricio López y Verónica Maribel Pailiacho 



\section{ALGORITMO DE BOOTH EN OPERACIONES DE EXPONENCIACIÓN MODULAR}

\section{BOOTH ALGORITHM IN MODULAR EXPONENTIATION OPERATIONS}

Jesús Ayuso Pérez ${ }^{1}$

1. Compositor musical y desarrollador. Licenciado en Ingeniería Informática por la Universidad Carlos III de Madrid (UC3M). E-Mail: ayusoperez@terra.com

\section{Citación sugerida:}

Ayuso Pérez, J. (2017). Algoritmo de Booth en operaciones de exponenciación modular. 3C TIC: Cuadernos de desarrollo aplicados a las TIC, 6(2), 1-12. DOI: $<$ http://dx.doi.org/10.17993/3ctic.2016.56.1-12/>. 


\section{RESUMEN}

El algoritmo dado por Andrew Donald Booth en 1950 (Booth, 1951), presenta un comportamiento más natural de cara al cruce de operaciones y sucesiones de las mismas, cuando éstas se encuentran en el mismo estrato algebraico (Ayuso 2015, pp. 113-119). De ahí que el presente documento proponga varios algoritmos de exponenciación entre enteros basados en el concepto ideado por Booth. Mostrando distintas aportaciones para realizar ese cómputo, y sobre todo con la novedad de apoyarse en operaciones que igualmente ya explotan el concepto introducido por Booth, solucionando así el proceso de reducción en un contexto modular. $Y$ jugando con el hecho de advertir que, para lograr el resultado final, se requerirán una gran cantidad de cálculos los cuales explotan estos conceptos.

\section{ABSTRACT}

The algorithm given by Andrew Donald Booth in 1950 (Booth, 1951), presents a more natural behavior to the crossing of operations and successions of the same, when these are in the same algebraic stratum (Ayuso 2015, pp. 113-119). Hence in this paper, we propose several algorithms of exponentiation between integers based on the concept devised by Booth. We will see different contributions to realize this computation, and above all with the novelty of supporting us in operations that equally already exploit the concept introduced by Booth, thus solving the reduction process in a modular context. And playing with the fact of warning that to achieve the final result, will require a lot of calculations which exploit these concepts.

\section{PALABRAS CLAVE}

Booth, Algoritmo, Adición, Exponenciación, Modular.

\section{KEYWORDS}

Booth, Algorithm, Addition, Exponentiation, Modular. 


\section{INTRODUCCIÓN}

El concepto de Booth aplicado dentro de una aritmética modular permite ir reduciendo el resultado a la par que se van calculando las operaciones primitivas (Ayuso 2015, pp. 222229), tales como las de adición o sustracción, de manera que al término de las mismas, obtenemos el resultado ya reducido, ahorrándonos así posteriores cómputos para encuadrar el elemento dentro del módulo en que estamos trabajando. Este tipo de cálculos son muy utilizados en distintos campos y especialmente en el mundo de la Criptografía (Diffie, W., and E. Hellmen 1976, pp. 644-654).

Partiendo de lo anterior, la operación de exponenciación es planteada como una sucesión de multiplicaciones y/o divisiones, entendidas estas últimas, al estar en un contexto modular, como multiplicaciones por el inverso modular, en las que la modularidad vendrá facilitada, por apoyarse en las implementaciones de primitivas modulares referenciadas: multiplicación, inverso, adición, sustracción... (Ayuso 2015/2016, pp.222-229/255-221/28-41) Concretamente, se detallarán los algoritmos usados para la operación de multiplicación modular, ya que serán adaptados un poco, buscando una consonancia perfecta con la operación que se busca construir: la de exponenciación modular. E igualmente, como se adelantaba, al tratar la división como una multiplicación por el inverso modular, también se detallará la implementación utilizada para el cálculo del inverso multiplicativo de un entero.

\section{METODOLOGÍA Y RESULTADOS}

En este apartado, lo primero que se hará será dar la implementación de multiplicación modular sobre la que se basará el presente artículo. Más concretamente, se procede a dar una versión partiendo de las implementaciones que se describen en la referencia bibliográfica titulada: 'Booth algorithm modular arithmetic operations of multiplication' (Ayuso 2015, pp. 255-221).

Se tiene que la multiplicación de dos números, $a$ y $b$, módulo $m$, los 3 de longitud $n$, sería:

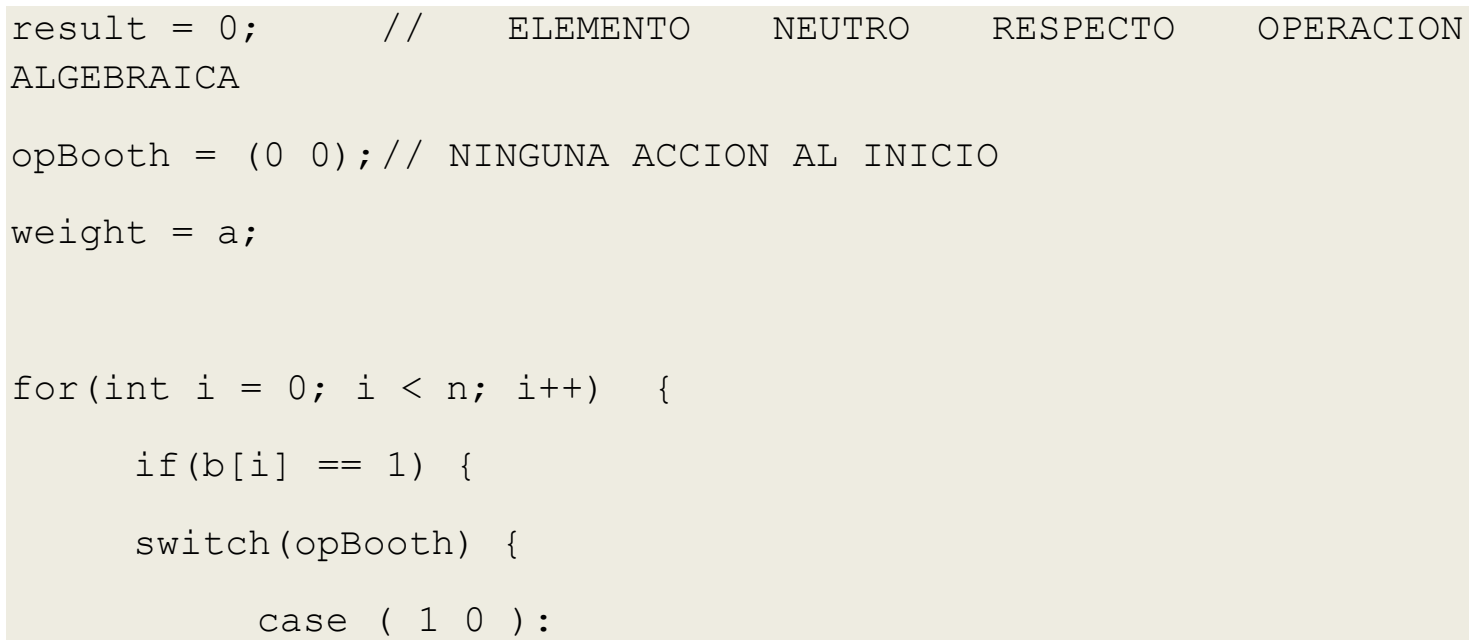




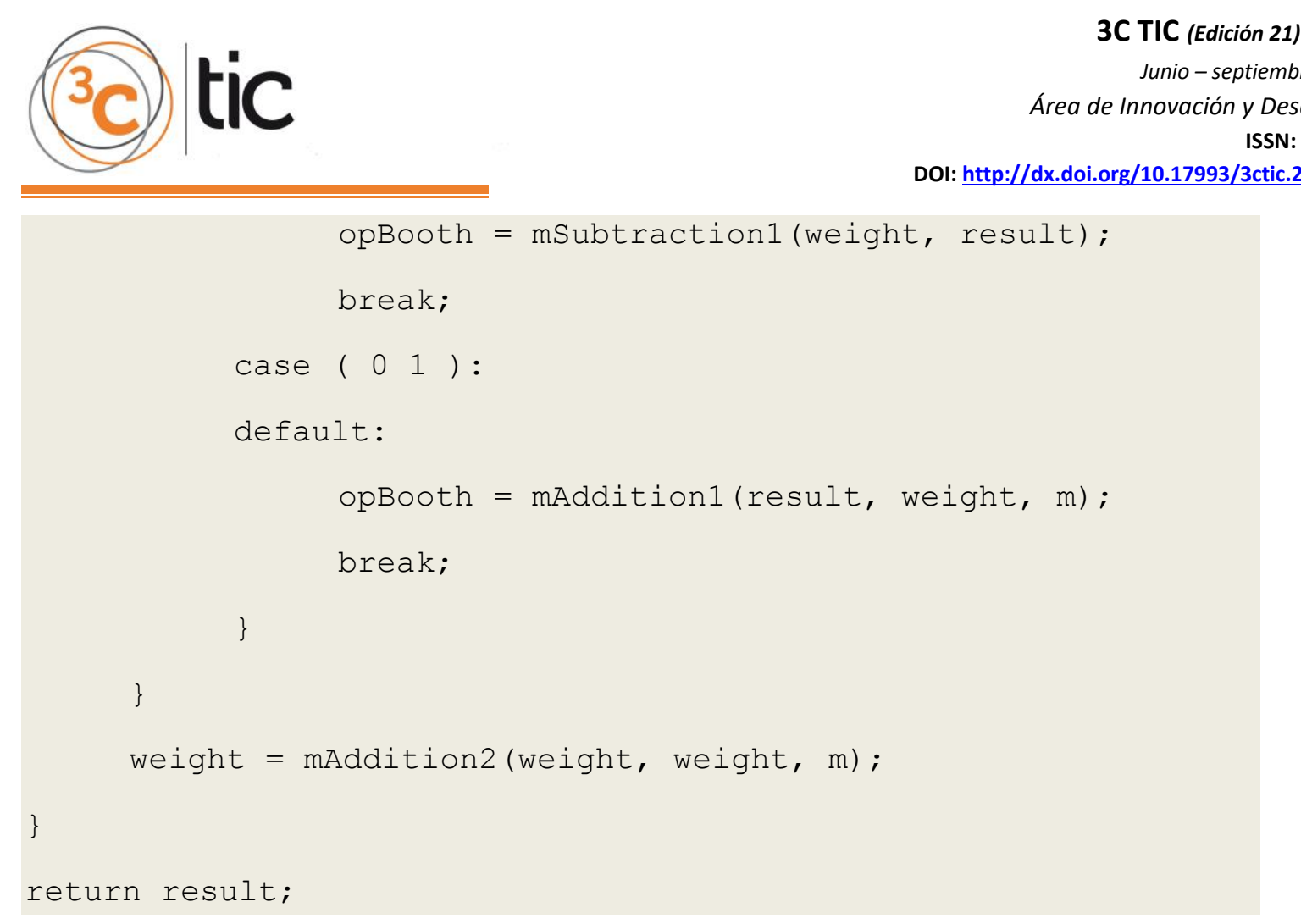

Figura 1: Algoritmo de multiplicación modular 1 (mMultiplication1).

Fuente: elaboración propia.

Puede observarse que la anterior implementación es exactamente igual que la que se expone en el trabajo 'Booth algorithm modular arithmetic operations of multiplication' (Ayuso 2015, pp. 255-221) con la salvedad de que, comparados bien las 2 , se aprecia que en la presente alternativa, cuando el resultado final no es el elemento correcto, sino el congruente del mismo, en el módulo en cuestión, no es realizado el último cálculo para obtener el resultado real; sino que éste es dejado tal cual ha sido obtenido. Más adelante queda explicado al detalle el porqué de esta decisión. También puede verse que ha sido etiquetada la operación (al pie del código), con el nombre de mMultiplication1, merece la pena destacarlo porque esa implementación será referida a con ese nombre, en lo que resta de documento.

Como se ha adelantado, la presente operación de división va a ser concebida como una operación de multiplicación por el inverso modular. Por ello, para construir nuestra versión del algoritmo de Booth para el cálculo de la exponenciación modular, se requerirá de la capacidad de poder obtener el inverso modular de un número a módulo $\mathrm{m}$. Para ello, es utilizada la versión binaria del algoritmo de Euclides extendido (Euclid 1557). Dicho método está de sobra documentado, y figura como referencia en la bibliografía, el trabajo de Euclides donde se describe. A pesar de ello, a continuación se hace constar el pseudocódigo del algoritmo utilizado, ya que igualmente en su implementación se hace uso de primitivas que explotan el concepto de Booth, además de retocarlo también un poco. Tendríamos que el cálculo del inverso modular del número, $a$, módulo $m$, los 2 de longitud $n$, sería:

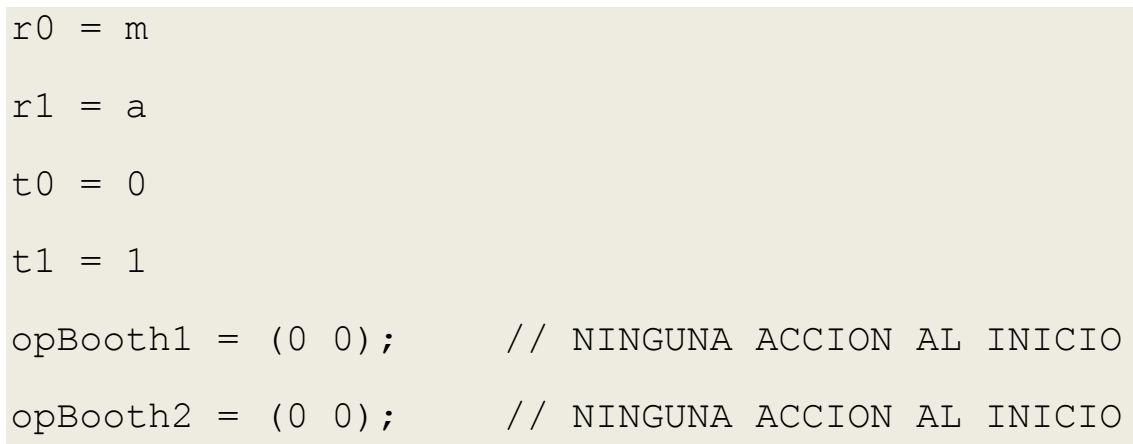




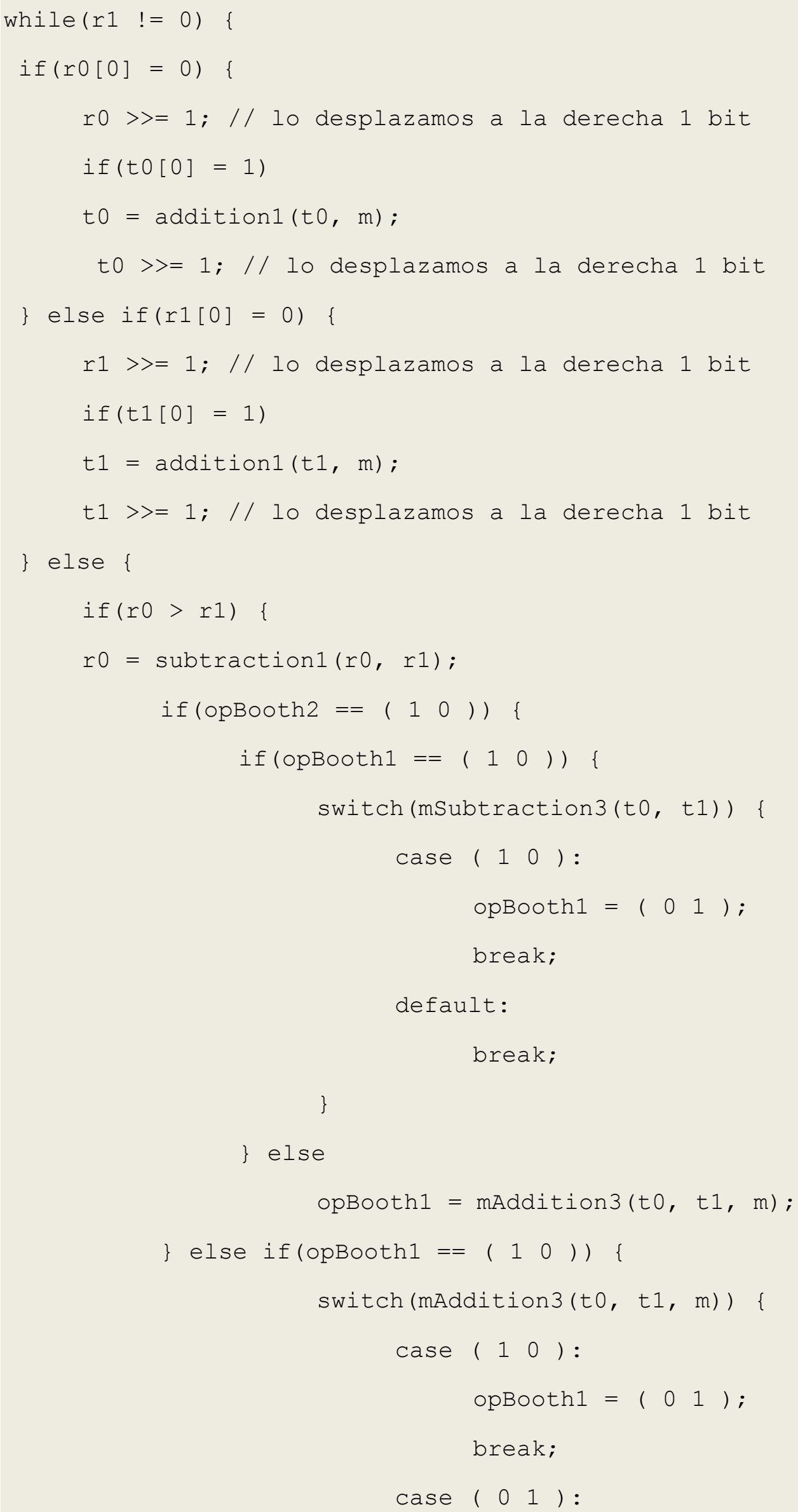




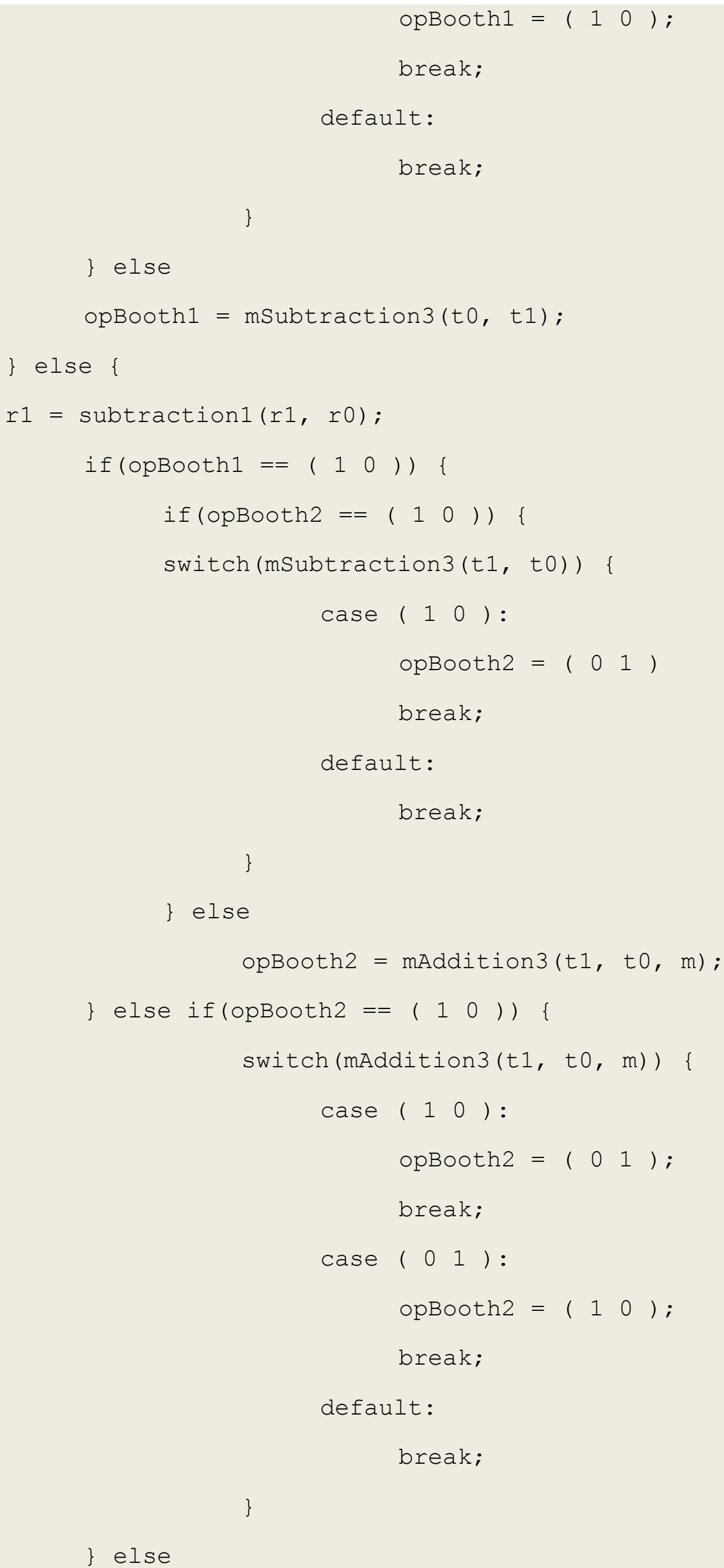




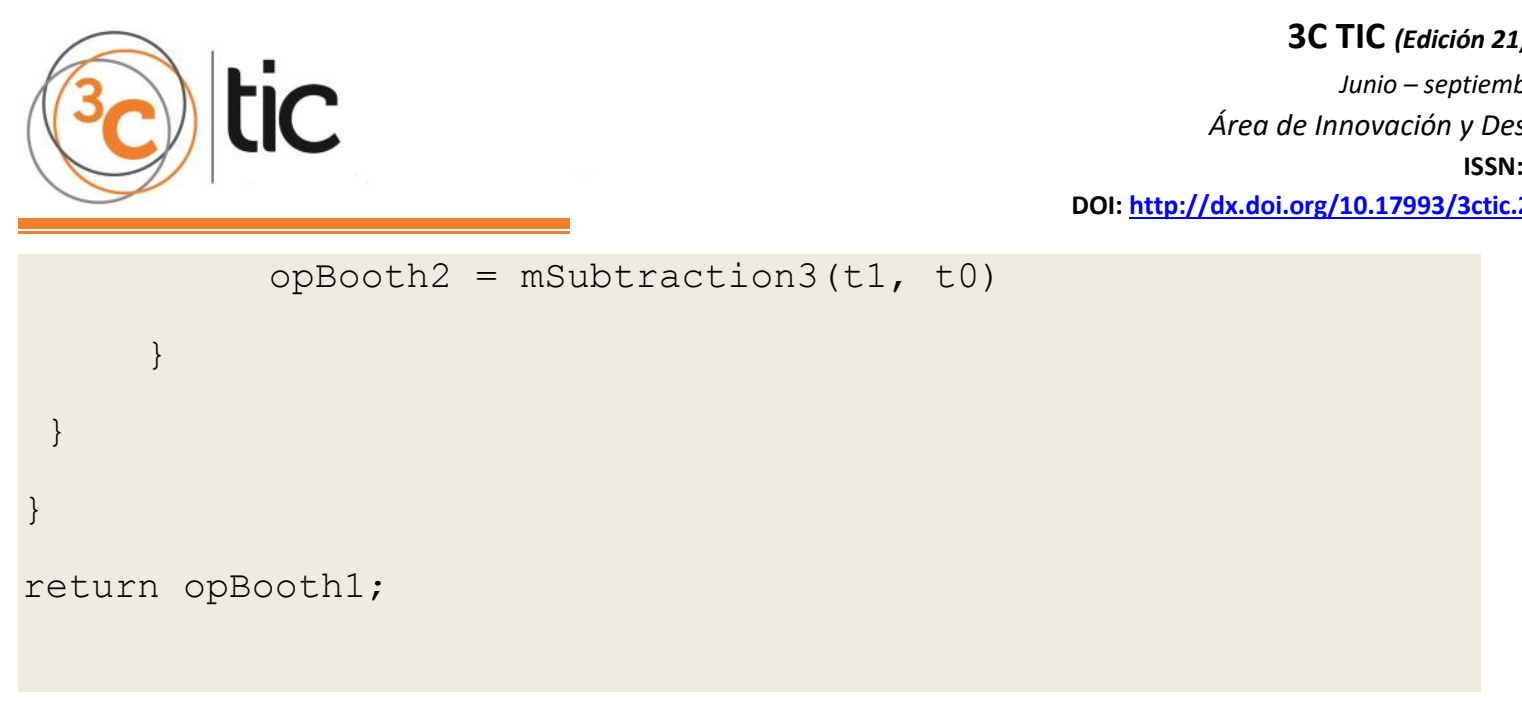

Figura 2: Algoritmo de Euclides Extentido versión binaria (extendedEuclideanBinary).

Fuente: elaboración propia.

Tirando de bibliografía, es comprobable que la implementación anterior es exactamente igual que la que se expone en el trabajo 'Algoritmo de Booth en operaciones de Inverso Modular' (Ayuso 2016, pp. 28-41) con la salvedad de que, al término del algoritmo, no se comprueba que el valor contenido en opBooth1 sea una acción de Booth que indique que el resultado es el elemento correcto, en lugar de su inverso (aditivo, en este caso). Se toma la misma política que antes, al igual que con el algoritmo de multiplicación modular; de nuevo, insistir que más adelante se verá el porqué de estas decisiones.

En este punto, destacar que, como ha podido deducirse, que todas las versiones de los algoritmos utilizados retornan un valor que hace referencia a una acción de Booth, por ello se entiende, o se toma por convenio, que dejan el resultado del cómputo en la primera variable que se le pase como parámetro en la llamada. Por simplicidad.

Ahora se repasa la tabla dada por Booth para reducir el número de operaciones necesarias, la cual se apoya en la propiedad invertible de la operación con la que se construye nuestro cálculo sobre cierta estructura algebraica:

Tabla 1. Acciones de Booth.

\begin{tabular}{|c|c|c|c|}
\hline bit menos significativo & bit extra & Interpretación & Acción \\
\hline $\mathbf{0}$ & $\mathbf{0}$ & intermedio cadena de 0s & ninguna \\
\hline $\mathbf{0}$ & $\mathbf{1}$ & final cadena de $1 \mathrm{~s}$ & operación \\
\hline $\mathbf{1}$ & $\mathbf{0}$ & comienzo cadena de $1 \mathrm{~s}$ & $\begin{array}{c}\text { operación inversa / } \\
\text { inverso misma }\end{array}$ \\
\hline $\mathbf{1}$ & $\mathbf{1}$ & intermedio cadena de $1 \mathrm{~s}$ & $\begin{array}{c}\text { operación } \\
\text { ninguna }\end{array}$ \\
\hline
\end{tabular}

Fuente: elaboración propia.

Partiendo de la tabla anterior, por fin se entra en la operación que nos ocupa: la exponenciación modular. Nuestro algoritmo de Booth aplicado a la exponenciación de dos enteros, $a$ elevado a $b$ módulo $m$, los 3 de longitud $n$ quedaría: 


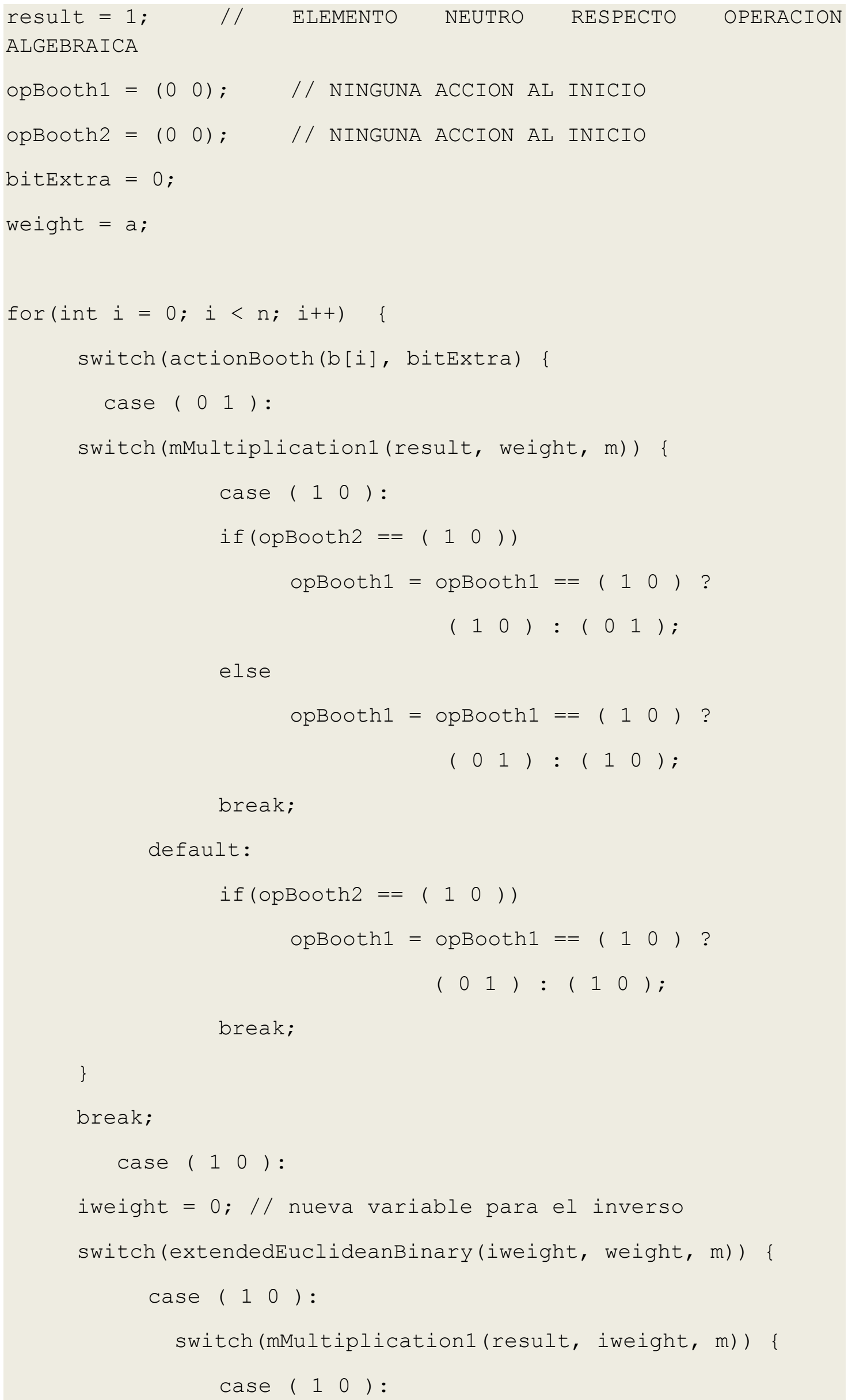




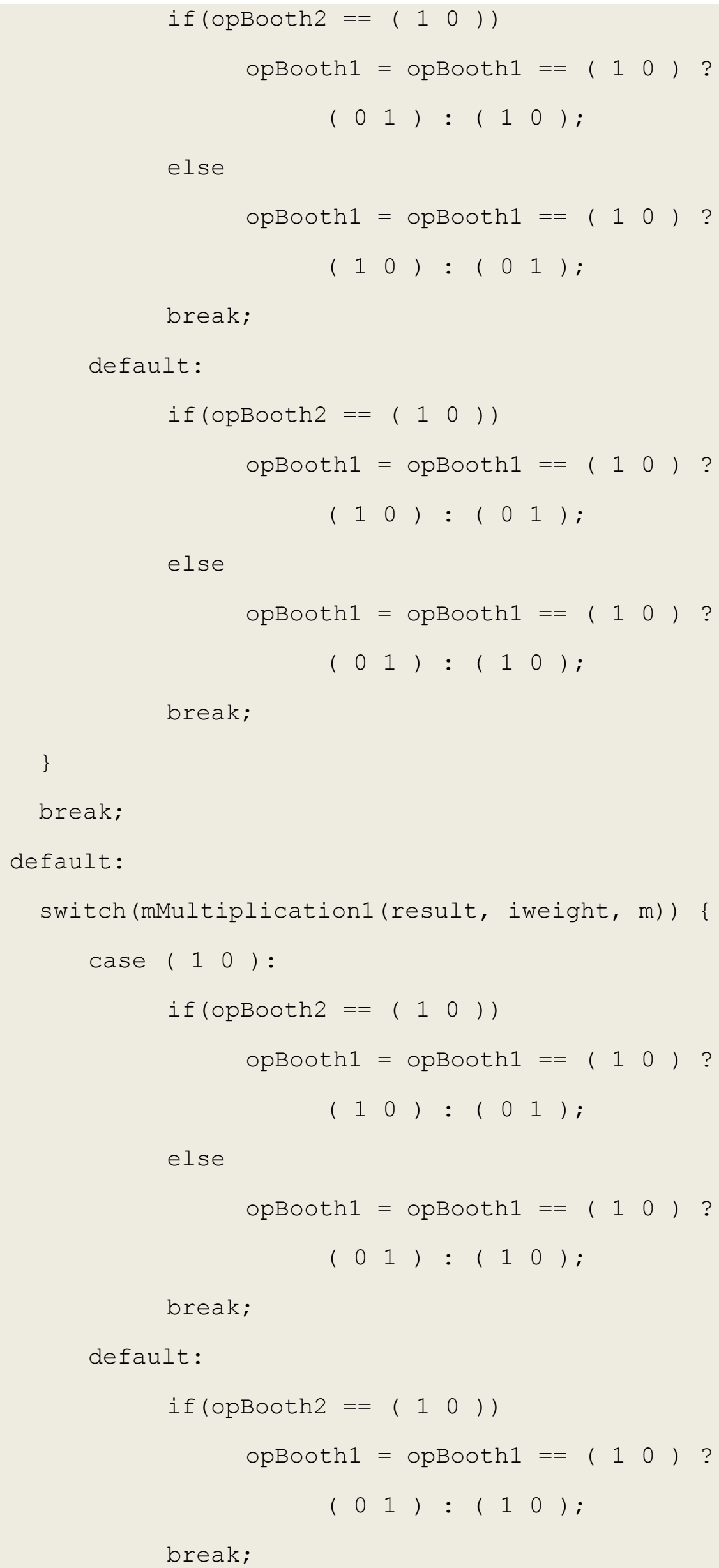




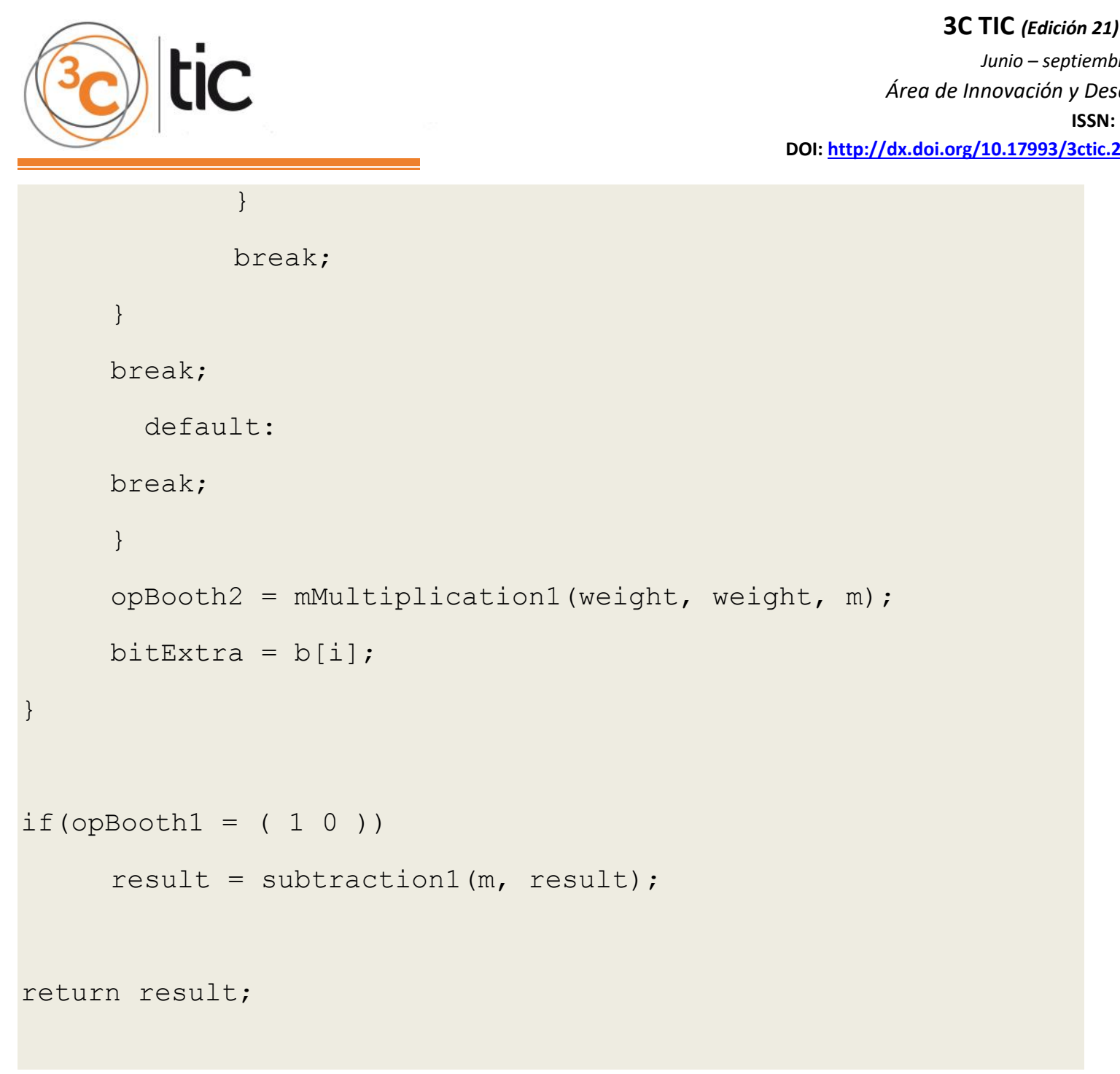

Figura 3. Algoritmo de exponenciación modular.

Fuente: elaboración propia.

Es importante el hecho que se está dando por sentado que las operaciones, salvo subtraction1, retornan una acción de Booth, tal y como se especifica en su implementación, y el resultado del cálculo es dejado en la primera de las variables que le llega por parámetro en la llamada.

También apostillar que el concepto de Booth requiere la invertibilidad de la operación, luego en el algoritmo dado se entiende que trabaja siempre sobre una estructura algebraica donde todo elemento es invertible, es decir, para el caso que nos ocupa, entendemos que estamos ante un grupo multiplicativo.

Es necesario tener clara la forma en la que se aplica el concepto de Booth en cada parte del algoritmo anterior, para su completa compresión. Si nos fijamos, el primer switch, aplica el concepto de Booth en el sentido más clásico: reduce el número de operaciones a realizar apoyándose en la operación inversa; para el caso que nos ocupa, si entendemos la exponenciación como una sucesión de multiplicaciones, conseguimos reducir el número de multiplicaciones a realizar, ayudándonos de operaciones de división. Por otro lado, los switchs anidados nos sirven para ayudarnos de elementos inversos, y nuevamente reducir el número de operaciones; de ahí que en la métodos de multiplicación e inverso que hemos dado, hayamos eliminado la última operación, ya que ésta nos supondría un coste añadido, pues vamos a hacer cientos o miles de operaciones de este tipo para obtener el resultado de 


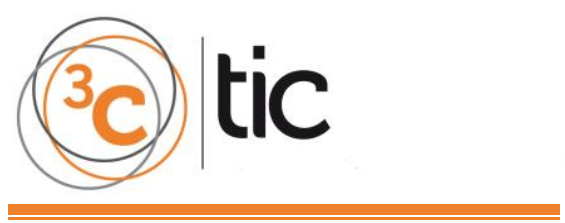

la exponenciación, y en cambio el concepto de Booth nos permite trabajar con elementos inversos. De los cuales sabemos que, si operan en el mismo estrato algebraico que la operación que vamos a realizar, tendrá el efecto inverso, como si operáramos por la operación inversa. En el caso que no ocupa, simplemente hemos de tener constancia de este detalle, para ser conscientes de que estamos proyectados contra un inverso, para poder deshacer dicha proyección algebraica en busca del elemento correcto. Por ello, cabe destacar esa última comprobación al final del código, en caso de que al salir del bucle, hayamos terminado obteniendo en elemento inverso, en lugar del elemento resultado: obtenemos su valor real con una simple resta contra el módulo sobre el que estamos trabajando (por tratarse de un inverso aditivo). No entramos en detalle de la implementación de esa operación de resta, subtraction1, porque es exactamente igual a la que figura en la bibliografía.

Evidentemente, también es posible utilizar la versión que soluciona el peor caso del algoritmo de Booth, donde 0s y $1 \mathrm{~s}$ van intercalados en relación de uno a uno. Además, en cuanto a utilizar la representación NAF de los operandos (Reitwiesner 1960, pp. 231-308), para reducir aún más el número de operaciones, podría ser de gran ayuda de cara a ser pasado en dicha representación el módulo en que estamos trabajando a las operaciones primitivas de adición y sustracción, ya que, el valor de módulo, evidentemente, permanece inmutable, luego podríamos sacar un gran incremento en el rendimiento en la exponenciación si previamente al bucle de exponenciación, calculamos la representación NAF del módulo y trabajamos con ella en las operaciones primitivas. Además, existe una versión del algoritmo de exponenciación que evita ese cálculo constante del inverso modular, haciendo un recorrido a la inversa de los bits del exponente; también podría ser un buena técnica con la que complementar los conceptos aquí expuestos.

\section{CONCLUSIONES}

Aplicar el algoritmo de Booth en métodos que requieren de sucesivas operaciones relacionadas algebraicamente, nos ofrece un gran repertorio de herramientas para ahorrar operaciones ayudándonos de su inversa, apoyarnos en elementos inverso evitando actuaciones o eliminar operaciones cruzadas. Además, esa naturalidad con la que se comporta el concepto ideado por Booth en las distintas estructuras algebraicas lo suele hacer perfectamente compatible con el resto de técnicas de optimización que existan para el procedimiento que estemos estudiando.

En conclusión, los conceptos propuestos por Booth, son extensibles a distintos ámbitos y aplicables a muchos métodos que acaben trabajando sobre una aritmética construida con operaciones invertibles, ofreciendo la posibilidad de reducir el número de operaciones necesarias para determinados cálculos sobre dicha aritmética. Además de resultar mucho más elegante, traduciéndose en algoritmos con una convergencia mucho más natural y rápida. Como posible futura línea de investigación, se pueden tratar de aplicar los conceptos descritos en la aritmética de Montgomery (Montgomery 1985, pp. 519-521), ya que ésta permite realizar la operación de exponenciación de una manera más eficiente. Por lo que sería una técnica complementaria a la presente. 


\section{REFERENCIAS BIBLIOGRÁFICAS}

Booth, A. D. (1945), "A method of calculating reciprocal spacings for X-ray reflections from a monoclinic crystal," J. Sci. Instr, Vol. 22, p. 74.

Booth, A. D. and Britten, K. H. V. (1947), "General Considerations in the Design of an Electronic Computer".

Booth, A. D. (1951), "A signed binary multiplication technique", Q.J. Mech. and Appl. Math. Vol 4, No.2, pp.236-240.

W. Reitwiesner, George (1960), "Binary Arithmetic", 231-308.

Diffie, W., and E. Hellmen (1976). New directions in cryptography. IEEE Transactions on Information Theory,22(6), 644-654.

Peter Montgomery (1985.). Modular Multiplication Without Trial Division, Math. Computation, vol. 44, pp. 519-521.

Ayuso, J., "Booth algorithm operations addition and subtraction", 3C TIC. Vol 4, No.2, 2015, pp. 113-119.

Ayuso, J. (2015), "Booth algorithm modular arithmetic operations of addition and subtraction", 3C TIC. Vol 4, No.3, pp. 222-229.

Euclid of Alexandria (1557), "Elements", T.L. Heath's.

Ayuso, J. (2015), "Booth algorithm modular arithmetic operations of multiplication", 3C TIC. Vol 4, No.4, pp. 255-221.

Ayuso, J. (2016), "Algoritmo de Booth en operaciones de inverso modular", 3C TIC. Vol 5, No.2, pp. 28-41. 


\section{DISEÑO E IMPLEMENTACIÓN DE UN SISTEMA DE INFORMACIÓN PARA EL} SEGUIMIENTO DE PROYECTOS DE SENTENCIAS EN EL TRIBUNAL DE LO CONTENCIOSO ADMINISTRATIVO

\section{DESIGN AND IMPLEMENTATION OF AN INFORMATION SYSTEM FOR THE FOLLOW-UP OF PROJECTS OF SENTENCES IN THE COURT OF ADMINISTRATIVE CONTENT}

Juan Manuel Fernández Álvarez ${ }^{1}$ Antonio Moreno Jauregui ${ }^{1}$

M. en C. Juan García Virgen ${ }^{2}$ M. en C. J. Reyes Benavides Delgado ${ }^{2}$

1. Estudiante de la Maestría en Sistemas Computacionales en la División de Estudios de Posgrado e Investigación Instituto Tecnológico de Colima (México.

E-mail: juangogof1@gmail.com ingantonmor@gmail.com

2. Profesor de la Maestría en Sistemas Computacionales en la División de Estudios de Posgrado e Investigación Instituto Tecnológico de Colima (México).

E-mail: jgarcia@itcolima.edu.mx, rbenavides@itcolima.edu.mx

E-mail de contacto: juangogof1@gmail.com

\section{Citación sugerida:}

Fernández Álvarez, JM., Moreno Juaregui, A., García Virgen, J. y Benavides Delgado, R. (2017). Diseño e implementación de un sistema de información para el seguimiento de proyectos de sentencias en el tribunal de lo contencioso administrativo. 3C TIC: Cuadernos de desarrollo aplicados a las TIC, 6(2), 13-27. DOI: <http://dx.doi.org/10.17993/3ctic.2017.56.13-27/>. 


\section{RESUMEN}

En esta investigación se desarrolló un sistema de información que da seguimiento a los proyectos de sentencias en un ambiente web gestionados por el Tribunal de lo Contencioso Administrativo para mejorar la impartición de justicia. El sistema prevé una mejora en la productividad de los procesos involucrados para el dictamen de sentencias, utilizando bitácoras para el registro histórico de las actividades incluyendo los tiempos respectivos de cada actividad involucrada durante el proceso y estableciendo puntos de verificación para conocer el avance del litigio.

\section{ABSTRACT}

In this research, was developed an information system to follow up the draft sentences in a web environment managed by the Administrative Contentious Court to improve the delivery of justice. The system provides for an improvement in productivity of the processes involved for the opinion of judgments, using logs for the historical record of the activities including their respective time for each activity used during the process and checkpoints were established to know the progress of the litigation.

\section{PALABRAS CLAVE}

Seguimiento de Proyecto de Sentencias, Aplicación Web, Dictamen de Sentencias, productividad en los procesos jurídicos.

\section{KEYWORDS}

Follow-up of Sentences Project, Web Application, Sentence Opinion, productivity in legal processes. 


\section{INTRODUCCIÓN}

Desde que se decretó, por medio del "Compromiso de Túnez" (Mundo, 2005), el uso de las TIC's en los procesos judiciales, se ha instituido un cambio dentro del Marco Jurídico Internacional y se ha buscado poder tener una implementación para proporcionar una mejor eficiencia, aunque esto ha sido un poco difícil, ya que al implementar estas tecnologías se minoriza el uso de la presencia de sujetos para algunas de las actuaciones del proceso. El Tribunal de lo Contencioso Administrativo del Estado de Colima (TCAEC, 1996) lleva una serie de procesos para poder llevar a juicio una demanda, determinar una sentencia y darle seguimiento: Cuando la demanda llega a manos del proyectista, este determina y justifica cual va a ser la sentencia que se va a realizar, que actualmente es un proceso ineficiente, ya que tiene que revisar los documentos del demandante, demandado y las leyes que intervienen en la promoción para poder determinar dicha sentencia. Después de realizar este análisis, la sentencia propuesta pasa a manos del magistrado, el cual también realiza la misma acción de leer los documentos y la justificación de la sentencia propuesta por el proyectista y determinar si esta procede o no y, después de haberse aceptado este veredicto, se le da seguimiento para comprobar que se haya cumplido por la parte demandada. En caso de no haberse cumplido el demandante podrá realizar una promoción para externar el no cumplimiento del mismo, así como también la parte demandada podrá hacer una promoción para un amparo. Ya que este proceso se lleva de una manera manual, lo cual resulta poco eficiente al momento de realizar la búsqueda y consulta de documentos, con el desarrollo del sistema se busca reducir ese tiempo y tener una recuperación inmediata de la información registrada.

Esta investigación es parte de un trabajo que integra tres etapas: almacenamiento y minería de la información, seguimiento de demandas y seguimiento de sentencias dentro del TCAEC, esta última etapa corresponde al trabajo de investigación que se describe en este documento, tal como se ilustra en la sección resaltada en rojo de la figura 1.

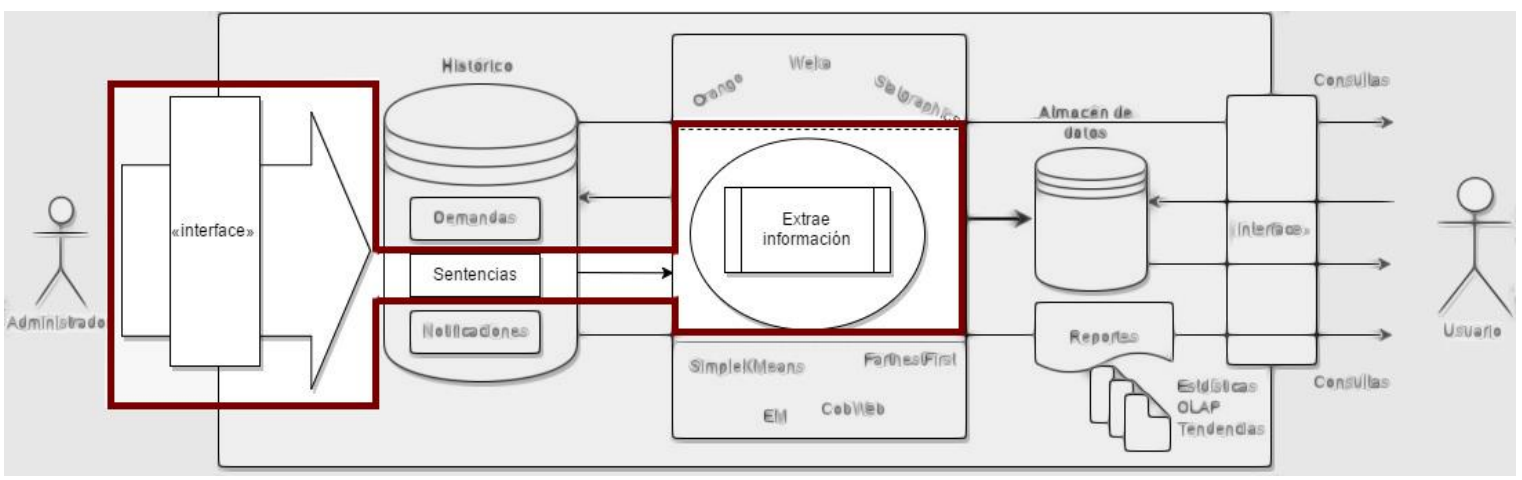

Figura 2. Modelo conceptual.

Urdapilleta, (2015), en su Artículo "Notas generales del Juicio en Línea” menciona también que el proceso jurídico que se sigue es el mismo de revisar cada una de las promociones, pruebas y actuaciones. También se siguen dictando las sentencias y acuerdos, la única diferencia es que ya no son documentos físicos con firmas autógrafas, sino que ya son documentos electrónicos con firma electrónica avanzada, por lo cual facilita la búsqueda de información y documentos y 


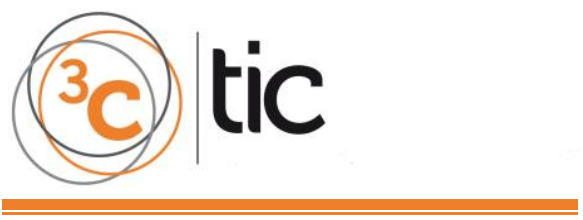

de seguimiento de expedientes, y propone que las dependencias correspondientes tomen la iniciativa para utilizar estas herramientas e implementarlas en los procesos que se siguen de cada uno de ellos. Gustavo Quintero Navas, en su artículo "Contencioso Administrativo y medios electrónicos: un gran paso hacia la modernización del ejercicio de la justicia administrativa" (Navas, 2011), brinda un enfoque general acerca de la importancia de la impleentación de las TIC's en el seguimiento de un proceso judicial electrónico y define algunas de las opciones y métodos que se pueden implementar para el buen funcionamiento de un Sistema de Seguimiento de este proceso. Brinda algunas herramientas y propone llevar un proceso de digitalización tanto de documentos como de firmas digitales, así como también notificaciones electrónicas. Una propuesta para mejora de esta investigación es indagar a fondo acerca del proceso de elaboración de cada uno de los acuerdos para llevar a cabo un buen seguimiento a este proceso, ya que el solo implemetar la digitalización es unicamente para tener en electrónico el expediente pero no muestra un seguimiento como tal del proceso juridico-administrativo.

Considerando las áreas de oportunidad detectadas en diferentes investigaciones revisadas en el punto anterior y habiendo analizado los proyectos ya implementados en algunas dependencias de otros estados, la más común, es que a pesar de tener un seguimiento de las demandas y sentencias dictadas, no se les da un seguimiento con alguna bitácora para determinar el tiempo en horas hombre en que dura el proceso de la redacción, validación y cumplimiento o no cumplimiento de cada una de ellas, por lo cual se propone desarrollar un sistema informático automatizado en un ambiente web, para mejorar el proceso del litigio.

\section{PROCESO DE DESARROLLO DEL SISTEMA}

Para el desarrollo de este proyecto se utilizó la metodología de Proceso Unificado Ágil (Métodos de desarrollo Ágil, 2016). A cada uno de los usuarios se elaboraron interfaces interactivas para que se desarrolle el proyecto de sentencia, se haga una revisión del mismo, y, una vez aprobado, se lleve a las firmas correspondientes de autorización para notificación a las partes involucradas. Cada uno de los diagramas se elaboró con la herramienta de desarrollo UML Enterprise Architect. La implementación de la base de datos se realizó con MySQL y para el desarrollo de las vistas se utilizó Codelgniter (Alejandro Morales Gámez, 2015), que es un framework PHP para el desarrollo rápido de aplicaciones web y ha permitido desarrollar el sistema web para el seguimiento de proyectos de sentencia en el Tribunal de lo Contencioso Administrativo del Estado de Colima. Para la elaboración de este proyecto se realizó una planeación para cada una de las fases de la metodología empleada, la cual se ilustra en la figura 2. En la Figura 3 se ilustra la arquitectura de Codeigniter, el modelo se refiere a todo el código que tiene que ver con el acceso a base de datos, en la vista codifica y mantiene la presentación final de nuestra aplicación de cara al usuario y en el controlador guardamos la lógica de nuestras páginas y realizamos todas las acciones que sean necesarias para generarlas, ayudados del modelo o la vista. 


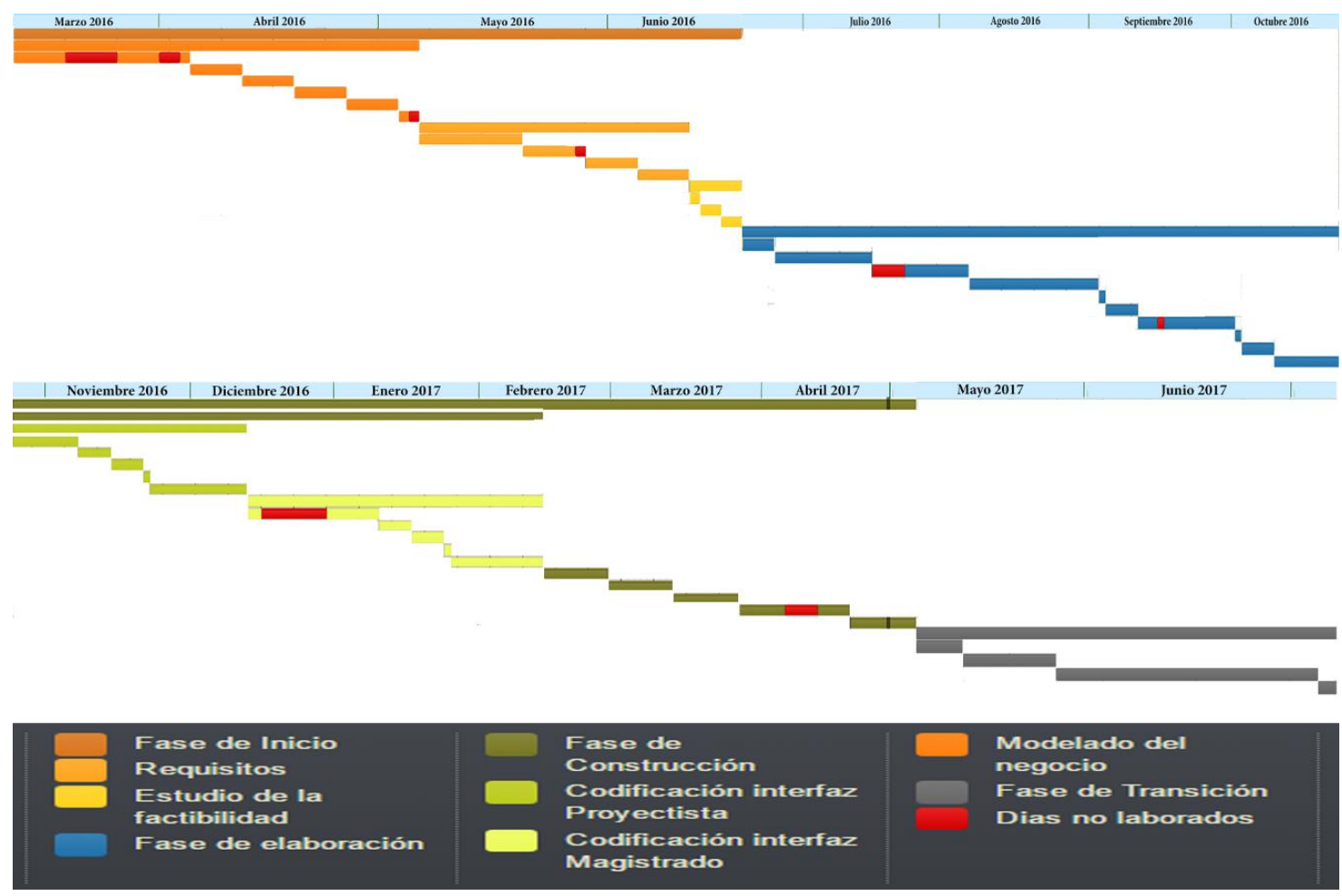

Figura 3. Gráfica de Gantt, Fases de desarrollo de SISESE.

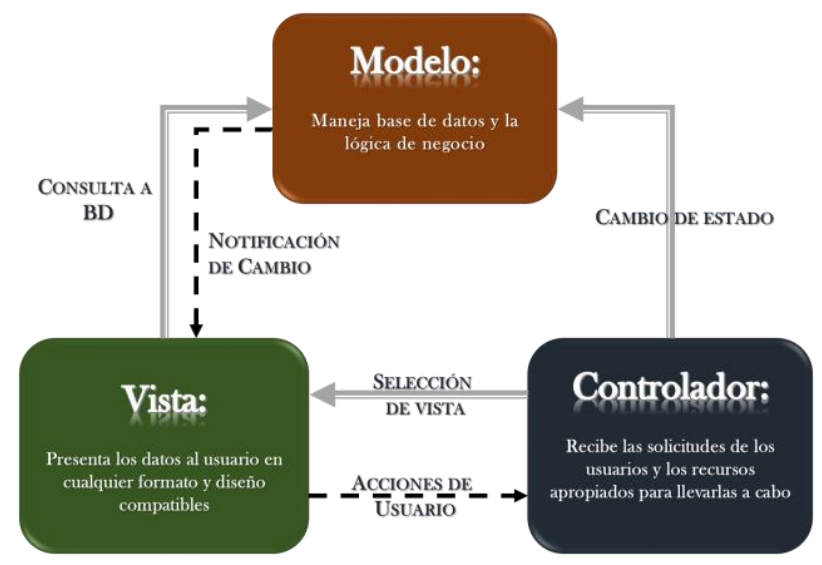

Figura 4. Arquitectura Modelo, Vista, Controlador de Codelgniter Fuente: Alejandro Morales Gámez, 2015.

Algunas de estas interfaces son utilizadas por los usuarios para la redacción, tanto del proyecto de sentencia, como su revisión y elaboración de diferentes tipos de acuerdos y/o documentos correspondientes a la sentencia, a continuación se muestra el desarrollo de la aplicación web. 


\section{DESARROLLO}

\subsection{ANÁLISIS}

En esta fase se detectaron cada una de los requerimientos para poder llevar a cabo la elaboración del sistema. Para ello, se hizo una entrevista con cada uno de los actores involucrados en el sistema, los cuales se ilustran en la figura 4.
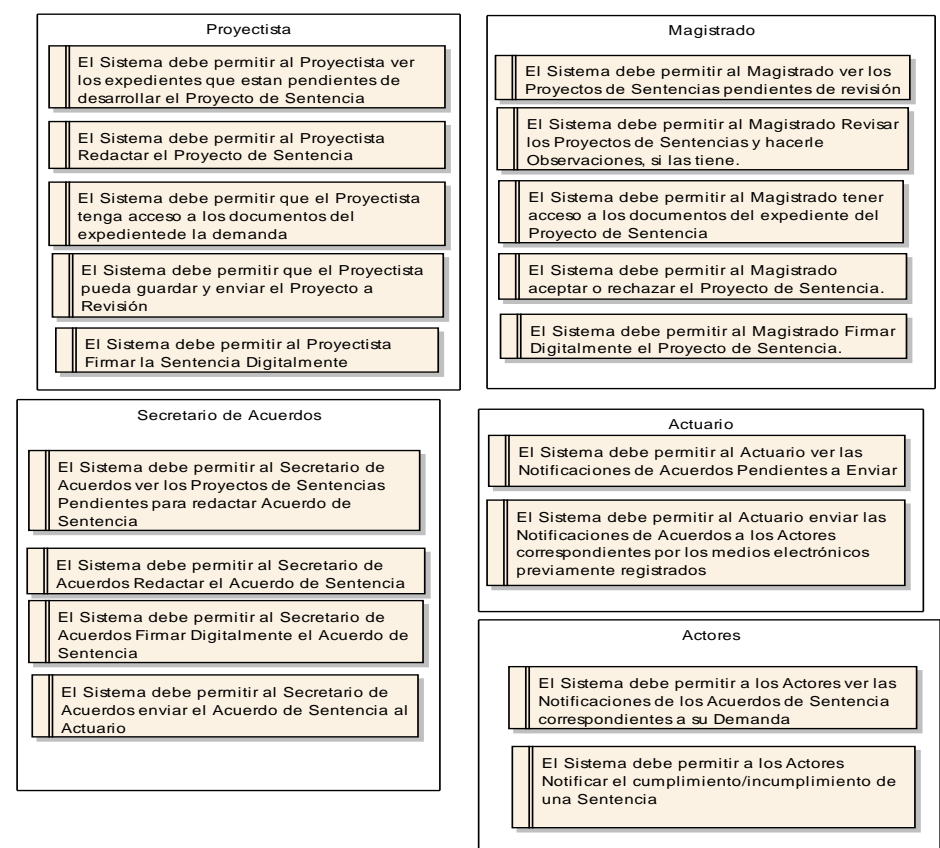

Figura 5. Requerimientos Funcionales.

\subsection{CASOS DE USO}

En la Figura 5 se ilustran los casos de uso general del Sistema SISESE. Cada uno de ellos nos muestra la interacción de cada uno de los usuarios con el Sistema, teniendo como usuarios principales al Proyectista, que es quien desarrolla el Proyecto de Sentencia y lo envía a ser evaluado para su aprobación o corrección. El Magistrado es el encargado de hacer esta evaluación del Proyecto de Sentencia.

Una vez aprobado entra en función el Secretario de acuerdos, en conjunto con el Proyectista y Magistrado proceden a firmar la Sentencia para poder pasar al Actuario, quien notifica a las partes involucradas en la Demanda, que es la Sentencia correspondiente a la misma. 


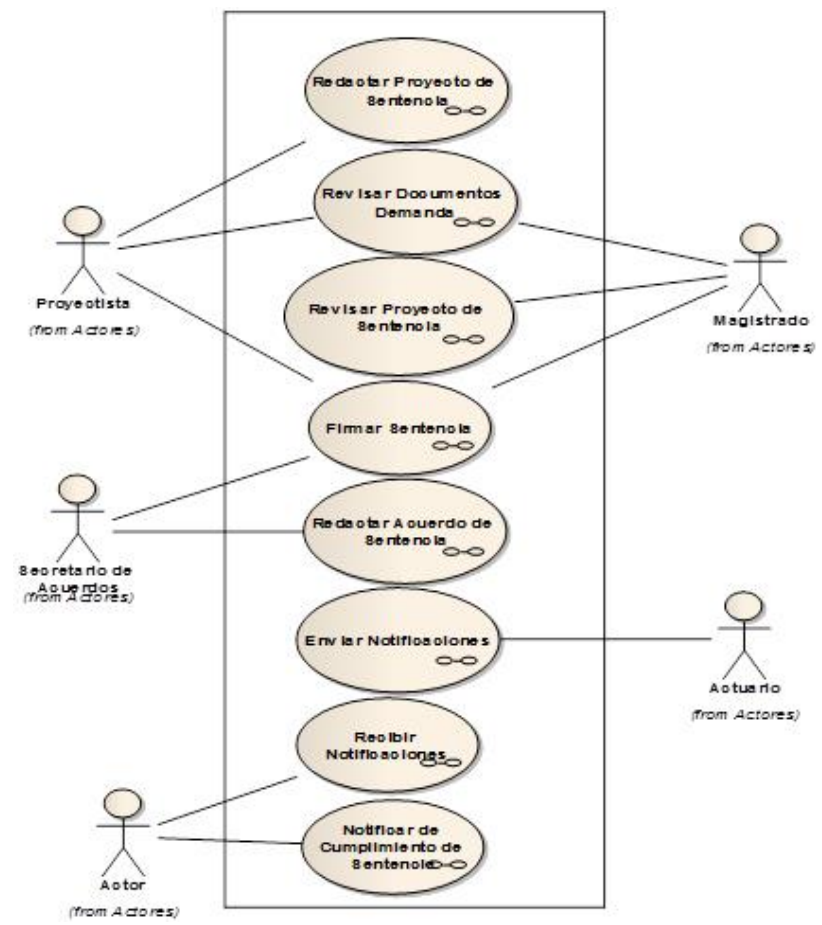

Figura 6.Diagrama de casos de uso SISESE.

\subsection{DISEÑO DE INTERFACES}

Para la navegación entre las interfaces de los usuarios se realizaron las interfaces con la herramienta Enterprise Architect 8.0, que fueron diseñadas para después ser codificadas. En la figura 5 se ilustra el mapa de navegación del Usuario Magistrado, el cual, después de tener acceso a su cuenta, puede revisar las propuestas de sentencias realizadas por cada uno de los Proyectistas y tiene la opción de leer los documentos que pertenecen a esa Demanda para validar la información. También puede hacerle modificaciones, si las requiere, aceptar el proyecto para enviarlo a los Actores involucrados o rechazar la propuesta para que se vuelva a realizar.

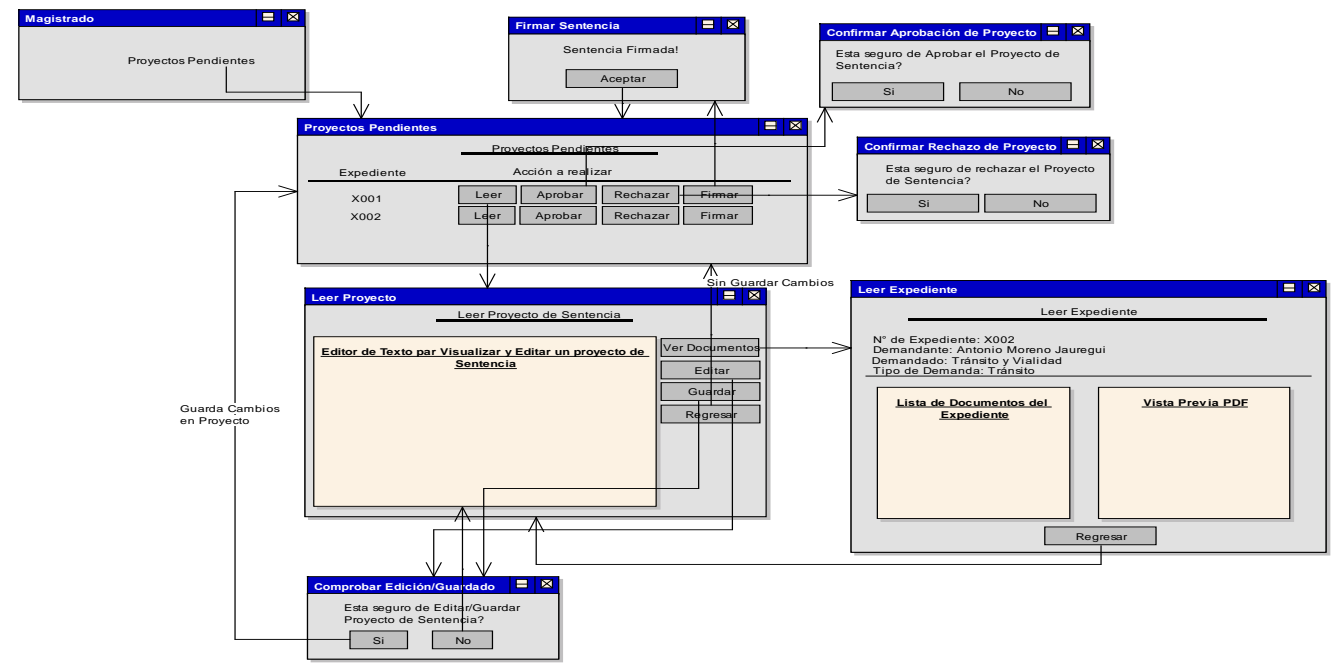

Figura 7. Diagrama de Navegación Magistrado. 


\subsection{CODIFICACIÓN DE INTERFACES (VISTAS)}

Para el desarrollo de cada una de las interfaces se utilizó el framework Codelgniter (Gámez, 2015), así como también el editor de texto Sublime para la realización de esta codificación.

En la figura 6 se ilustra el diseño de la Vista para redactar/editar los documentos que se desarrollan por parte del Proyectista, Magistrado y Actuario, y para poder realizar la redacción se implementó el editor de texto para php CKEditor en su versión completa.

En la figura 7 se ilustra el controlador utilizado para guardar el documento que se ha redactado/editado. El documento se guardará en una carpeta llamada Proyectos que tendrá el nombre del documento incluyendo el folio de la demanda.

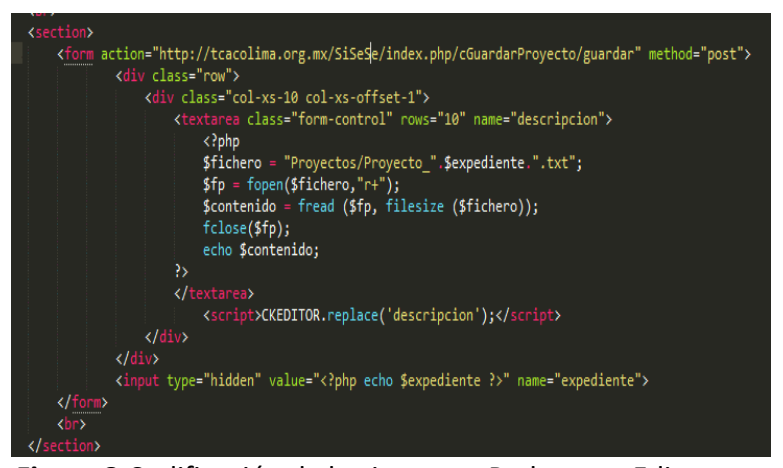

Figura 8.Codificación de la vista para Redactar o Editar un documento.

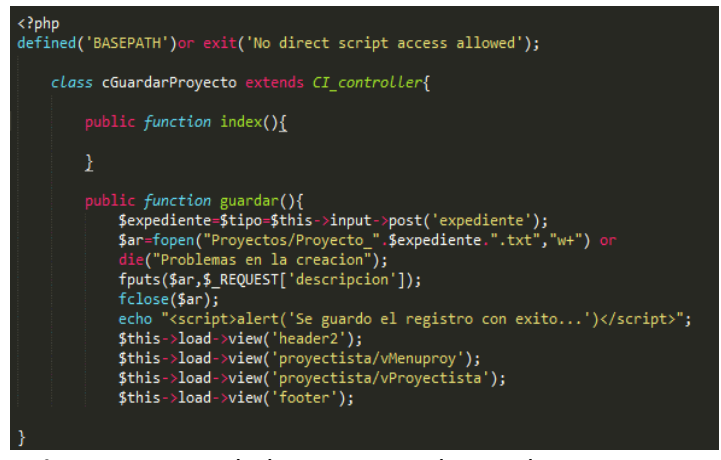

Figura 9. Controlador para guardar un documento.

\section{IMPLANTACIÓN}

La estrategia de implantación del sistema se determinó basándose en la información acumulada de las fases anteriores, en función del número de módulos del sistema de información implicados en la implantación, cuyo alcance depende de las características y complejidad de los sistemas de información.

El plan contempla las siguientes tareas, las cuales fueron nombradas como ISI (Implantación del Sistema de Información):

\section{Tarea ISI 1: En primer instancia de definió el plan de implantación}

Una vez analizada la información anterior, se desarrolló un plan de implantación que permita calcular adecuadamente el esfuerzo y los recursos necesarios para llevar a cabo con éxito la implantación.

Participantes: Equipo de usuarios, Administrador del sistema, Analista de Sistemas.

Responsable: Analista de sistemas. 


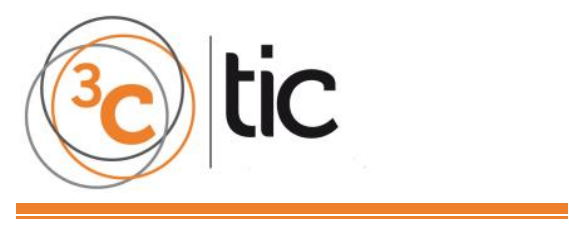

Para esta tarea se tomaron en cuenta los siguientes puntos:

- La capacitación necesaria para la implantación al equipo de trabajo que se encarga de realizar la implantación.

- La preparación de la infraestructura necesaria para la incorporación del sistema al entorno del proceso.

- La instalación de todos los componentes y procedimientos manuales y automáticos asociados a cada módulo del sistema de información implicados en la implantación.

- La ejecución de los procedimientos de carga inicial y migración de datos.

\section{Tarea ISI 2: Preparación del entorno del proceso}

El objetivo de la preparación del entorno del proceso es planificar que todos los recursos estén disponibles para la puesta en funcionamiento del Sistema de Información. Para esto se aseguró que hubiera disponibilidad del entorno y de los datos que se requieren para poner en ejecución el sistema.

Participantes: Administrador del sistema, Analista de Sistemas.

Responsable: Analista de sistemas.

\section{Tarea ISI 3: Capacitación para la implantación}

En esta tarea se dispone y se comparte la capacitación al equipo que participará en la implantación del sistema, y al personal de manejo del Sistema. Se realiza también el seguimiento de la capacitación de los usuarios finales para asegurar que la implantación se llevará a cabo correctamente.

Participantes: Usuarios del sistema, Administrador del sistema, Analista de Sistemas.

Responsable: Analista de sistemas.

\section{Tarea ISI 4: Presentación de procedimientos normativos}

Una vez que se ha realizado la evaluación de los procedimientos normativos en la fase de Construcción y Pruebas del Sistema, el Analista Funcional conjuntamente con el Líder y el Ejecutivo del Proyecto deben realizar todas las acciones necesarias para que el titular de la institución apruebe y ordene publicar estos procedimientos en el menor tiempo posible.

Participantes: Analista de sistemas, Coordinador del Proyecto, Administrador del sistema.

Responsable: Analista de sistemas. 


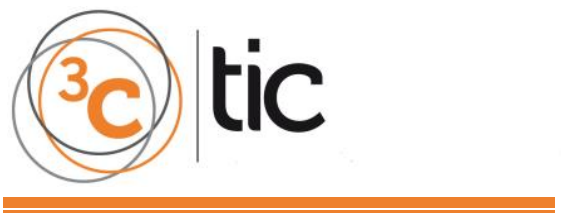

\section{Tarea ISI 5: Instalación del Sistema}

Esta tarea tiene como objetivo establecer el punto de inicio en que el sistema pasa a su instalación. Para ello es necesario que, se disponga del entorno del proceso perfectamente instalado en cuanto a hardware y software de base, componentes del nuevo sistema y procedimientos manuales y automáticos.

Participantes: Usuarios finales, Analista de Soporte Técnico, Analista de Sistemas, administrador del sistema.

Responsable: Administrador del Sistema.

\section{Tarea ISI 6: Puesta en marcha del sistema}

En esta actividad se pone en marcha el sistema y estará a cargo del equipo de Usuarios.

Participantes: Usuarios finales, Analista de Sistemas, Administrador del sistema.

Responsable: Usuarios finales.

\section{Tarea ISI 7: Reunión de trabajo para evaluación}

El objetivo de esta actividad es el evaluar el rendimiento del sistema, si cumple con las expectativas antes mencionadas en la formulación del Proyecto, de haber alguna modificación o ajuste a este proyecto, éste se realizará para mejora del sistema. En esta reunión se buscará la aprobación formal de la implantación del sistema por parte del Magistrado y el equipo de trabajo.

\section{PRUEBAS}

Las pruebas realizadas a la aplicación, previa a la implementación se derivaron en dos categorías: pruebas de validación y funcionales.

\section{Pruebas de validación}

Estas pruebas tienen como objetivo evaluar el cumplimiento de los requisitos de sistema, principalmente en los valores o datos que van a ser almacenados dentro de la base de datos, que cada uno de los campos tomen los valores correctos para su uso y manipulación.

\section{Pruebas funcionales}

Estas pruebas tienen como objetivo determinar el buen funcionamiento del sistema, comprobando la compatibilidad y funcionabilidad de las interfaces entre las distintas partes que conforman el sistema, cada una de ellas se evaluará de la siguiente forma: 


\section{Pruebas de usabilidad}

Estas pruebas determinan la facilidad del usuario para poder operar la aplicación. Como objetivos particulares, estas pruebas determinan si el usuario puede utilizar el sistema completando satisfactoriamente el proceso de búsqueda, otro de los puntos es comprobar si la interfaz es lo suficiente intuitiva para los usuarios que tengan experiencia en el manejo de este tipo de aplicaciones como para los que no la tienen y concluir si el sistema requiere de modificaciones para que se cumplan los objetivos anteriores.

\section{Pruebas de carga de datos}

Estas pruebas se le realizaron a la aplicación para comprobar los límites de carga de datos máxima que el sistema soporta en un momento determinado y así detectar a tiempo si hay algún problema por sobrecarga de información.

\section{Pruebas de desempeño}

El objetivo de esta prueba evalúa el desempeño del sistema en base a un tiempo de respuesta en las consultas para determinar si la aplicación es competente para operar dentro de un rango de tiempo aceptable y satisfacer las expectativas de los usuarios.

\section{Formato de pruebas}

En la tabla 1 se muestra el formato de pruebas que se utilizó para hacer una de las pruebas de funcionamiento en la vista del Proyectista, cada ITEM refiere a la prueba a ejecutar:

Tabla 1. Formato de pruebas, prueba funcional para vista de Proyectista.

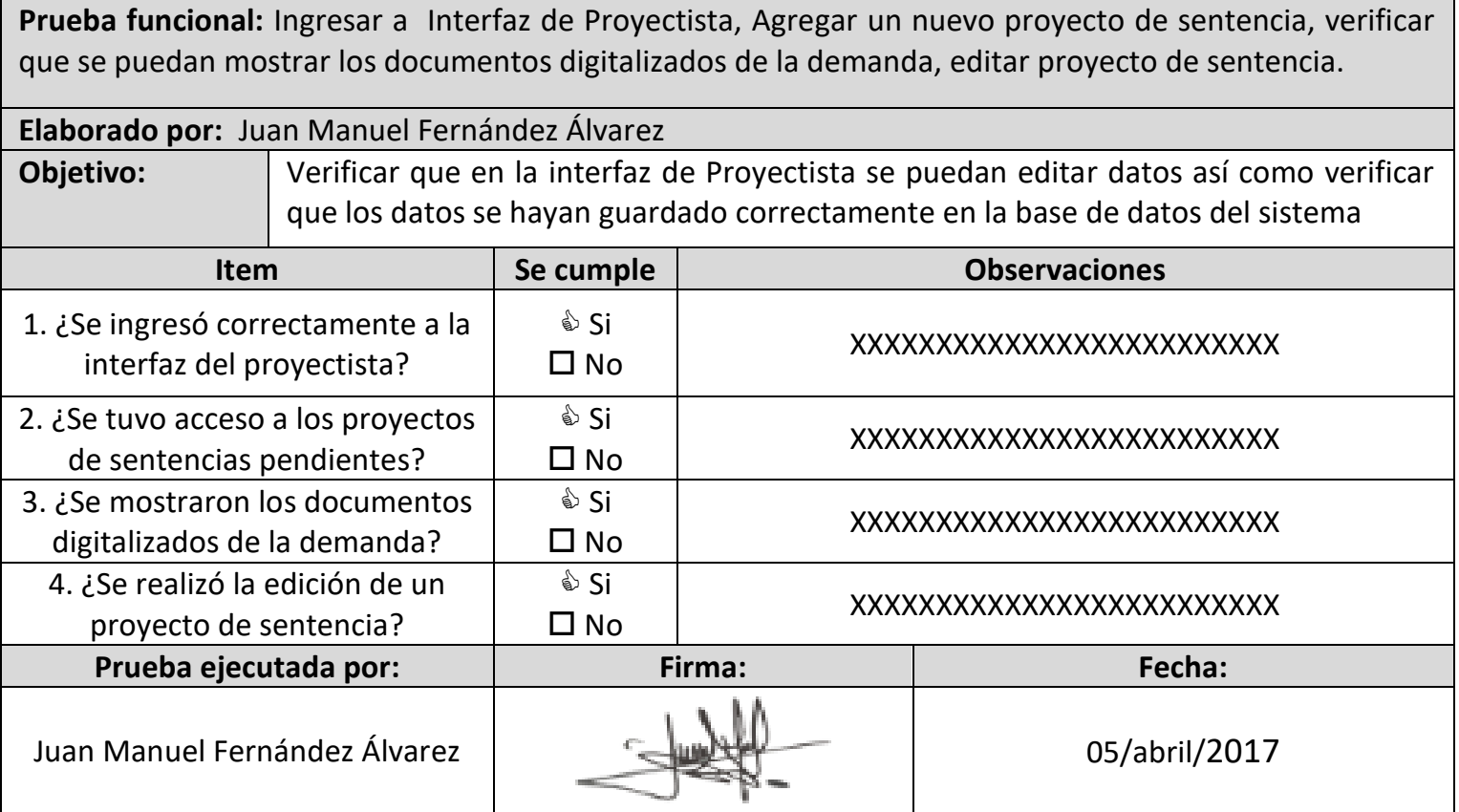

Fuente: elaboración propia. 


\section{RESULTADOS}

Después de haber realizado una codificación de cada una de las vistas se realizaron pruebas con el sistema de validación, verificación e instalación y se pudo observar que se cumple con los requerimientos anteriormente mencionados.

En la figura 9 se ilustra la vista lista de proyectos pendientes a realizar sentencia que llegan a cada uno de los proyectistas. Para poder comenzar la redacción, el proyectista realiza una lectura de los documentos que tienen relación con la demanda para así poder elaborar el proyecto de sentencia. En la figura 10 se ilustra la vista donde, tanto el proyectista como el magistrado pueden redactar, leer y/o editar las propuestas de sentencias que se han elaborado.

$\underline{T A}$ Tribunal de lo Contencioso Administrativo del Estado de
Colima

\begin{tabular}{|c|c|c|c|c|c|}
\hline \multicolumn{3}{|l|}{ SISeDe v1.0 } & Expedientes Pendientes 42 & Mi cuenta( Usuario ). & Cerrar sesión \\
\hline & Expediente & Fecha & Acción a realizar & & \\
\hline & 0001 & $2016-11-21$ 02:02:00 & Cà & & \\
\hline & 0002 & $2016-11-21$ 02:03:00 & Cà & & \\
\hline & 0003 & $0000-00-0000-00: 00$ & & & \\
\hline
\end{tabular}

Figura 10. Lista de Proyectos Pendientes a elaborar. 


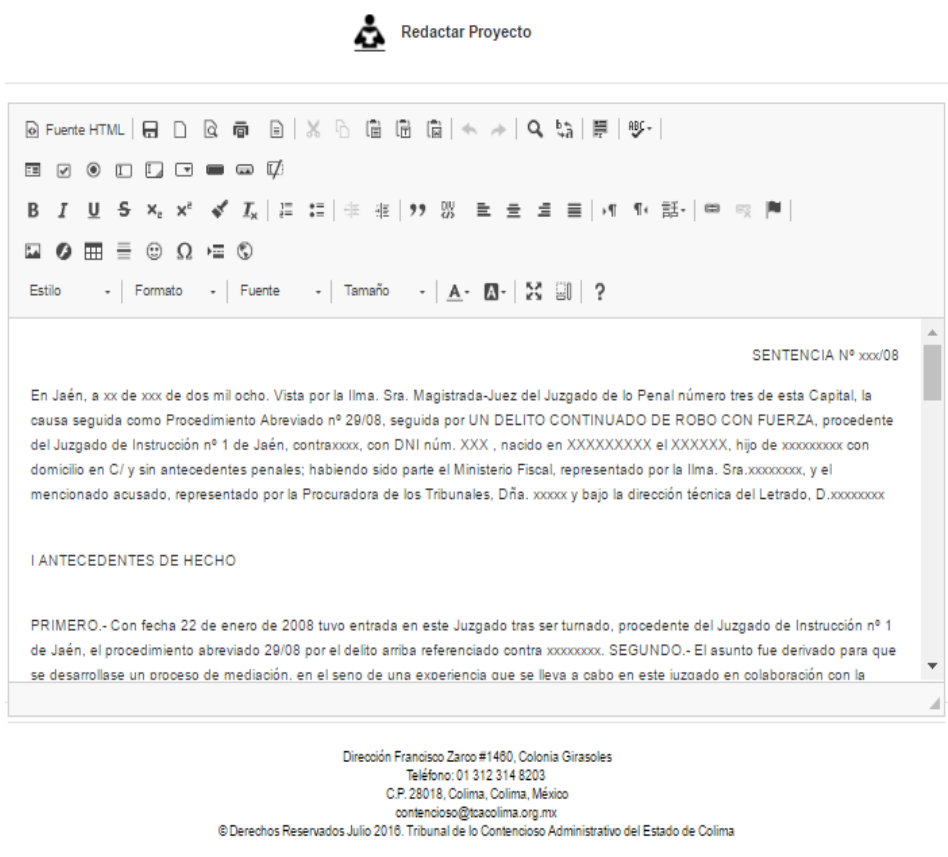

Figura 11. Vista redactar/editar proyecto de sentencia.

En la figura 11 se ilustran bitácoras para el registro histórico de las actividades utilizadas en el proceso de sentencias, ya que cada actividad tiene puntos de verificación para conocer el avance del litigio.

TA

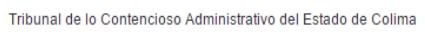

SISeDe v1.0

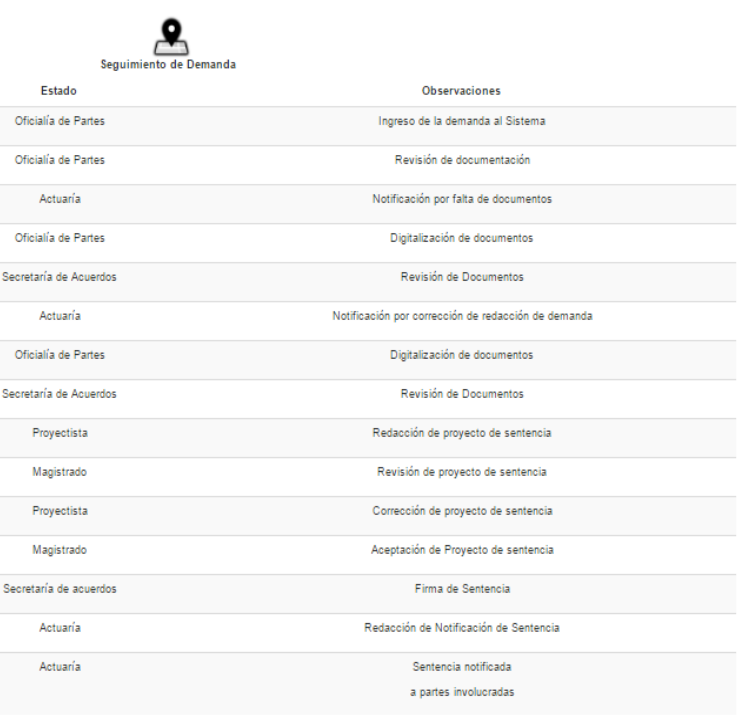

Figura 12. Seguimiento de demanda desde su ingreso hasta su notificación a partes involucradas. 


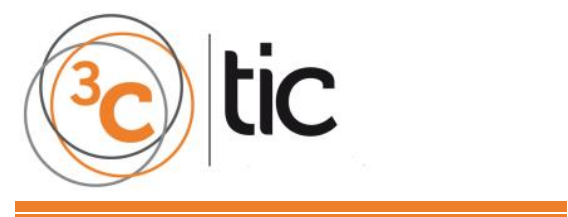

El uso de las TIC's en los procesos jurídicos administrativos contribuyen con una mejora en el proceso del litigio automatizando los procesos de seguimiento de proyectos de sentencias. Habitualmente, cada uno de los procesos que involucran a un proyecto de sentencia correspondiente a una demanda causaba un retraso en los tiempos de respuesta para poder dictar una sentencia definitiva para cada una de ella y espacio físico de almacenamiento.

\section{DISCUSIÓN Y CONCLUSIONES}

Este proyecto prevé un cambio total en el software, a través del cual el TCAEC realiza un seguimiento de los distintos trámites por los que va transitando un expediente judicial. Habilitada la gestión de sentencias con TIC's de vanguardia que favorecen la comunicación entre los actores que intervienen, se determinó que el desarrollo de un sistema web de seguimiento de sentencias mejora la administración de los procesos judiciales en el Tribunal de lo Contencioso Administrativo del Estado de Colima, ya que se desarrolló bajo un enfoque innovador utilizando bitácoras para el registro histórico de las actividades utilizadas en el proceso de sentencias. Se establecieron puntos de verificación para conocer el avance del litigio llevando el control del proceso en horas hombre, característica que los sistemas similares no tienen considerado.

Para continuar con este trabajo, se recomienda que cada uno de los documentos que se van a manejar en cada una de las partes involucradas en el proceso sean codificados para evitar el robo o alteración de cada uno de ellos ya que dentro de la seguridad informática ha habido muchos ataques cibernéticos para robo de información de empresas y personas físicas. 


\section{DISCUSIÓN Y CONCLUSIONES}

Gámez, A. M. (2015). Manual de Codeigniter.

Métodos de desarrollo Ágil. (2016). Obtenido de Proceso Unificado Agil (PUA): http://metodosdesarrolloagil.wikispaces.com/-+Proceso+Unificado+Agil+(PUA)

Mundo, R. d. (2005). Cumbre mundial sobre la Sociedad de la Información. Compromiso de Túnez. Ginebra.

Navas, G. Q. (2011). Contencioso Administrativo y medios electrónicos: un gran paso hacia la modernización del ejercicio de la justicia administrativa. Revista de Derecho, comunicaciones y Nuevas Tecnologías, 1-27.

TCAEC. (1996). Tribunal de lo Contencioso Administrativo del Estado de Colima. Obtenido de Presentación: http://tcacolima.org.mx/presentacion.php

Urdapilleta, M. C. (2015). Notas Generales del juicio en línea. PRAXIS de la Justicia Federal, 120. 


\title{
SISTEMA DE GESTIÓN DE
}

\section{MANAGEMENT INFORMATION SYSTEM IN THE WAREHOUSES OF THE CONSTRUCTOR COMPANY OF ARCHITECTURE WORKS AND INDUSTRIAL \#4 OF GRANMA}

\author{
Ángel Enrique Figueredo León ${ }^{1}$ \\ Agustín Alejandro Ortiz Díaz ${ }^{2}$ \\ Elena Martínez Pérez ${ }^{3}$
}

1. Master en Informática Aplicada. Profesor Asistente de la Universidad de Granma, Bayamo, (Cuba). afigueredol@udg.co.cu

2. Doctor en Ciencias. Profesor Asistente de la universidad de Granma, Bayamo, (Cuba). aortizd@udg.co.cu

3. Ingeniería en Ciencias Informáticas. Profesora Instructora de la Universidad de Granma, Bayamo, (Cuba). emartinezp@udg.co.cu

Citación sugerida:

Figueredo León, Á.E, Ortiz Díaz, A.A. y Martínez Pérez, E. (2017). Sistema de gestión de la información en los almacenes de la empresa constructora de obras de arquitectura e industriales \#4 de Granma. $3 C$ TIC: Cuadernos de desarrollo aplicados a las TIC, 6(2), 28-37. DOI: $<$ http://dx.doi.org/10.17993/3ctic.2017.56.28-37/>. 
En la Empresa Constructora de Obras de Arquitectura e Industriales \# 4 de Granma en Cuba se realizan varios procesos dentro de los que se incluye la gestión de la información en los almacenes, el cual se torna difícil debido a que se efectúan mediante modelos confeccionados en Microsoft Office Excel y documentos impresos propiciando demora en la obtención de los resultados y la divulgación de la información. Atendiendo a estas necesidades la presente investigación tiene como objetivo desarrollar una aplicación web. Para su implementación, se empleó el framework Codelgniter en la programación de páginas dinámicas, PHP en su versión 5.5.11 como lenguaje del lado del servidor, HTML5 como lenguaje del lado del cliente, con soporte de base de datos en MySQL y la metodología de desarrollo Extreme Programing software.

\section{ABSTRACT}

In the Company Manufacturer of Works of Architecture and Industrial of Tree they are carried out several processes inside those that the administration of the information is included in the warehouses of the Company Manufacturer of Works of Architecture and Industrial of Tree, the one which you difficult restitution because they are made by means of models made in Microsoft Office Excel and printed documents propitiating delay in the obtaining of the results and the popularization of the information; what conditions the responsible personnel's exhaustion and the bad use of the available resources. Attending to this needs, this research aims to develop a web application. For its implementation, the Codelgniter framework was used in the programming of dynamic pages, PHP in its version 5.5.11 as server side language, HTML5 as client side language, with MySQL database support and development methodology Extreme Programing software.

\section{PALABRAS CLAVE}

Aplicación web, productos en los almacenes, gestión de información.

\section{KEYWORDS}

Web Application, Products in the warehouses, Information Management. 


\section{INTRODUCCIÓN}

Hoy en día, debido al auge en las nuevas tecnologías se trabaja en la digitalización y automatización de la información en todas las ramas de la sociedad, en la industria, las comunicaciones, el gobierno, la salud, la educación, entre otros sectores. El desarrollo de la Informática y las Comunicaciones ha traído como consecuencia que el intercambio de información entre las empresas, organizaciones y entidades sea más rápida, segura y eficaz.

Nada ni nadie escapan al paradigma y la nueva sociedad que ha creado las telecomunicaciones, la informática e Internet, y el mundo de la construcción no es ninguna excepción. Cada vez son más las empresas constructoras que se involucran en gestionar sus principales procesos de diseño, construcción e ingeniería empleando las tecnologías de la información y la comunicación para cumplir con calidad su encargo social (Ferrada y Serpell, 2009).

El Ministerio de la Construcción es el organismo rector de la política de desarrollo de los Servicios de Diseño, Ingeniería y Construcción, Producción de Materiales de Construcción y del Sistema de la Vivienda en Cuba, además de dirigir y ejecutar en lo que le compete y controla la política del Estado y el Gobierno en cuanto a las investigaciones ingeniero-geológicas aplicadas a la construcción (MICONS, 2014). Todo esto no podría ser posible sin la correcta gestión de los materiales de la construcción necesarios para los procesos antes mencionados, es por ello que es de vital importancia el trabajo que se realiza en los almacenes de las instituciones del MICONS. Dicho proceso genera información de gran utilidad para el personal que allí labora. Esta se lleva de forma manual mediante modelos impresos y documentos manuscritos, condicionando que en el aspecto informativo se presente una excesiva centralización de la información y un flujo abundante de documentos impresos. Adicionalmente, las personas que necesitan la información no disponen de ella en el momento y espacio adecuado. Esta situación genera problemas organizativos y no cubre todas las demandas informativas al incurrirse en atrasos en la entrega de reportes.

La Empresa Constructora de Obras de Arquitectura e Industriales \# 4 (ECOAI4) de Granma es una de las dependencias del Ministerio de la Construcción que dentro de su estructura presenta el proceso antes mencionado. Cuenta con una alta productividad y eficiencia económica logrando construcciones competitivas, dotado de un personal motivado y elevado sentido de pertenencia. También cuenta con toda la industria modernizada y máxima calidad en las obras minimizando los daños en el entorno con una fuerte imagen corporativa que permite satisfacer a los clientes nacionales e internacionales.

La gestión de la información es el proceso de organizar la información, evaluar, presentar, comparar los datos en un determinado contexto, controlar la calidad, veracidad, que sea oportuna, significativa, exacta, útil y que esté disponible en el momento que se le necesite (Vidal y Araña 2012; Torres 2015). Teniendo en cuenta esta consideración y en aras de solucionar la ineficiencia en el proceso de gestión de la información relacionada con los productos en los almacenes en la ECOAI4, se propone en esta investigación desarrollar una aplicación web que lo realice de manera rápida y eficiencia. 
Inicialmente, se hizo un estudio en la ECOAI4 para constatar las deficiencias en la gestión de la información relacionada con los productos en los almacenes y determinar la mejor vía para solucionarlo. Se utilizaron métodos y técnicas como el análisis y síntesis para recopilar y procesar la información necesaria, la revisión documental para conocer con claridad los datos que son de interés, la entrevista para obtener datos detallados sobre su procesamiento, y la observación para ver las funcionalidades del jefe de la dirección técnica. Se realizó una búsqueda de sistemas informáticos que pudieran emplearse para resolver las deficiencias detectadas, y al no encontrarse ninguno, se desarrolló una aplicación web con este objetivo que se ajustara a sus necesidades.

Para su desarrollo se hizo una revisión bibliográfica sobre las posibles herramientas, tecnologías y lenguajes a utilizarse según sus prestaciones, tendencias actuales y novedades, con el fin de mantener la mayor integración posible y seleccionar las adecuadas (Gutiérrez, 2008; Hernández y Greguas, 2010). Se empleó el proceso de desarrollo para guiar la metodología Extreme Programing, ya que es una metodología ágil que se basa en la realimentación continua entre el cliente y el equipo de desarrollo, comunicación fluida entre todos los participantes y simplicidad en las soluciones (Bautista, 2015; Díaz, 2009; Tinoco, Rosales y Salas, 2010). Se utilizaron los lenguajes de programación del lado del cliente HTML 5 (Gauchat, 2012) y del lado del servidor PHP en su versión 5.5.11 (Gutiérrez, 2015). Este último permite la creación de páginas web dinámicas y facilita la conexión a diferentes tipos de servidores de bases de datos. Como gestor de base de datos se hizo uso de MySQL (Casillas y Luis Alberto, 2010), ya que cuenta con un completo soporte para tablas e índices en un único archivo por base de datos, soporte transaccional, rapidez, escaso tamaño y su completa portabilidad. Se utilizó el framework Codelgniter (Álvarez, 2009) por las facilidades para la creación de sitios web complejos. Se implementa el patrón de arquitectura ModeloVista-Controlador a través del entorno de desarrollo integrado NetBeans (Corporation, 2015). Las fases que se siguieron teniendo en cuenta lo que la metodología XP establece fueron las siguientes:

1. Exploración. En ella se definió el alcance del proyecto, se especificaron las funcionalidades que se deseaban informatizar para satisfacer las necesidades del cliente mediante 30 historias de usuario, estimándose el tiempo de desarrollo de cada una, que no era superior a los tres días. Entre las definidas se encuentran: actualizar y visualizar datos de los productos, obras, almacenes, incidencias de la seguridad informática, comportamiento de la conectividad (enlace conmutado y arrendado), mantenimientos, salidas de productos de los almacenes, los datos de los usuarios con correo y conexión nacional e internacional, inventario por obras, inventario por almacenes, entre otras.

2. Plan de entrega. Se realizó una estimación detallada del tiempo a emplearse en el desarrollo de las historias de usuario y para eso se dividieron en tres iteraciones. En el cronograma de entregas se estimó que la duración de la primera iteración fuera de cuatro semanas, la segunda y la tercera tres semanas cada una. 


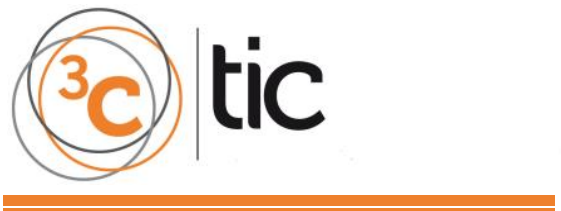

3C TIC (Edición núm. 21) Vol.6 - № 2

Junio - septiembre ' $17,28-37$

Área de Innovación y Desarrollo, S.L.

ISSN: $2254-6529$

DOI: http://dx.doi.org/10.17993/3ctic.2017.56.28-37

3. Iteraciones. Se planificó la etapa de implementación, definiéndose las tareas para desarrollar cada historia de usuario en términos de diseño y programación, se describió cada una y se estimó el tiempo de duración.

4. Producción. Se diseñó, codificó y probó la aplicación web. Tras ser creada la primera iteración, se trabajó en las nuevas.

$\checkmark$ Diseño: para lograr un sistema robusto, reutilizable y basados en las prácticas de la metodología seleccionada, se trabajó en un diseño sencillo y evolutivo. La base de datos se diseñó con 27 tablas normalizadas hasta la $3^{\text {ra }}$ Forma Normal mediante la herramienta Embarcadero ER/Studio.

$\checkmark$ Codificación: se tuvo en cuenta la reutilización de código para agilizar la implementación. Se estableció un estándar de codificación para lograr uniformidad y facilitar la comprensión del código.

$\checkmark$ Pruebas: se realizaron pruebas unitarias y de aceptación para evaluar la calidad de la aplicación web de forma pragmática y descubrir errores. Las unitarias o de caja blanca fueron desarrolladas por los programadores para verificar el código, es decir, los detalles procedimentales (la lógica del sistema). Las de aceptación también llamadas pruebas funcionales o de caja negra fueron supervisadas por el cliente, basándose en los requerimientos tomados de las historias de usuario se verificó el resultado esperado de una transacción determinada, y se llevaron a cabo sobre la interfaz. Estas pruebas permitieron encontrar errores como: funciones incorrectas, errores de interfaz, errores en estructuras de datos, errores de inicialización, errores ortográficos y la no actualización correcta de los datos. Todos los errores detectados fueron corregidos a tiempo, lográndose una aplicación web de mayor calidad.

5. Mantenimiento. Durante el desarrollo se tuvieron en cuenta las opiniones del cliente. En esta etapa se identificaron necesidades que propiciaron cambios en la aplicación web, lo que dio lugar a mantenimiento de tipo adaptativo, correctivo y perfectivo.

6. Muerte del Proyecto. Se generó la documentación final y al no requerirse más cambios en la arquitectura, al cliente no tener más historias de usuario que incluir y al estar satisfecho con el sistema, pues éste generó los beneficios esperados, se dio por terminada la aplicación web.

Una vez que finalizó la implementación de la aplicación web, esta se desplegó en la ECOAl4 y se capacitó al personal que interactúa con la misma. Además, se proporcionó un manual de usuario que contiene detalles de cómo se opera con ella para que pudiera evacuar cualquier duda sobre su manejo en el futuro. 


\section{RESULTADOS}

La aplicación web cuenta con una serie de funcionalidades que la hacen una herramienta útil para gestionar la información relacionada con productos de los almacenes de la ECOAI4. En su desarrollo se intentó satisfacer las necesidades del cliente. Su interfaz es cómoda y facilita la navegación. Es configurable, permitiendo ser implantado con gran facilidad en cualquier grupo empresarial o empresa que controle la misma información, con características similares.

En aras de garantizar la seguridad y confiabilidad de los datos que se gestionan, cuenta con una jerarquía de usuario para acceder a cualquier opción del sistema, dígase: introducir, modificar o eliminar e incluso visualizar los reportes, garantizándose así que la información que se introduzca la hagan personas debidamente autorizadas. Se tuvo en cuenta que solo accedan a los registros de la empresa a la que pertenecen y que a nivel de grupo empresarial se tenga acceso a todo. La contraseña se encriptó en la base de datos mediante el método md5. La figura 1 muestra la página de inicio.

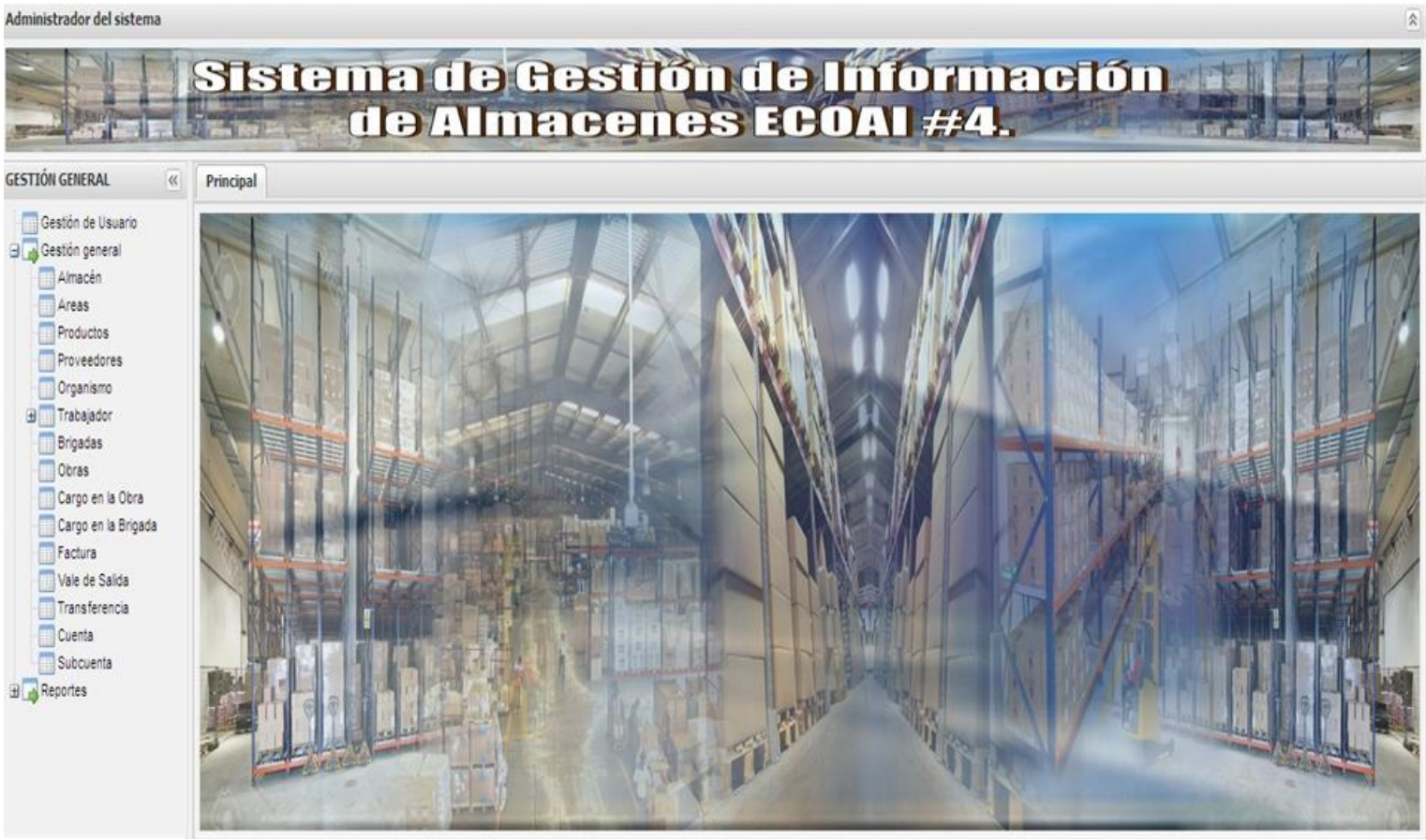

Figura 1. Página de inicio de la aplicación web.

Fuente: elaboración propia.

Entre la información que se gestiona mediante la aplicación web se encuentra la referente a los productos. En la figura 2 se observa el formulario con esta opción. Se siguió el mismo diseño para que sea cómodo al usuario, por ejemplo, el botón adicionar es para insertar un nuevo producto. 


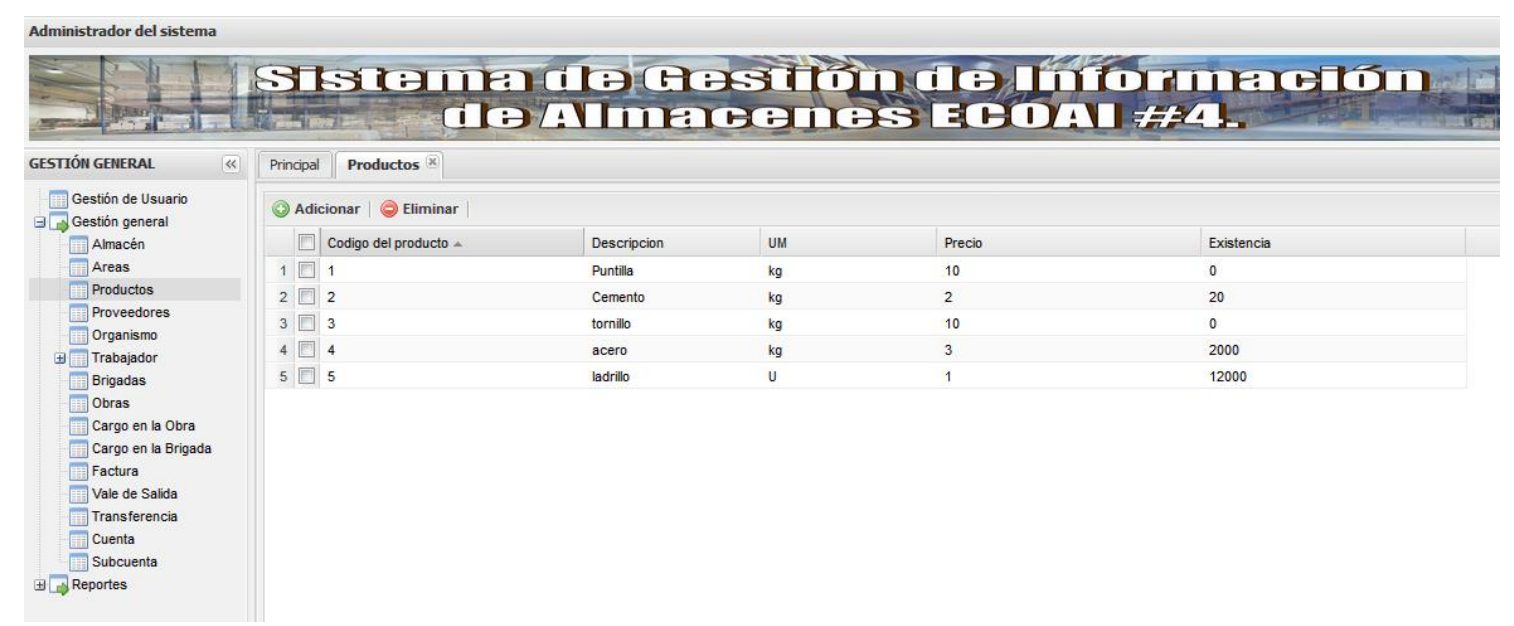

Figura 2. Gestión de los productos.

Fuente: elaboración propia.

También se pueden obtener reportes relacionados con el inventario de los productos en los almacenes, las transferencias emitidas en un intervalo de tiempo de un almacén a otro, entre otros, sustituyendo cálculos manuales y obteniendo los resultados de una forma más eficiente. Por ejemplo en la figura 3 se muestra el inventario de un almacén determinado.

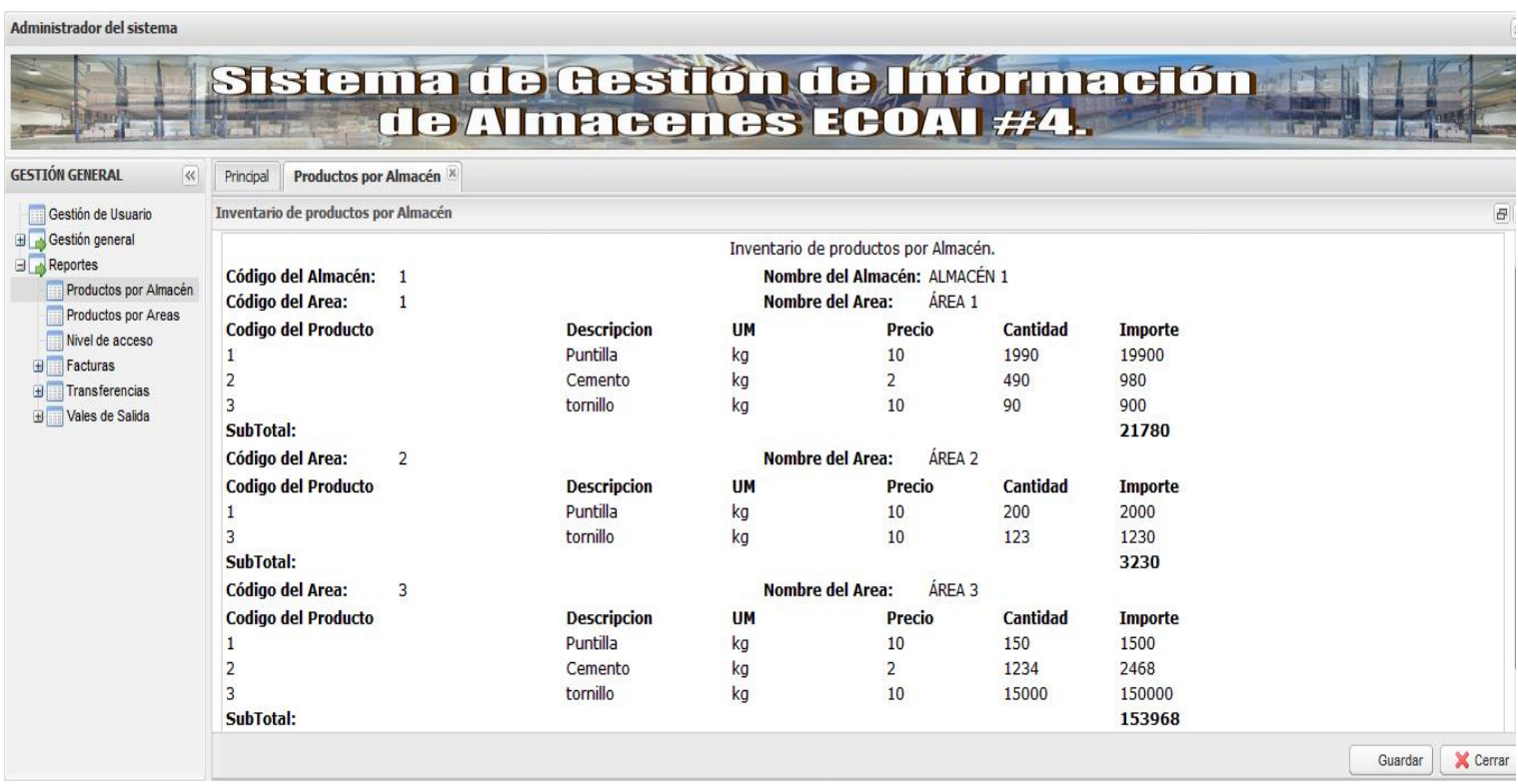

Figura 3. Reporte emitido por la aplicación web sobre inventario de un almacén determinado.

Fuente: elaboración propia.

La aplicación web brinda la facilidad de realizar salva(s) de seguridad de la base de datos cuando se estime necesario para garantizar la seguridad de la información ante la rotura del servidor o cualquier otra eventualidad. 


\section{DISCUSIÓN}

El éxito de un software se puede definir como calidad del sistema, de los datos y del servicio. La aplicación web impacta de manera positiva en los procesos y decisiones de la ECOAI \# 4, al repercutir en todos estos aspectos. Con su implantación, no es necesario mejorar el equipamiento del que se dispone pues se desarrolló en función de sus requerimientos técnicos. Las tecnologías que requiere para su funcionamiento están basadas en software libre, por lo que puede ser modificado en caso de cualquier error técnico. Se logra el ahorro de una serie de recursos como el papel al estar almacenada la información en formato digital y el combustible debido a lo distantes que están los almacenes unos de otros y en ocasiones las obras de los almacenes. Representa beneficios en cuanto al factor tiempo, los errores humanos se minimizan y el control es más sistemático.

No genera empleo ni desempleo, se facilita en gran medida la realización de las actividades laborales. Se requiere de un mínimo de esfuerzo para utilizar la aplicación web, evita el estrés y mejora la calidad de vida al poder realizarse las operaciones con mayor rapidez. Se contribuye a elevar el nivel profesional y cultural de todos los trabajadores, ya que están interactuando con la tecnología que es utilizada en la mayor parte del mundo en cuanto a medios de comunicación e informatización.

El usuario, una vez que interactuó con la aplicación web fue capaz de percibir los beneficios que esta le proporciona para evaluar su calidad se empleó el criterio de expertos mediante el método Delphi. Éste consiste en la utilización sistemática del juicio intuitivo de un grupo de expertos para obtener un consenso de opiniones informadas. Es considerado como uno de los métodos subjetivos de pronosticación más confiables (Blanco, López y Mengual, 2010; García y Suárez, 2013).

Los expertos que evaluaron la calidad de la aplicación web fueron 30. Respondieron una encuesta que se confeccionó a partir de los siguientes indicadores generales de evaluación:

1. Resulta una interfaz amigable y fácil de operar.

2. Garantiza la disponibilidad de la información actual e histórica.

3. Facilita el análisis de la información actualizada.

4. Garantiza la seguridad de la información.

5. Constituye una herramienta útil para la toma de decisiones.

6. Disminuye el tiempo de respuesta.

7. Eleva la calidad de la información.

8. Garantiza la obtención de todos los reportes que necesita.

9. Garantiza la obtención correcta de la información.

Después de realizado el procesamiento de la encuesta, se obtuvieron resultados a favor de la calidad y el impacto que tuvo la puesta en práctica en la ECOAI4 de la aplicación web para la gestión de información de los almacenes. 


\section{CONCLUSIONES}

En la presente investigación se efectuó un análisis del proceso de gestión de la información en los almacenes de la Empresa Constructora de Obras de Arquitectura e Industriales \# 4 de Granma.

Se desarrolló un sistema informático que automatiza el proceso antes mencionado facilitándole a esta institución una herramienta eficiente que reduce a cero los costos de transportación para garantizar el flujo de la información contable desde los almacenes hacia la oficina central de la empresa. La solicitud de los materiales antes de implantado el sistema dependía del transporte y de la distancia entre obras y almacenes y con el sistema es instantáneo la misma. Además, el tiempo de servir un pedido de material se redujo en más de un $80 \%$ con respecto a cómo se hacía antes de instalado el sistema. Por último, también reduce considerablemente el tiempo para efectuar los controles necesarios a la gestión de los almacenes. 


\section{REFERENCIAS BIBLIOGRÁFICAS}

Álvarez, M. A. (2009). Codelgniter es un framework PHP para la creación rápida de aplicaciones web. Recuperado el 25 de noviembre, 2015, a partir de: $<$ http://www.desarrolloweb.com/manuales/manual-codeigniter.html/>.

Bautista, J. M. (2015). EXTREME PROGRAMMING (XP). [Recuperado el de Item]. Caballero, D. (2015). Sistema de gestión de contratos Gnsis9. Recuperado el 16 de febrero, 2016, a partir de: <http://ofertas.cu/a/24895/sistema-de-gestion-de-contratos-gnsis9.html/>.

Blanco, J.E., López, A. y Mengual, S. (2010). Validación mediante método Delphi de un cuestionario para conocer las experiencias e interés hacia las actividades acuáticas con especial atención al Windsurf. ÁGORA, 12(1), 75-96.

Casillas, y. c., Luis Alberto (2010). Bases de datos en MySQL. Recuperado de: $<$ http://ocw.uoc.edu/computer-science-technology-and-multimedia/bases-dedatos/bases-de-datos/P06 M2109 02151.pdf/>.

Corporation, L. (2015). Entorno de desarrollo integrado. Recuperado el 25 de noviembre 2015, a partir de: <http://es.slideshare.net/NIRVANA27/entorno-de-desarrollointegrado?qid=ead0555a-a9c1-4e45-a1fa4673a364e30c\&v=qf1\&b=\&from search=2/>.

Díaz, J. (2009). Las metodologías ágiles como garantía de calidad del software. Revista Española de Innovación, Calidad e Ingeniería del Software (REICIS), 5(3), 40-43.

Ferrada, X.V. y Serpell, A. (2009). La gestión del conocimiento y la industria de la construcción. Revista de la Construcción, 8(1), 46-58.

García, M. y Suárez, M. (2013). El método Delphi para la consulta a expertos en la investigación científica. Revista Cubana de Salud Pública, 39(2), 253-267.

Gauchat, J. (2012). El gran libro de HTML5, CSS3 y Javascript. Barcelona España.

Gutiérrez, C. (2008). Diseño web y arquitectura de información para sitios 2.0. Cuadernos de Información, 22, 58-65.

Gutiérrez, E. G. (2015). ¿Qué es php? ¿Para qué sirve php? Un potente lenguaje de programación para crear páginas web. [Recuperado el de Item].

Hernández, R.L. y Greguas, D. (2010). Estándares de Diseño Web. Ciencias de la Información, 41(2), 69-71.

MICONS. (2014). Modelo del profesional de la especialidad Construcción Civil. Consultado: 7 de noviembre de 2014, a partir de: <http://micons.netcons.com.cu/>.

Tinoco, O., Rosales, P. P. y Salas, J. (2010). Criterios de selección de metodologías de desarrollo de software. Industrial Data, 13(2), 70-74. 


\title{
SISTEMA INFORMÁTICO PARA EL DISEÑO Y GESTIÓN DE RECORRIDOS VIRTUALES PARA TOURDROID
}

\section{THE COMPUTATIONAL THINKING ABOUT PROMOTING DEVELOPMENT OF SKILLS RELATED CREATIVE SOLVING PROBLEMS}

\author{
Viana de la Cruz Leyva ${ }^{1}$ \\ Yoel Adrián Ortiz Pacheco² \\ Noel Ernesto Enamorado Selema ${ }^{3}$
}

1. Profesora del Departamento de Informática de la Universidad de Granma. Cuba.

vleyva@udg.co.cu

2. Administrador de Redes del Partido Provincial en Granma. Cuba.

3. Profesor de la Universidad de Ciencias Informáticas. Cuba.

\section{Citación sugerida:}

Cruz Leyva, V. de la, Ortiz Pacheco, Y.A. y Enamorado Selema, N.E. (2017). Sistema informático para el diseño y gestión de recorridos virtuales para Tourdroid. 3C TIC: Cuadernos de desarrollo aplicados a las TIC, 6(2), 38-51. DOI: <http://dx.doi.org/10.17993/3ctic.2017.56.38-61/>. 


\section{RESUMEN}

En la Facultad de Ciencias Informáticas de la Universidad de Granma existe el sistema de información geográfica Tourdroid Bayamo para dispositivos móviles con soporte Android en su versión 2.3 o superior. Es una guía virtual que asocia información geográfica y visual de sitios de interés histórico, económico y cultural de la región. La investigación tiene como objetivo crear un sistema informático para agilizar el proceso de diseño y gestión de los recorridos virtuales para Tourdroid.

\section{ABSTRACT}

In the Faculty of Computer Science of the University of Granma there is the geographical information system Tourdroid Bayamo for mobile devices with Android support in version 2.3 or higher. It is a virtual guide that associates geographic and visual information of sites of historical, economic and cultural interest of the region. The research aims to create a computer system to streamline the process of design and management of virtual tours for Tourdroid.

\section{PALABRAS CLAVE}

Android, móviles, Tourdroid, virtual.

\section{KEY WORDS}

Android, mobile, Tourdroid, virtual. 


\section{INTRODUCCIÓN}

El desarrollo social y tecnológico de una región está muy ligado a la gestión y potencialización de su territorio. Para realizar la gestión de un territorio es necesario definir la localización y características esenciales del mismo, de manera que exista claridad para generar información segura que permita optimizar la planificación y gestión de las actividades económicas. Los SIG son las herramientas que se han desarrollado mundialmente para llevar a cabo estas tareas.

Un SIG es una colección organizada de hardware, software, datos geográficos y personal designado para capturar, almacenar, actualizar, manipular, analizar y mostrar todas las formas de información geográfica referenciada, o sea, un sistema capaz de mantener y usar datos que están asociados a lugares en la superficie terrestre.

En la actualidad, los SIG tienen una fuerte implantación en los llamados servicios basados en la localización (LBS, Location Based Service) debido a la masificación de los sistemas de posicionamiento global (GPS, Global Position System) integrado en dispositivos móviles. Los LBS permiten a los dispositivos móviles con GPS mostrar su ubicación respecto a puntos de interés fijos: restaurantes, gasolineras, cajeros, hoteles, entre otros.

Los SIG, con la evolución de la telefonía móvil, han encontrado una plataforma de interés para su implementación. En el mundo se han realizado varios SIG para celulares, ejemplo de esto son, MapDroid y Locus.

En Cuba, la empresa Geosi desarrolló el SIG Andariego para dispositivos móviles con sistema operativo Android. Esta herramienta brinda información detallada sobre todas las provincias de Cuba, además cuenta con servicio GPS que le permite al usuario ver su localización en el mapa y su recorrido mientras se mueve. Para su actualización, es necesario acceder a Internet a través de una computadora personal y descargar los datos actualizados.

En la Facultad de Ciencias Informáticas de la Universidad de Granma se desarrolló el SIG Tourdroid Bayamo para dispositivos móviles con soporte Android en su versión 2.3 o superior. Tourdroid es una guía virtual que asocia información geográfica y visual de sitios de interés histórico, económico y cultural de una región. La información que brinda a los usuarios solo depende de la almacenada en la base de datos, por lo que sería necesario enfrentarse en una nueva versión de la aplicación, para agregarle nuevas funcionalidades.

Define una arquitectura estrictamente regida por la información almacenada en la base de datos, pensada inicialmente para hacerlo adaptable a cambios en tiempo real y que lograra independencia del cliente con el equipo de desarrollo. Hoy, la información que se brinda se considera obsoleta debido a que esta no puede ser actualizada una vez desplegado el producto, a menos que se sobrescriba la base de datos existente en los terminales móviles.

La obsolescencia de los datos almacenados en Tourdroid influye de forma negativa en el nivel de aceptación de la aplicación, ya que las instituciones promovidas podrían sufrir cambios en su estructura interna y no existe un mecanismo para la actualización de su información. Solamente depende de la capacidad de respuesta de un equipo de desarrollo que no es 


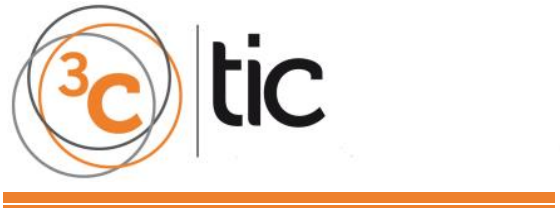

factible para los usuarios ni la empresa que la comercialice pues contradice varios principios de los sistemas de información geográfica, influyendo negativamente para definirlo como un producto de calidad.

Analizada la problemática antes expuesta se plantea como problema a resolver: ¿Cómo mejorar el diseño y gestión de la información contenida en la base de datos de Tourdroid?

El objeto de estudio de la presente investigación se enmarca en el diseño y gestión de recorridos virtuales.

Una vez analizado el problema científico en cuestión, se define como objetivo general de la investigación: desarrollar el sistema informático para el diseño y gestión de recorridos virtuales para Tourdroid.

El campo de acción se centra en el diseño y gestión de recorridos virtuales para Tourdroid.

Se establece como idea a defender que con el desarrollo del sistema informático para el diseño y gestión de recorridos virtuales para Tourdroid se agilizará el proceso de actualización de la información almacenada en su base de datos.

\section{SISTEMA DE INFORMACIÓN GEOGRÁFICA TOURDROID}

Tourdroid es un sistema de información geográfica para dispositivos móviles con sistema operativo Android en su versión 2.3 o superior, capaz de brindar información geográfica y visual de los distintos sitios de interés de un entorno. Aunque inicialmente fue concebido para la ciudad de Bayamo, la herramienta posee una arquitectura adaptable para estandarizarla a otros entornos, lo cual se sustenta en que solo es necesario la modificación de los datos contenidos en su base de datos a menos que se incremente un valor agregado a sus funcionalidades.

El sistema permite:

$\checkmark$ Visualizar la información descriptiva del recorrido virtual perteneciente al lugar escogido.

$\checkmark$ Observar las imágenes panorámicas cilíndricas referentes a las salas de un recorrido virtual.

$\checkmark$ Visualizar la descripción correspondiente a la sala, lo que le facilita a los usuarios conocer en detalle la instalación.

$\checkmark$ Ampliar y disminuir un área de la imagen panorámica perteneciente a la sala visualizada. Con ello, se consigue mayor exactitud en la visualización de los objetos pequeños que se encuentran en la escena. 
$\checkmark$ Desplazarse en una imagen panorámica de forma horizontal y vertical, brindándole a los usuarios mayor efecto de realismo.

$\checkmark$ Seleccionar un objeto de interés incluido en una sala.

$\checkmark$ Apreciar la descripción correspondiente al objeto seleccionado, lo que le facilita a los usuarios conocer información detallada de los elementos que forman parte de la escena.

$\checkmark$ Visualizar una imagen ampliada del objeto seleccionado correspondiente a una sala de un recorrido virtual.

La herramienta posee un mecanismo de acceso a los datos, que recibe las solicitudes de almacenamiento o recuperación de información y envía las respuestas a las peticiones, este se basa en la correcta y precisa manipulación de los datos.

\subsection{RECORRIDOS VIRTUALES EN TOURDROID}

La visualización de los recorridos virtuales en Tourdroid se realiza de la forma tradicional, es decir, basado en la visualización en $360^{\circ}$ de un conjunto de imágenes panorámicas relacionadas entre sí. No obstante, están implementadas para dispositivos móviles con sistema operativo Android, el cual cuenta con la librería de código abierto PanoramaGLAndroid que posee la propiedad de visualizar imágenes panorámicas esféricas, cilíndricas y cúbicas, y que además permite ampliar y disminuir la imagen visualizada mediante el zoom. También facilita el desplazamiento en la panorámica hacia cualquier dirección, con el uso del acelerómetro del teléfono inteligente. Ofrece compatibilidad con OpenGL ES 1.1 y soporte para el uso de hotspots. En contraposición, para su correcto funcionamiento se necesita la máquina virtual de Java para Android, Dalvik Virtual Machine, instalado en su dispositivo móvil.

\section{PROPUESTA DE SOLUCIÓN}

Para lograr el desarrollo de una aplicación con calidad que satisfaga las necesidades del cliente, en el trabajo actual se define la metodología que guiará el proceso de desarrollo del software, así como los lenguajes y herramientas que se utilizarán para el desarrollo de la aplicación. Se describen las funcionalidades que debe brindar el sistema informático propuesto, así como su arquitectura y modelo de diseño. 


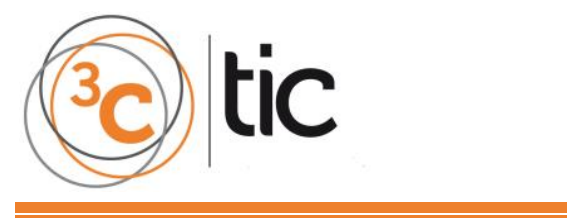

\subsection{ESTUDIOS DE SIMILARES}

\section{DVista Virtual Tour Standard}

3DVista Virtual Tour Standard permite crear visitas virtuales espectaculares que pueden ser incluidas en cualquier web y vistas desde cualquier dispositivo u ordenador. Convierte un grupo de fotos en una escena de 360․ Incluye 3DVista Stitcher 4 y un Publicador que convierte los panoramas en visitas virtuales de alta calidad con interfaz gráfico totalmente personalizable (“3DVista," 2016).

\section{DVista Virtual Tour Pro}

3DVista Virtual Tour Pro permite crear visitas virtuales multimedia que cautivan por su interactividad e impresionante rango de opciones, tales como Live Panorama, HDR Adaptativo, Hotspots, Piloto automático, Video interactivo, Albums de Fotos, Planos y Audio Inmersivo. Incluye también 3DVista Stitcher 4 y un Publicador. 3DVista ha desarrollado la tecnología "HDR Adaptativo" que adapta la luz de un panorama según la zona donde mire el usuario. Con solo unos clics se obtiene visitas virtuales profesionales compatibles con todos los dispositivos móviles, tabletas y ordenadores ("3DVista," 2016).

\section{Dermandar}

Dermandar es una herramienta online que permite hacer fotografías panorámicas de forma muy cómoda e insertarlas en los sitios web. Tiene versiones para Android y iPhone (Google Play - Apple Store) que facilitan el trabajo, pues son las que hacen el montado de las fotografías. Soporta HTML5 (Raúl, 2012).

\subsection{DESCRIPCIÓN DE LA SOLUCIÓN PROPUESTA}

Se propone el desarrollo de un sistema informático que posibilite el diseño y gestión de recorridos virtuales para Tourdroid, mediante un ambiente amigable. El sistema debe permitir la gestión de la información almacenada, la creación, modificación y eliminación de recorridos virtuales, salas y hotspots. Los datos geográficos referentes a los recorridos virtuales podrán ser verificados mediante su visualización en un espacio geográfico simulado por un mapa. Posibilitará generar una base de datos con la información del sistema para su posterior divulgación. Se propone además el desarrollo de un sistema de transmisión de datos para la actualización de la información almacenada en los dispositivos móviles que cuenten con Tourdroid. 


\subsection{METOdOLOGÍA DE DESARROLlO DE SOFTWARE ESCOGIDA}

Las metodologías de desarrollo de software brindan un conjunto de procedimientos, técnicas, herramientas y soporte documental que ayuda a los desarrolladores a realizar un mejor producto, al estructurar, planificar y controlar el proceso de desarrollo del software.

Una metodología es un conjunto de métodos eficientes orientados a conseguir un objetivo definido, un grupo de procesos que, organizados, brindan una secuencia de pasos a seguir para obtener los hitos propuestos y, finalmente el producto (2010).

Las metodologías de desarrollo de software se pueden clasificar en ágiles y robustas, y la aplicación de una de ellas depende de las características del producto que se desee desarrollar. En la presente investigación se utilizará un enfoque de desarrollo ágil debido a las características del software que se realizará.

Se seleccionó como metodología de desarrollo de software SXP, porque al ser un híbrido creado a partir de lo mejor de SCRUM y XP, se adapta al proyecto en cuestión y permite cambios en los requisitos en dependencia de las necesidades del usuario. El equipo de desarrollo está compuesto por pocas personas y esta metodología es ideal para equipos pequeños. Solo genera los artefactos necesarios, lo que permite utilizar el tiempo en otras actividades y agilizar el desarrollo del software. Además permite mantener de forma organizada los artefactos que se generan por cada una de las fases.

SXP

Es un híbrido entre las metodologías SCRUM y XP, la cual ofrece una estrategia tecnológica a partir de la introducción de procedimientos ágiles que permiten actualizar los procesos de software para el mejoramiento de la actividad productiva. Se fomenta el desarrollo de la creatividad, se aumenta el nivel de preocupación y responsabilidad de los miembros del equipo y se ayuda al líder del proyecto a tener un mejor control del mismo. Consiste en una programación rápida o extrema, cuya particularidad es tener como parte del equipo, al usuario final, pues es uno de los requisitos para llegar al éxito del proyecto (Abel Meneses, 2009).

SXP cuenta con cuatro fases:

1. Planificación-definición: en esta fase se establece la visión, se fijan las expectativas y se realiza el aseguramiento del financiamiento del proyecto.

2. Desarrollo: aquí es donde se realiza la implementación del sistema hasta que se encuentre listo para ser entregado, además se realizan las pruebas al software.

3. Entrega: puesta en marcha del producto.

4. Mantenimiento: donde se realiza el soporte de la aplicación para el cliente. 


\subsection{LENGUAJES Y HERRAMIENTAS}

Python ha sido diseñado por Guido Van Rossum y está en un proceso de continuo desarrollo por una gran comunidad de desarrolladores. Es un lenguaje de programación interpretado y orientado a objetos. Está libremente disponible en archivos binarios o de código fuente. Una ventaja fundamental de Python es la gratuidad de su intérprete.

Python presenta una serie de ventajas que lo hacen muy atractivo, tanto para su uso profesional como para el aprendizaje de la programación. Entre las más interesantes desde el punto de vista didáctico aparecen las siguientes (Isabel García, 2003):

$\checkmark$ Es un lenguaje muy expresivo, es decir, los programas Python son muy compactos: un programa Python suele ser más corto que su equivalente en lenguajes como $C$.

$\checkmark$ Es muy legible. Su sintaxis es muy elegante y permite la escritura de programas cuya lectura resulta más fácil que si se utilizaran otros lenguajes de programación.

$\checkmark$ Ofrece un entorno interactivo que facilita la realización de pruebas.

$\checkmark$ Puede usarse como lenguaje imperativo procedimental o como lenguaje orientado a objetos.

$\checkmark$ Posee un rico juego de estructuras de datos que se pueden manipular de modo sencillo.

$\checkmark$ Es fácil de comprender y está considerado por muchos que será el lenguaje de programación de elección por los nuevos programadores.

Se selecciona del lenguaje de programación Python para el desarrollo de la aplicación porque es un lenguaje libre, multiplataforma, orientado a objetos, muy fácil de aprender y tiene una sintaxis muy simple que hace que los programas escritos en él sean legibles.

\section{Lenguaje unificado de modelado}

UML (Unified Modeling Language) es el estándar industrial de notación de modelado para sistemas orientados a objetos, constituye la plataforma inicial para el desarrollo rápido de aplicaciones. Es un lenguaje gráfico para visualizar, especificar, construir y documentar artefactos de un software (Roger S. Pressman, 2002). Se utiliza UML para modelar el sistema, ya que se compone de elementos que permiten la representación del software mediante diagramas. Además, sirve de guía a la mayoría de los procesos orientados a objetos, capta la información sobre la estructura estática y el comportamiento dinámico del sistema.

\section{Herramienta CASE}

De acuerdo a Roger S. Pressman, las herramientas CASE (Computer Aided Software Engineering) "Son un complemento de la caja de herramientas del ingeniero del software que le proporciona, la posibilidad de automatizar actividades manuales y de mejorar su visión 
general de la ingeniería. Al igual que las herramientas de ingeniería y diseño asistidos por computadora que utilizan de otras disciplinas, las herramientas CASE ayudan a asegurar que la calidad sea algo diseñado antes de llegar a construir el producto" (Roger S. Pressman, 2002).

Estas herramientas ayudan a los gestores y practicantes de la ingeniería del software en todas las actividades asociadas a los procesos de software. Automatizan las actividades de gestión de proyectos, gestionan todos los productos de los trabajos elaborados a través del proceso y ayudan a los ingenieros en el trabajo de análisis, diseño y codificación. Las herramientas CASE se pueden integrar dentro de un entorno sofisticado.

\section{Visual Paradigm}

Visual Paradigm es una herramienta profesional que soporta el ciclo de vida del desarrollo de software. Ayuda a una rápida construcción de aplicaciones de calidad a un menor coste. Permite dibujar todos los tipos de diagramas de clases, generar código desde diagramas y documentación. Es compatible con sistemas GNU/Linux y está registrado bajo la licencia de software libre.

Algunas de las principales ventajas que ofrece son las siguientes (n.d.):

$\checkmark$ Usa un lenguaje estándar común a todo el equipo de desarrollo y facilita la comunicación.

$\checkmark$ Tiene capacidades de ingeniería directa e inversa.

Tiene modelos y códigos que permanecen sincronizados en todo el ciclo de desarrollo.

$\checkmark$ Presenta disponibilidad de múltiples versiones, para cada necesidad y múltiples plataformas.

Se emplea Visual Paradigm por sus ventajas y facilidad de uso, además, utiliza UML como notación para elaborar los modelos y comunicar de manera eficiente a todos los agentes del proyecto aquellas decisiones que se toman con respecto a la arquitectura del sistema en discusión. La misma permite realizar rápidamente el modelado necesario para el desarrollo de la aplicación.

\section{Entorno de desarrollo integrado}

Un entorno de desarrollo integrado (IDE, Integrated Development Environment) es un conjunto de herramientas de programación para escribir aplicaciones, todo activado desde unos menús e interfaces de usuario común. Es un procedimiento estándar necesario para el desarrollo de programas (n.d.).

Estos incluyen un editor de código fuente, un compilador y usualmente un depurador que trabajan conjuntamente al construir un software. El IDE le sigue la pista a todos los archivos 
relacionados con un proyecto y provee una interfaz central para el código fuente que escribe. A continuación se describe el empleado en el desarrollo de la aplicación.

Geany es un editor de texto con las características básicas de un entorno de desarrollo integrado, desarrollado para que tuviera pocas dependencias de otros paquetes. Su principal objetivo es ser lo más independiente posible de entornos de escritorios especiales, solo requiere de las bibliotecas en tiempo de ejecución GTK2. Posee características como: autocompletado en la construcción del código fuente, coloreado de sintaxis, compatible con la mayoría de los lenguajes de programación, verifica que todas las etiquetas estén cerradas y consume poca memoria RAM (Random Access Memory). Se puede ejecutar bajo varias plataformas incluidas Windows y Linux, su código está disponible bajo los términos de la Licencia Pública General de GNU (n.d.).

\subsection{ESPECIFICACIÓN DE LOS REQUISITOS DEL SISTEMA}

Es vital en la producción de un software lograr una comunicación efectiva entre los usuarios y el equipo de desarrollo, con el objetivo de llegar a un entendimiento de lo que se debe hacer. La correcta identificación de los requisitos es el punto de partida para desarrollar un producto de calidad que satisfaga para el cliente.

"Un requerimiento es una característica que el sistema debe tener o es una restricción que el sistema debe satisfacer para ser aceptada por el cliente" (n.d.).

Tras conocer las necesidades del cliente se identificaron los requisitos funcionales (RF) y no funcionales (RNF).

\section{Requisitos funcionales}

Los requisitos funcionales son declaraciones de las características que debe proporcionar el sistema. Describen la interacción entre el sistema y su ambiente independientemente de su implementación. El ambiente incluye al usuario y cualquier otro sistema externo que interactúa con el sistema (n.d.).

A continuación se muestran los RF de la aplicación a desarrollar:

1. Autenticar usuario: el sistema debe validar una vez que el usuario intente acceder al sistema que el nombre de usuario y contraseña sean correctos.

2. Gestionar usuario: permite al administrador del sistema, insertar, modificar o eliminar un usuario.

3. Gestionar un recorrido virtual: permite al usuario insertar, modificar o eliminar un recorrido virtual. 
4. Gestionar las salas o espacios incluidos en el recorrido virtual: permite al usuario insertar, modificar o eliminar las imágenes panorámicas, así como los vínculos entre ellas.

5. Gestionar objetos: permite al usuario insertar, modificar o eliminar los objetos más importantes de una sala.

6. Insertar mapa: permite al usuario agregar un mapa del entorno que mostrará la información geográfica de los recorridos virtuales.

7. Generar actualización: permite al usuario generar la base de datos de Tourdroid incluyendo los últimos cambios realizados.

8. Actualizar Tourdroid: permite al usuario actualizar la base de datos de Tourdroid en los dispositivos móviles que cuenten con dicha aplicación.

\section{Requisitos no funcionales}

Los requisitos no funcionales son aquellos requerimientos que no se refieren directamente a las funciones específicas que proporciona el sistema, sino a las propiedades emergentes de este como la fiabilidad, capacidad de almacenamiento y el tiempo de respuesta. De forma alternativa, definen las restricciones del sistema como la capacidad de los dispositivos de entrada/salida y las representaciones de datos que se utilizan en las interfaces del sistema (n.d.).

A continuación, se muestran los requisitos no funcionales del sistema:

- Requisitos de usabilidad: El sistema propuesto podrá ser usado por usuarios con conocimiento básicos de informática, ya que estará estructurado de forma sencilla. El sistema proporcionará un mejor escenario en el proceso de diseñar y gestionar los recorridos virtuales para Tourdroid.

- Requisitos de seguridad: El sistema deberá garantizar el tratamiento adecuado de las excepciones mediante el lanzamiento de un tipo de excepción en dependencia de la situación anómala que ocurra, manejándola, una vez que se conozca el error ocurrido. El sistema deberá garantizar que el usuario reciba de forma segura la actualización de la información de la base de datos de Tourdroid. El sistema deberá garantizar que para que un usuario pueda acceder al sistema, antes, debe estar autenticado con un usuario válido. El sistema solo le mostrará a cada usuario las funcionalidades sobre las cuales tiene permiso.

- Requisitos de software: Sistemas operativos: GNU/Linux o Microsoft Windows.

- Requisitos de hardware: El sistema deberá desplegarse en una PC, que cuente con los requerimientos mínimos de un microprocesador Pentium IV de $3.0 \mathrm{GHz}$, con una memoria RAM de $512 \mathrm{MB}$ y un disco duro con al menos $50 \mathrm{MB}$ de capacidad disponible. Los dispositivos móviles que cuenten con Tourdroid, necesitan tener 


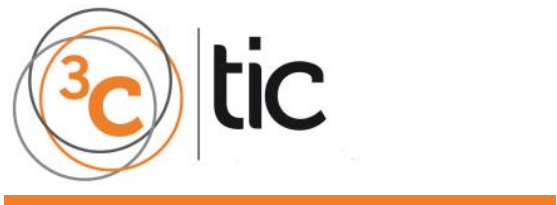

implementado el estándar IEEE 802.11. En la red donde se despliegue el producto se debe disponer de un punto de acceso inalámbrico.

- Restricciones de diseño e implementación: Uso de plataforma libre, se programará en el lenguaje Python, se hará uso del Qt Designer para el diseño de las interfaces de la aplicación y se utilizará el comando de Python pyuic4 para convertir las interfaces.ui creadas en el Qt Designer a interfaces.py.

\subsection{DESCRIPCIÓN DE LAS HISTORIAS DE USUARIO}

A continuación se describe la historia de usuario (HU) Autenticar_usuario de la aplicación a desarrollar.

Tabla 2. Descripción de la HU Autenticar_Usuario.

\begin{tabular}{|l|l|}
\hline Número: 2 & Nombre historia de usuario: Autenticar_usuario \\
\hline $\begin{array}{l}\text { Usuario: Yoel Adrian Ortiz Pacheco } \\
\text { Noel Ernesto Enamorado Selema }\end{array}$ & Iteración asignada: 1 \\
\hline & \multicolumn{2}{|c|}{ Puntos estimados: 1} \\
\hline Programador responsable: Yoel Adrian Ortiz Pacheco \\
\hline Prioridad en negocio: Alta & $\begin{array}{l}\text { Riesgo en desarrollo: Alto } \\
\text { Descripción: la HU comienza cuando el usuario desea acceder a la aplicación. Para autenticarse se } \\
\text { debe insertar el nombre de usuario y la contraseña correctamente. Al presionar el botón “Aceptar” } \\
\text { terminará la HU. }\end{array}$ \\
\hline \begin{tabular}{l} 
Prototipo de interfaz: Figura B.1 \\
\hline
\end{tabular}
\end{tabular}

Fuente: elaboración propia.

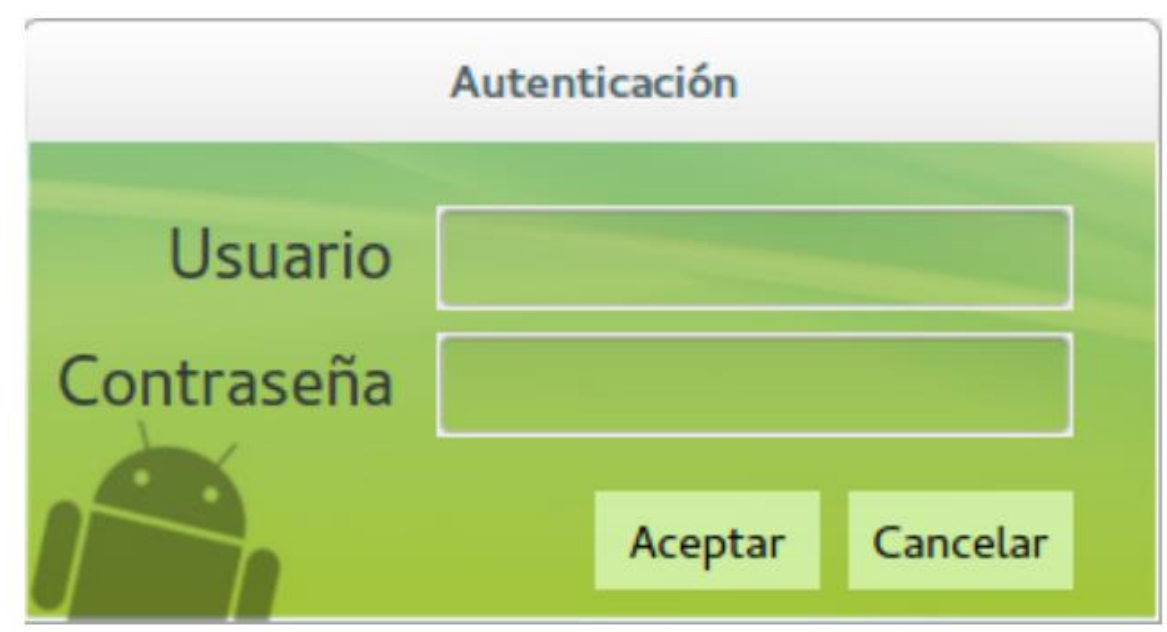

Ilustración 1. Autenticar_Usuario. 


\section{CONCLUSIONES}

Con el desarrollo del sistema informático para el diseño y gestión de recorridos virtuales para Tourdroid, se obtuvo un sistema que agiliza el proceso de actualización de su información, dándole solución a la problemática existente. La información que brindará Tourdroid podría considerarse actualizada, lo que aumentaría el nivel de aceptación de la aplicación. El desarrollo del producto estuvo guiado por la metodología de desarrollo de software SXP, la cual permitió hacer uso de las ventajas del manifiesto ágil y documentar correctamente toda la información manejada, mediante un expediente de proyecto con artefactos bien definidos.

Un estudio de sistemas similares reveló que estos no se adaptaban a los requerimientos de la aplicación a implementar, ya que sus recorridos virtuales definen una arquitectura distinta a los de Tourdroid y se desarrollan sobre tecnologías privativas; aunque apoyó en la concepción del negocio para el desarrollo del sistema.

El sistema ofrecido permite, mediante un ambiente amigable, la gestión de la información almacenada en la base de datos de Tourdroid, y brinda un sistema de transmisión inalámbrica para su actualización. Implementándose correctamente todos los requisitos que el cliente solicitó, con la adecuada aplicación de metodologías, herramientas y lenguajes de código abierto.

El servicio web como mecanismo de comunicación, unido a la tecnología de transmisión inalámbrica IEEE 802.11, constituyeron una solución correcta para lograr la transferencia de los datos actualizados hacia los usuarios finales. Se consiguió mediante la implementación de una nueva funcionalidad a Tourdroid, como un valor agregado, algo que solo era posible al modificar manualmente la base de datos contenida en el dispositivo móvil.

Se validó el sistema mediante una estrategia de pruebas que demostró el correcto funcionamiento de la aplicación, así como la satisfacción del cliente con el producto ofrecido. Las pruebas realizadas fueron un elemento crítico para la garantía de calidad del software y representaron una revisión final de las especificaciones, el diseño y la codificación. 


\section{REFERENCIAS BIBLIOGRÁFICAS}

3DVista. (2016). Retrieved June 13, 2017, from http://www.3dvista.com/es/products/virtualtour

Abel Meneses. (2009). SXP, Metodología ágil para el desarrollo de software.

Geany. (n.d.). Retrieved from http://geany.org

Integrated development environment. (n.d.). Retrieved from http://www.pcmag.com/ encyclopedia/term/44707/ide.

Isabel Garcia, A. M. (2003, September). Introducción a la programación con Python.

Juan Pablo Quiroga. (n.d.). Requerimientos Funcionales y No Funcionales.

Metodologías Tradicionales vs. Metodologías Agiles. (2010). Universidad Técnica Particular de Loja, Ecuador.

Raúl. (2012, November 21). En la nube TIC. Retrieved June 13, 2017, from http://www.enlanubetic.com.es/2012/11/imagenes-panoramicas-condermandar.html

Roger S. Pressman. (2002). Ingeniería del Software: Un enfoque práctico (Quinta). McGrawHill.

VISUAL PARADIGM. UML tool, business process modeler and database desig-ner for software development team. (n.d.). Retrieved from http://www.visual-paradigm.com 


\title{
BUSINESS MODEL CANVAS AS A TOOL OF ENTREPRENEURS FOR DISABLED PEOPLE. AN APPROACH FROM TECHNOLOGY
}

\author{
Enrique Xavier Garcés ${ }^{1}$ \\ Galo Mauricio López ${ }^{2}$ \\ Verónica Maribel Pailiacho ${ }^{3}$
}

1. Ingeniero de Sistemas y Computación. Magister en Administración de Empresas, mención Planeación. Magister en Tecnologías de la Información. Pontificia Universidad Católica del Ecuador, Docente de la Escuela de Ingeniería en Sistemas, Ambato - Ecuador. E-mail: egarces@pucesa.edu.ec

2. Ingeniero en Sistemas. Magister en Informática. Docente de la Escuela de Ingeniería en Sistemas, Pontificia Universidad Católica del Ecuador, Ambato - Ecuador. E-mail: glopez@pucesa.edu.ec

3. Ingeniera en Sistemas Informáticos. Magister en Gerencia Informática. Pontificia Universidad Católica del Ecuador, Docente de la Escuela de Ingeniería en Sistemas, Ambato Ecuador. E-mail: vpailiacho@pucesa.edu.ec

\section{Citación sugerida:}

Garcés, E.X., López, G.M. y Pailiacho, V.M. (2017). Lienzo de modelo de negocios como herramienta de emprendimiento para personas con capacidades especiales. Un enfoque desde la tecnología. 3C TIC: Cuadernos de desarrollo aplicados a las TIC, 6(2), 52-69. DOI: <http://dx.doi.org/10.17993/3ctic.2017.56.52-69/>. 


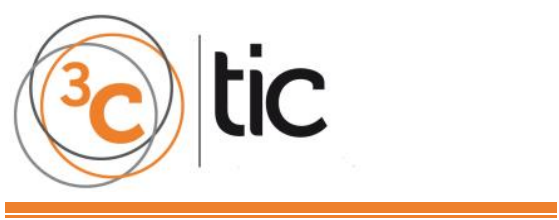

\section{RESUMEN}

En el presente artículo se detalla el uso de la tecnología y la aplicación del lienzo del modelo de negocios como una herramienta de emprendimiento para personas con capacidades especiales, y se describe cómo se estructuró un aula virtual con cinco bloques de aprendizaje que permitieron el estudio de: Introducción a la plataforma, Lienzo de modelo de negocios, El emprendimiento, Consideraciones legales para emprender y Herramientas tecnológicas para emprendedores. Al finalizar el evento, se logró fomentar la cultura del emprendimiento en las personas con capacidades especiales, a través del desglose de los factores claves de un negocio y la puesta en marcha con herramientas digitales.

\section{ABSTRACT}

This article details the use of technology and the Business Model Canvas application as an entrepreneurship tool for disabled people, and it was described how a virtual class was structured with five learning blocks that allowed the study of: Introduction to the platform, business model canvas, the Entrepreneurship, Legal considerations to undertake and Tech tools for entrepreneurs. At the end of the event, it was possible to promote entrepreneurship culture in people with disabilities, through the breakdown of the business key factors and the Start up with digital tools.

\section{PALABRAS CLAVE}

Emprendimiento, herramientas tecnológicas, capacidades especiales, modelo de negocio CANVAS, educación virtual.

\section{KEY WORDS}

Entrepreneurship, technology tools, disabled people, Business model canvas, e-learning. 


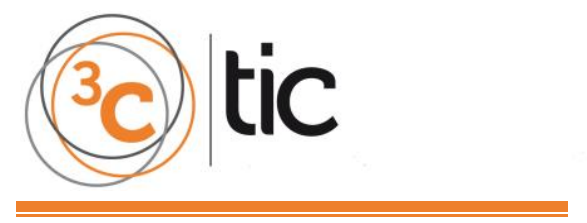

\section{INTRODUCCIÓN}

Al plantear una idea inicial de un negocio, ésta no resulta sencilla de trasladar desde la mente del emprendedor a una realidad tangible, de manera que pueda ser rentable a corto o mediano plazo. Es por ello que las distintas escuelas de negocio plantean estrategias que permitan asegurar que la iniciativa pueda tener éxito. $Y$ es que estos distintos modelos no siempre representan las mejores soluciones para las necesidades.

Así, nace una herramienta que describe de manera lógica la forma en que las organizaciones crean, entregan y capturan valor de sus ideas y negocios, ésta herramienta es el modelo Canvas. Éste modelo plantea un anteproyecto básico y ágil para diseñar e innovar en el modelo de negocio.

Bajo estas premisas se busca fortalecer la cultura de emprendimiento por medio del modelo Canvas en personas con capacidades especiales, detectando sistemáticamente los elementos que generan valor a un posible negocio, usando para esto los nueve módulos básicos del modelo que explican el proceso cómo una empresa genera ingresos y hace rentable un emprendimiento. Así también, se plantean los mecanismos y las herramientas tecnológicas que deben conjugarse con el modelo Canvas para generar conocimientos en el manejo de herramientas para emprender negocios que tengan una plataforma de difusión por medio de internet.

\section{CONTEXTUALIZACIÓN}

Existen numerosos factores que determinan el éxito de un negocio, en este contexto toma importancia el concepto de modelo de negocio; así, para Blasco, (2015) es una herramienta conceptual cuyos elementos se relacionan para expresar la lógica del negocio. Laos Sudea (2006) establece que el plan de negocios detalla información de la empresa o del negocio, sin tener un modelo concreto plasmando las propias ideas y hasta donde se quiere llegar. En tanto, Mendoza, (2012) plantea al modelo de negocio como una "simplificación que describe las bases sobre las que una empresa va a tratar de crear valor". En definitiva, un modelo de negocio es el mecanismo por el que se busca generar ingresos.

Osterwalder \& Pigneur, (2013) con la idea de simplificar este mecanismo plantean una herramienta que la llaman el lienzo del modelo de negocio (Business Model Canvas), en el que según Castro \& Rufino (2015) se pretende desglosar el concepto en partes más pequeñas para ser analizadas individualmente o mediante el análisis de sus interrelaciones. 

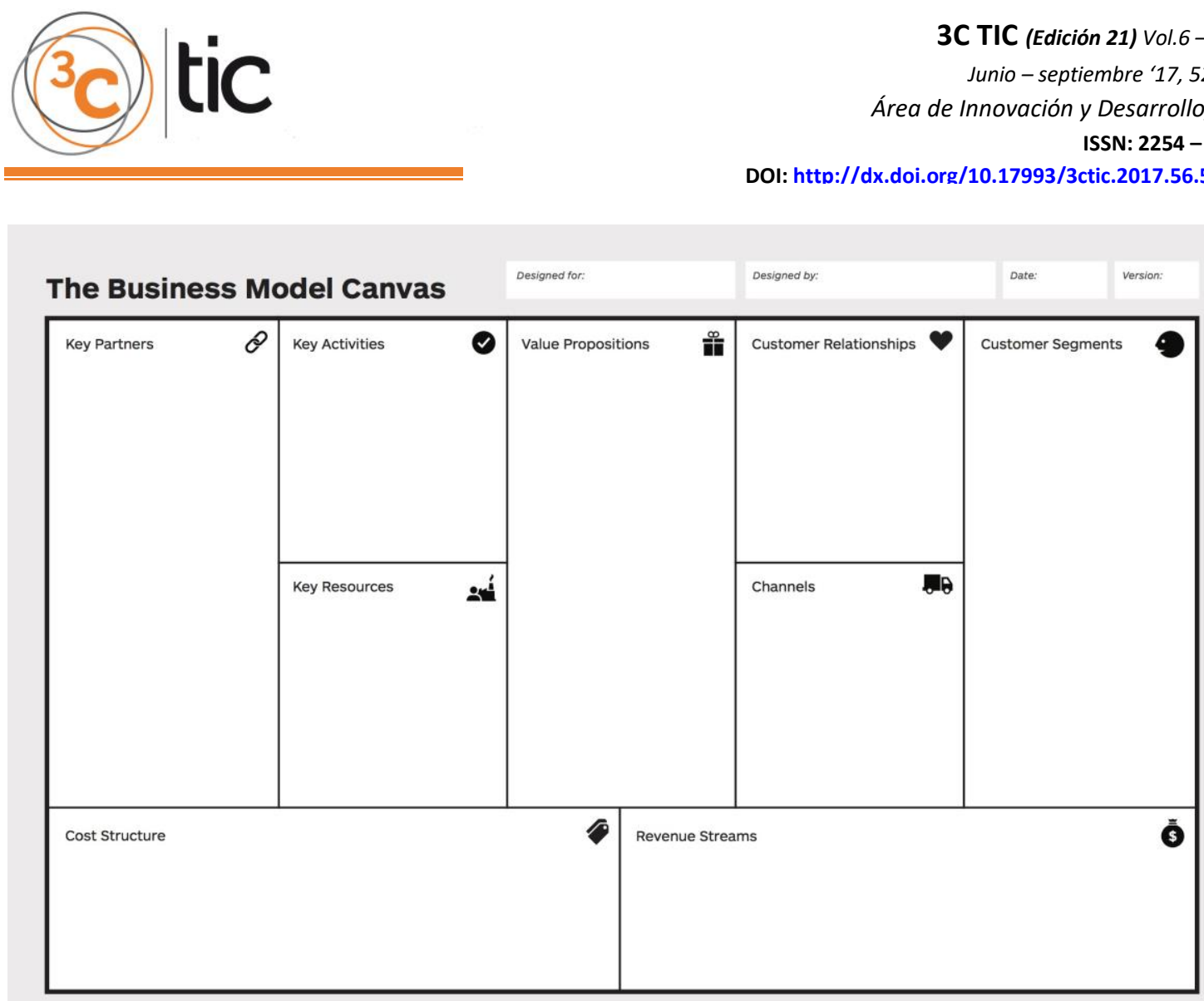

Figura 13. Business Model Canvas.

Fuente: Strategyzer.com.

Estas partes más pequeñas permiten describir de manera intuitiva el negocio y específicamente los factores o módulos que lo conforman, es decir: clientes, oferta, infraestructura y viabilidad económica. Los nueve módulos que conforman la propuesta de lienzo del negocio son:

- Segmentos de mercado: también llamado Clientes, según lo mencionan Silva et al. (2014), el mercado son las personas y organizaciones que están interesadas y dispuestas a comprar un producto en particular para satisfacer un deseo o necesidad particular disponiendo de recursos de dinero y tiempo para dicha actividad.

- Propuesta de valor: describe los productos o servicios que se van a proponer con el objeto de generar valor, es decir, se describe él o los problemas a solucionar o la necesidad a satisfacer del segmento de mercado, según lo plantean Castro \& Rufino (2015).

- Los canales: para Paz, (2008) "son las actividades necesarias para poner el producto al alcance del consumidor meta, con el objetivo de facilitar su compra", es decir, son los canales para producir el contacto con los clientes.

- Relaciones con los clientes: en este apartado se define el tipo de relación que se desea establecer con el segmento de mercado o cliente objetivo del emprendimiento. 
- Fuentes de ingresos: representa las arterias del negocio, por cuanto establece los distintos flujos de ingreso por medio de los cuales se crea y genera valor en el mercado.

- Recursos clave: Castro y Rufino, (2015) explican que: "para crear valor, distribuirlo a sus segmentos de mercado, establecer relaciones con sus clientes y conseguir ingresos, requiere unos determinados recursos clave"; es decir representan los activos más importantes para hacer funcionar un negocio.

- Actividades clave: describen las acciones más importantes que cumple la empresa para que el negocio funcione.

- Asociaciones clave: se detalla la red de proveedores y socios que hacen funcionar el modelo de negocio. Pueden constituirse en alianzas para reducir riesgos o para adquirir recursos.

- Estructura de costos: según Castro y Rufino (2015) se deberán detallar los costos de la operación del negocio y será imprescindible tratar de minimizarlos.

En los siguientes apartados se fundamentarán aspectos sobre la modalidad virtual en la que se desarrolló el presente trabajo y el apoyo de herramientas tecnológicas y redes sociales.

Cruz, (2015) menciona que la formación a distancia es un sistema de educación que reemplaza la interacción en el aula por una acción conjunta de elementos didácticos de apoyo tutorial y aprendizaje autónomo, esto dispuesto en algún medio. En el caso descrito en el presente artículo, los elementos didácticos están dispuestos en un entorno virtual de aprendizaje organizado en bloques de aprendizaje que incluyen contenidos, recursos y actividades dispuestas de forma que se da respuesta a una necesidad de enseñanza flexible.

Según (Cruz, 2015) establece que "la eficacia de la educación a distancia depende de una adecuada organización de los elementos que intervienen en ella", por lo que se sugiere poner énfasis en:

- Plantear adecuadamente los contenidos que se van a desarrollar, y

- Organizar adecuadamente la acción formativa, ya sea por medio de apoyo tutorial, expertos en elementos tecnológicos, etc.

Como se mencionó, los beneficiarios son personas con capacidades especiales. Asís, (2015) menciona que "la discapacidad es un concepto que evoluciona y que resulta de la interacción entre las personas con deficiencias y las barreras debidas a la actitud y al entorno que evitan su participación plena y efectiva en la sociedad (...)". En tal sentido, el proyecto que resulta en el presente artículo pretende romper esas barreras por medio de elementos tecnológicos, usados en la construcción del Lienzo del modelo de negocio que permita justamente lo que se mencionó y es: permitir una participación plena y efectiva en la sociedad de las personas con capacidades especiales. 
Según Organismos internacionales, se menciona que existen en el mundo millones de personas con discapacidad en edad de trabajar. Según De Lorenzo (2004) son personas que tienen todo el potencial para incorporarse en algún trabajo, o desarrollar y emprender el suyo propio. Algunas empresas han descubierto ese potencial y muchos gobiernos han definido leyes que impulsan la ocupación de personas con estas capacidades especiales. Sin embargo, muchas personas con discapacidad viven en condiciones económicas no tan favorables y su situación relativa al empleo es sombría.

Según la Ley Orgánica de Discapacidades de la República del Ecuador (2012) aprobada en la Asamblea Nacional y publicada en el Registro Oficial del 25 septiembre del 2012 "se considera persona con discapacidad a toda aquella que, como consecuencia de una o más deficiencias físicas, mentales, intelectuales o sensoriales, con independencia de la causa que la hubiera originado, ve restringida permanentemente su capacidad biológica, sicológica (...)"; constituyéndose esta ley en un instrumento de lucha para lograr la participación y la igualdad de las personas con discapacidad, en defensa de la diversidad y de la búsqueda de soluciones innovadoras e inclusivas para el futuro.

De aquí se pueden desprender algunas oportunidades de inserción de personas con discapacidad en los mercados de trabajo, siendo más humano y socialmente digno además de rentable en términos económicos que estas personas desempeñen un rol activo y productivo, en lugar de ser entes pasivos y dependientes. Una de estas opciones de inserción es la del Emprendimiento, visto este como empleo autónomo o autoempleo con un gran potencial para las personas con discapacidad, mismo que se ha visto incrementado con el desarrollo de la informática, del teletrabajo y del comercio electrónico.

Según Senent y Ventura (2013); Moreno (2016); Osorio, Murillo y Gonzaléz (2015), emprendimiento proviene del francés entrepreneur que significa pionero, refiriéndose así a la capacidad de una persona para hacer un esfuerzo adicional por alcanzar una meta u objetivo, usándose también para referirse a la persona que inicia una nueva empresa o proyecto, en lo posterior este término fue aplicado a empresarios que fueron innovadores o agregaban valor a un producto o proceso ya existente. Esta persona tiene una necesidad de realización personal, aceptando los riesgos moderados y buscando ser autónomo e independiente.

Así, en una sociedad cada vez más individualizada en la que las relaciones sociales se desarrollan con mayor frecuencia de manera virtual, se busca por medio del apoyo tecnológico desarrollar la capacidad innata de emprender de las personas con capacidades especiales usando para ello el apoyo del Lienzo de Modelo de Negocio como herramienta que detone la idea y encamine a vencer la resistencia de las personas a arriesgar y emprender. Todo esto con una perspectiva y asesoramiento que garantice el mayor grado de autonomía del emprendedor o al apoyarse en la educación virtual. 


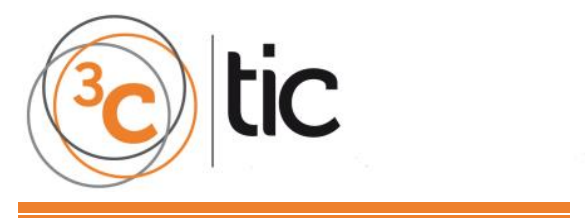

\section{DESARROLLO}

Para el desarrollo del evento de capacitación se estableció la secuencia de los módulos, de tal manera que la idea plasmada en el lienzo de modelo de negocios se pueda promocionar usando canales tecnológicos pertenecientes al social media, por lo que el aula virtual se dividió en cinco bloques de aprendizaje: Inducción a la plataforma educativa de la Universidad, Generación de un modelo de negocios utilizando el modelo canvas, el Emprendimiento, Consideraciones legales para emprender y Herramientas tecnológicas para emprender.

El público objetivo de esta capacitación, como se mencionó, son personas con discapacidad auditiva, visual o mental en un ligero grado, de tal manera que puedan realizar las actividades planteadas dentro de los bloques. Por tal razón, se definieron políticas de desarrollo de contenido para facilitar el proceso de aprendizaje teniendo en cuenta la condición de los asistentes y políticas de accesibilidad digital que proponen W3C, la Guía digital del Gobierno de Chile, Aguila et al. (2015) las cuales se resumieron en: escribir contenido en texto con tamaño de letra de 12 puntos, con tipografías de la familia Sans Serif, interlineado para agrupar en párrafos los textos, con lo se facilita su comprensión, alineación a la izquierda para ubicar fácilmente la línea en la que se encuentra el lector. Además, no apoyarse en colores de texto para fortalecer o denotar importancia en actividades o información, esto debido a los posibles problemas de daltonismo en los participantes, para usar videos se plantea colocar un texto resumen para apoyar el contenido y su fácil comprensión. La figura 2 y 3 evidencian errores comunes del texto respecto a las políticas de accesibilidad.

\section{Ideas generales:}

Para iniciar el trabajo de encontrar una idea vamos a partir de observar nuestro alrededor, que cosas pasan junto a nosotros, les invito a buscar esos problemas que están en el día a día nuestro.

Vamos a identificar problemas y cuales podrían ser las soluciones o solución que podría plantear, identificar quienes son o serían los usuarios o clientes a los cuales les ayudaría la solución (hipótesis) que estoy planteando, puede ser que la solución este ya planteada en el mercado, con lo cual mi nueva solución debería tener algo que la haga diferente o entregue un valor agregado nuevo.

Para hacer esto voy a explicarles valiéndome de la idea de Dan Roam que plantea el poder explicar el mundo en forma visual y encontrar soluciones a problemas en base a gráficos, si desean saber más sobre su obra les invito a leer el libro "tu mundo en una servilleta"

Figura 2. Ejemplo erróneo de texto apoyado en colores. 


\begin{abstract}
Ideas generales:
Para iniciar el trabajo de encontrar una idea vamos a partir de observar nuestro alrededor, que cosas pasan junto a nosotros, les invito a buscar esos problemas que están en el día a día nuestro.

Vamos a identificar problemas y cuales podrian ser las soluciones o solución que podria plantear, identificar quienes son o serian los usuarios o clientes a los cuales les ayudaria la solución (hipótesis) que estoy planteando, puede ser que la solución este ya planteada en el mercado, con lo cual mi nueva solución debería telner algo que la haga diferente o entregue un valor agregado nuevo.

Para hacer esto voy a explicarles valiéndome de la idea de Dan Roam que plantea el poder explicar el mundo en forma visual y encontrar soluciones a problemas en base a gráficos, si desean saber más sobre su obra les invito a leer el libro "tu mundo en una servilleta"
\end{abstract}

Figura 3. Ejemplo erróneo en la selección de la tipología.

Aplicando los lineamientos se presenta el mismo texto cumpliendo con los parámetros de accesibilidad, los mismos que se aplicaron en todos los contenidos del evento de capacitación.

\title{
Ideas generales:
}

Para iniciar el trabajo de encontrar una idea vamos a partir de observar nuestro alrededor, que cosas pasan junto a nosotros, les invito a buscar esos problemas que están en el día a día nuestro.

Vamos a identificar problemas y cuales podrían ser las soluciones o solución que podría plantear, identificar quienes son o serían los usuarios o clientes a los cuales les ayudaría la solución (hipótesis) que estoy planteando, puede ser que la solución este ya planteada en el mercado, con lo cual mi nueva solución debería tener algo que la haga diferente o entregue un valor agregado nuevo.

Para hacer esto voy a explicarles valiéndome de la idea de Dan Roam que plantea el poder explicar el mundo en forma visual y encontrar soluciones a problemas en base a gráficos, si desean saber más sobre su obra les invito a leer el libro "tu mundo en una servilleta"

Figura 4. Material diseñado aplicando los acuerdos.

El evento inicia con 108 inscritos, el primer bloque de inducción a la plataforma tuvo una duración de una semana y permitió a los usuarios capacitarse en el uso de la tecnología del entorno virtual de aprendizaje de la Universidad. 


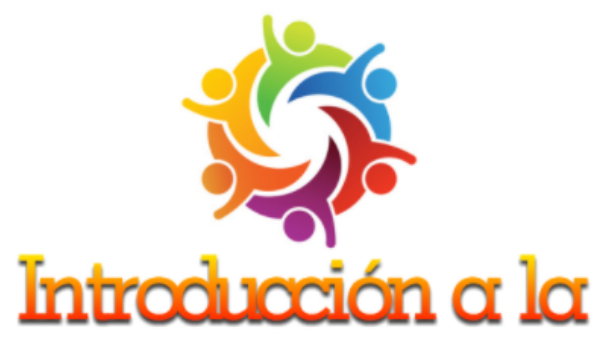

plataforma educativa

(2.)

Información general para revisar:

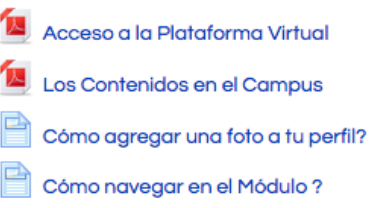

Foros

Figura 5. Bloque de aprendizaje: Introducción a la plataforma educativa.

El siguiente bloque se llama Modelo de negocio, para lo cual se utilizó el lienzo de modelo de negocios planteado por Osterwalder, dado que es una herramienta en la cual se puede plasmar los nueve componentes importantes para definir un modelo de negocio.

El modelo, como se explicó en el punto anterior, es una herramienta muy útil para validar y pulir una idea de emprendimiento o un negocio en funcionamiento. Dentro de este módulo se realizó un proceso de validación de ideas aplicando retroalimentación con tutores, estudiantes de apoyo de la Universidad y personas que ellos consideraron que podía enriquecer sus ideas, con el paso de los días e iteraciones, sus propuestas solucionaron una necesidad del entorno y el tiempo destinado a esta fase fue de dos semanas. 


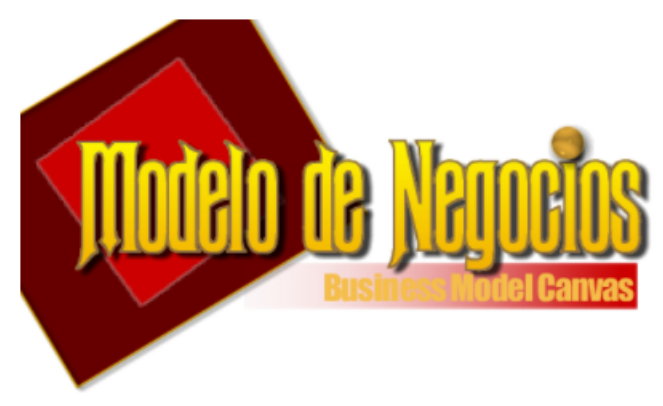

Información general para revisar:

西

Lineamientos generales y bienvenida al módulo

面 Rúbrica evaluación módulo

扈 Necesitas Ayuda módulo: Moledo de negocio

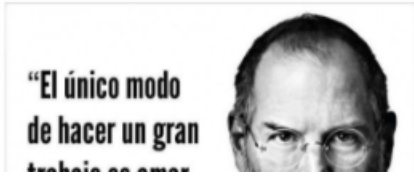

Figura 6. Bloque de aprendizaje: Modelo de negocios Business model canvas.

El tercer bloque se centró en el tema del Emprendimiento, en lo cual se expuso conceptos y herramientas que ayudaron a fortalecer la cultura de emprendimiento, afinando los modelos de negocios planteados. Se presentó contenido que les permitió escribir de forma rápida un plan a seguir para emprender mediante un pequeño plan de negocios, el tiempo de este bloque fue de tres semanas. 


\section{emprendimiento}

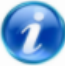

Información general para revisar:

Bienvenidos participantes a esta etapa del desarrollo de de Herramientas Tecnológicas de Emprendimiento, en la cual durante estas tres proximas semanas trabajaremos sobre el Emprendimiento.

Revisaremos varios temas relacionados al Emprendimiento, los cuales les ayudará al final de este modulo a plantear su propuesta en un Plan de emprendimiento.

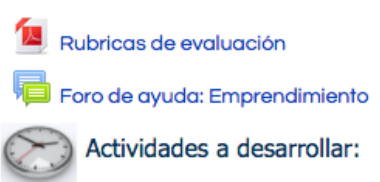

En este punto, los participantes del curso ya definieron y mejoraron sus ideas de emprendimiento, las cuales se fueron ajustando dentro de los elementos del lienzo de negocios, pues es la herramienta que debe estar presente todo el tiempo. El bloque de Consideraciones legales presentó material que cubre temas del aspecto legal de contratación de personal, aspectos Societarios y de Economía Popular y Solidaria aplicados dentro de las Leyes del Ecuador, temas que en el futuro pueden ayudar a no tener problemas legales por desconocimiento de leyes y reglamentos que regulan un negocio. El tiempo invertido en esta fase fue de dos semanas. 


\section{Consideraciones Legales \\ para emprender}

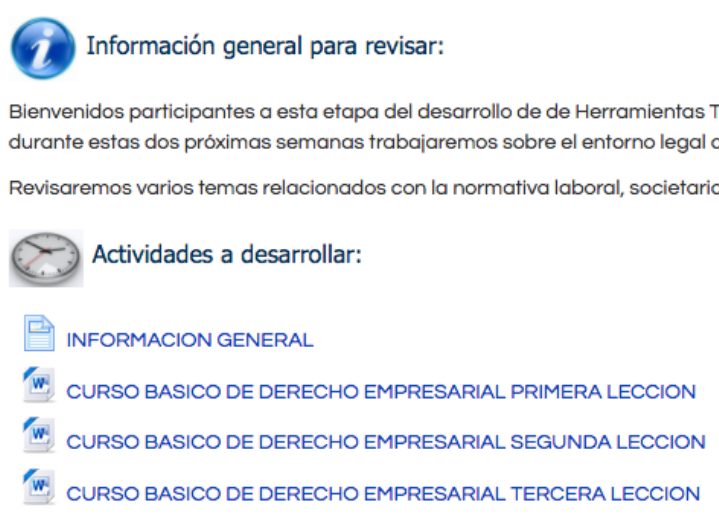

Figura 8. Bloque de aprendizaje: Consideraciones legales para emprender.

Finalmente, el bloque de Herramientas tecnológicas les permitió aplicar medios digitales para difundir sus emprendimientos. Se tomó a Facebook como una herramienta de social media por sus políticas de fan page que cubren las necesidades del sector empresarial, además de utilizar entornos de market place como Mercado libre y OLX, el tiempo para esta fase fue de tres semanas. 

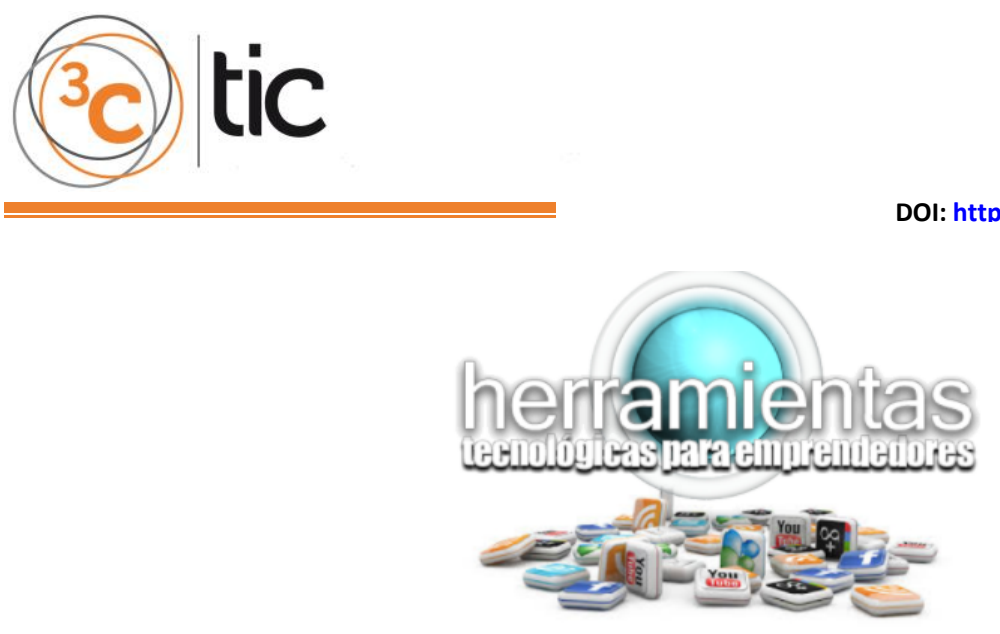

En esta sección aprenderemos a usar varias herramientas informáticas, que les permitirá poner en práctica su plan de negocio, usando herramientas en internet.

Cada semana se habilitará nuevos contenidos, podrá encontrar manuales y/o videos sobre los temas propuestos.

Si tiene dudas, respecto a las tareas recuerde escribir en el Foro de ayuda 911... ! que se encuentra en el bloque inicial del aula, siempre habrá alguien que pueda ayudarle a resolver sus dudas.

observe bien las fechas de entrega de las tareas, para no tener contratiempos al finalizar el módulo.

EXITOS!!!

Facebook para el emprendimiento

En el proceso de aprobación del curso desde el segundo bloque de capacitación, los participantes fueron entregando proyectos que fortalecen los modelos de negocios planteados, así como evaluaciones sobre los contenidos de las fases, el desarrollo de todo el proyecto se evidenció con los trabajos prácticos presentados en las diferentes plataformas de social media y market place mencionadas.

\section{RESULTADOS}

El evento finalizó con la aprobación de 74 personas, a las cuales se les aplicó una encuesta para conocer la percepción de la calidad del proyecto, sin embargo, solo se han considerado en este análisis las siguientes preguntas:

¿Le han parecido adecuados los objetivos y contenidos que se han planteado en el evento?

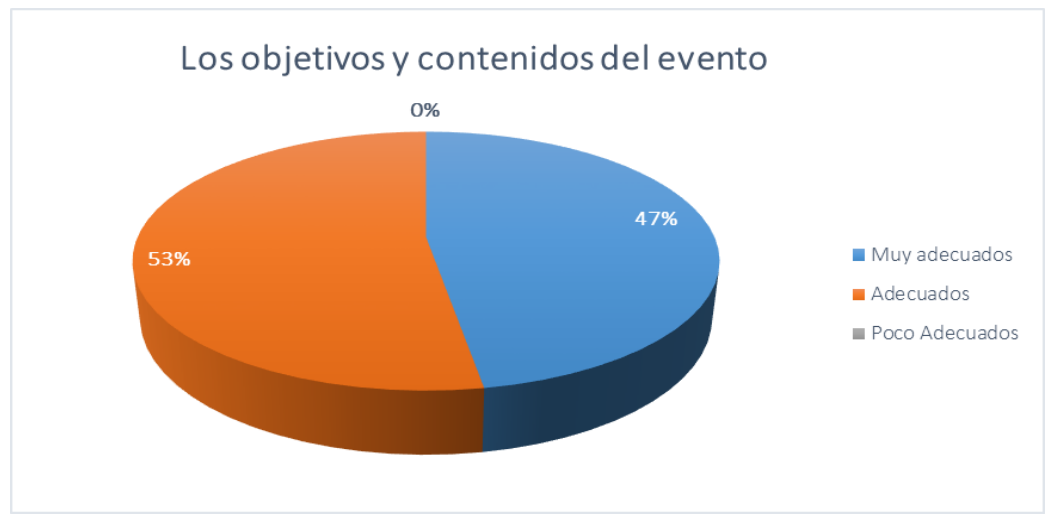

Figura 10. Diagrama estadístico sobre la apreciación de los objetivos y contenidos del evento.

Fuente: elaboración propia. 
Se puede observar que a la mayoría de personas les parecieron adecuados los objetivos y contenidos, apenas con una diferencia de 6 puntos menos los items en análsis fueron muy adecuados. Por lo que se puede concluir que tanto los objetivos como los contenidos fueron asimilados correctamente por los participantes.

¿Valora los conocimientos adquiridos en este evento?

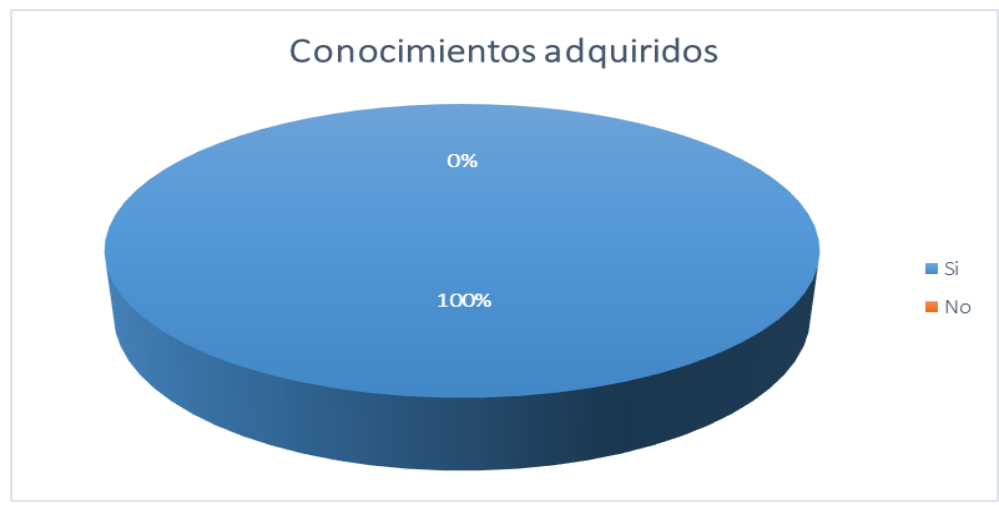

Figura 11. Diagrama estadístico sobre la apreciación de los contenidos adquiridos.

Fuente: elaboración propia.

Todos los participantes coinciden en que los conocimientos adquiridos durante el evento son válidos y oportunos, lo que reafirma que los contenidos desarrollados utilizando herramientas de educación b-learing se conjugaron correctamente, cumpliendo con los intereses de los participantes.

¿Con respecto a los módulos impartidos, en cuál tuvo más inquietudes?

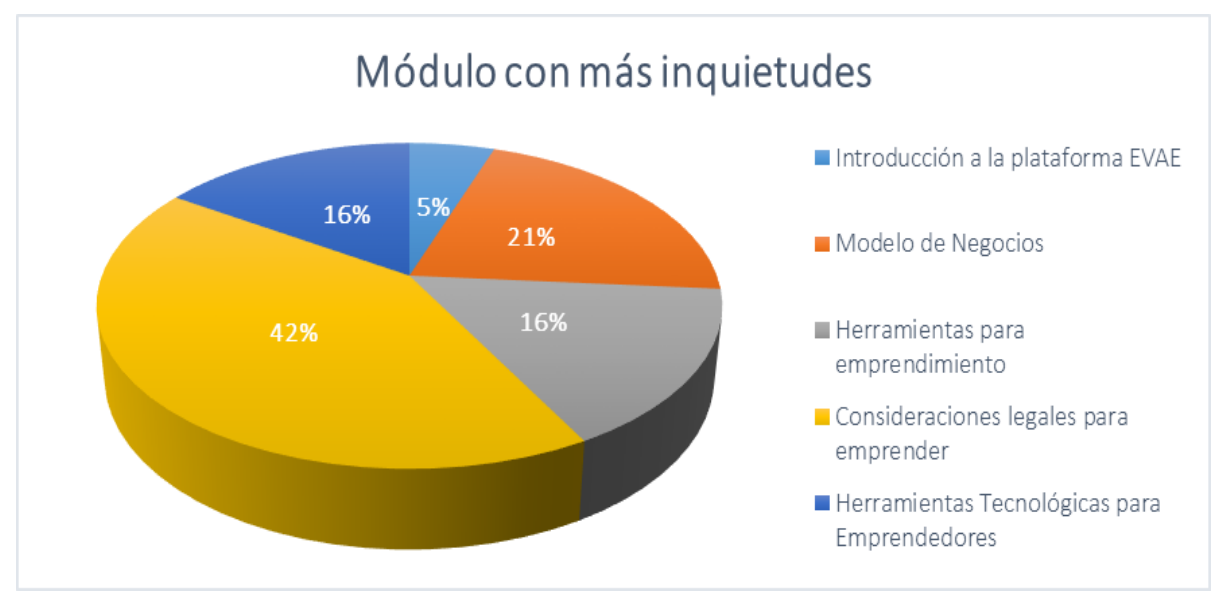

Figura 12. Diagrama estadístico sobre la apreciación de las inquitudes en los módulos estudiados.

Fuente: elaboración propia. 


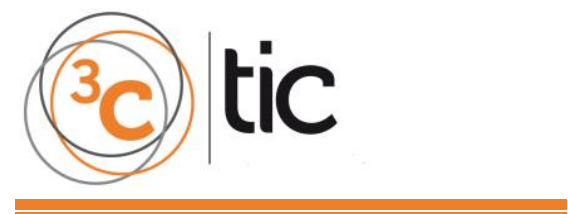

Se puede observar que el módulo Consideraciones legales para emprender precisó más tutorías virtuales en comparación con los otros. Esto se debe a que los aspectos legales tratados se deben revisar al detalle para poder aplicarlos en los emprendimientos.

Valore el evento a nivel global

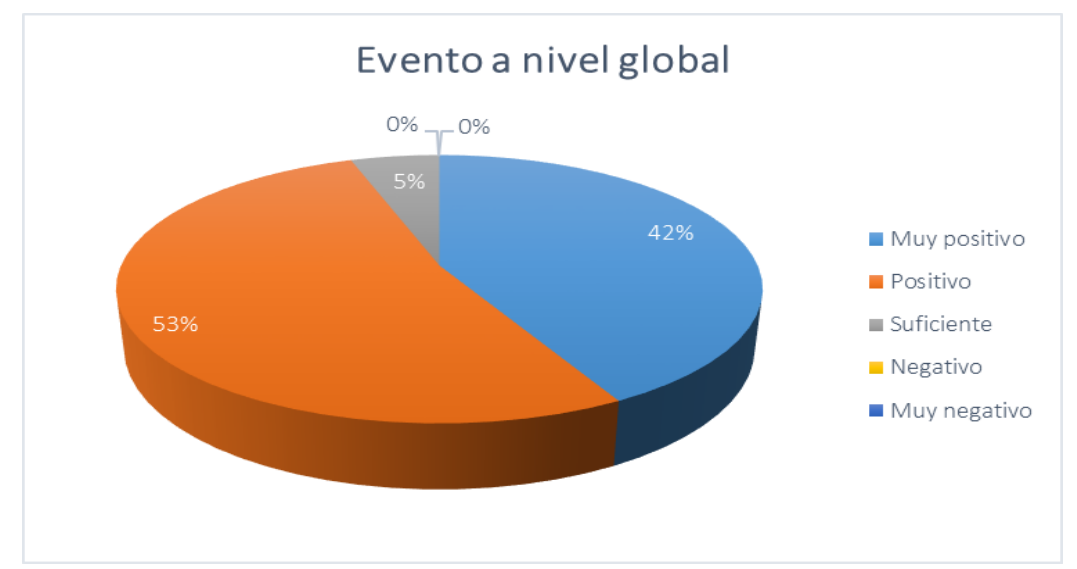

Figura 13. Diagrama estadístico sobre la valoración del evento a nivel global. Fuente: elaboración propia.

Se puede observar en el gráfico que el evento tuvo un excelente desarrollo, pues 9 de cada 10 participantes consideran que el evento cubrió sus expectativas y en general fue positivo.

Por la tanto, se puede resaltar que la enseñanza - aprendizaje del Modelo CANVAS a través del uso de herramientas tecnológicas para el emprendimiento tuvo buenos resultados y despertó el interés en la población objetivo. Tal es así que varias ideas de emprendimiento que surgieron de la capacitación se siguen desarrollando, como es el caso de:

- Mil aromas. - venta de perfumes bajo pedido

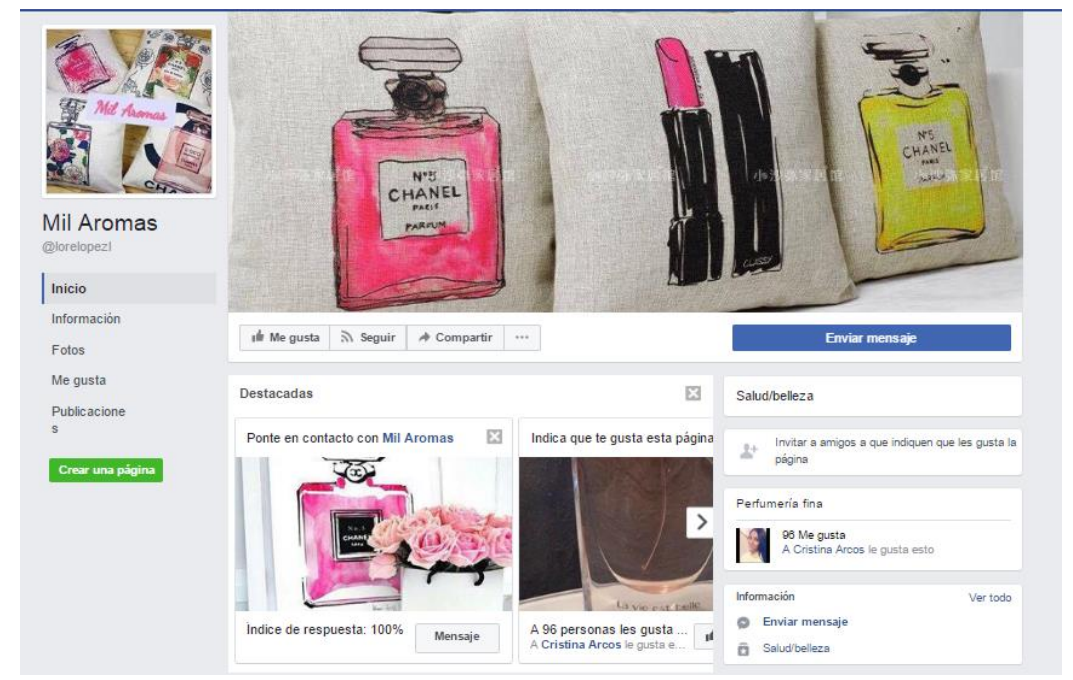

Figura 14. Fan page del emprendimiento Mil aromas.

Fuente: elaboración propia. 


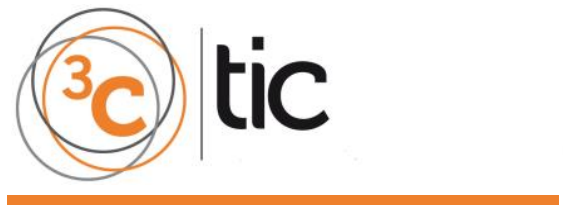

- Duel Corp.- es una tienda de Trading Card Game TCG, juegos y coleccionables en general.

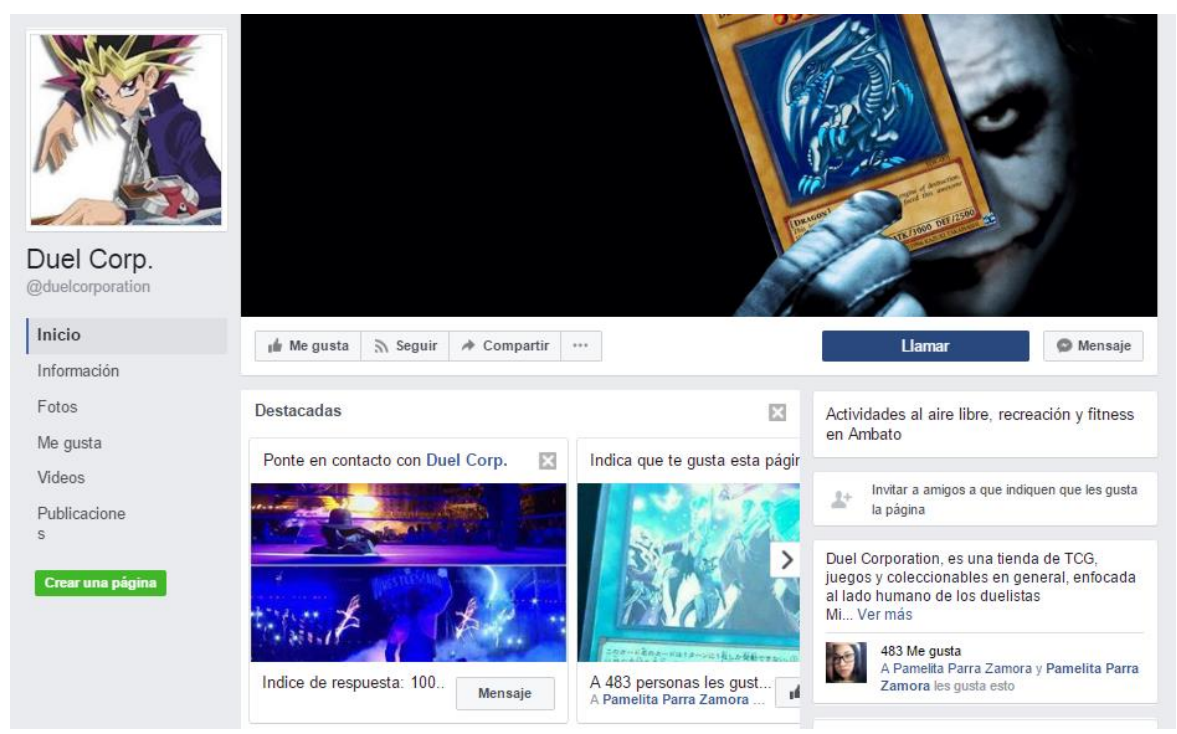

Figura 15. Fan page del emprendimiento Duel Corp.

Fuente: elaboración propia.

- Kprichos Kids.- Te ayudamos a organizar tu fiesta, con payasitos, mimos, coreografías, muñequitas, zanqueros, juegos y mucho más....!!!

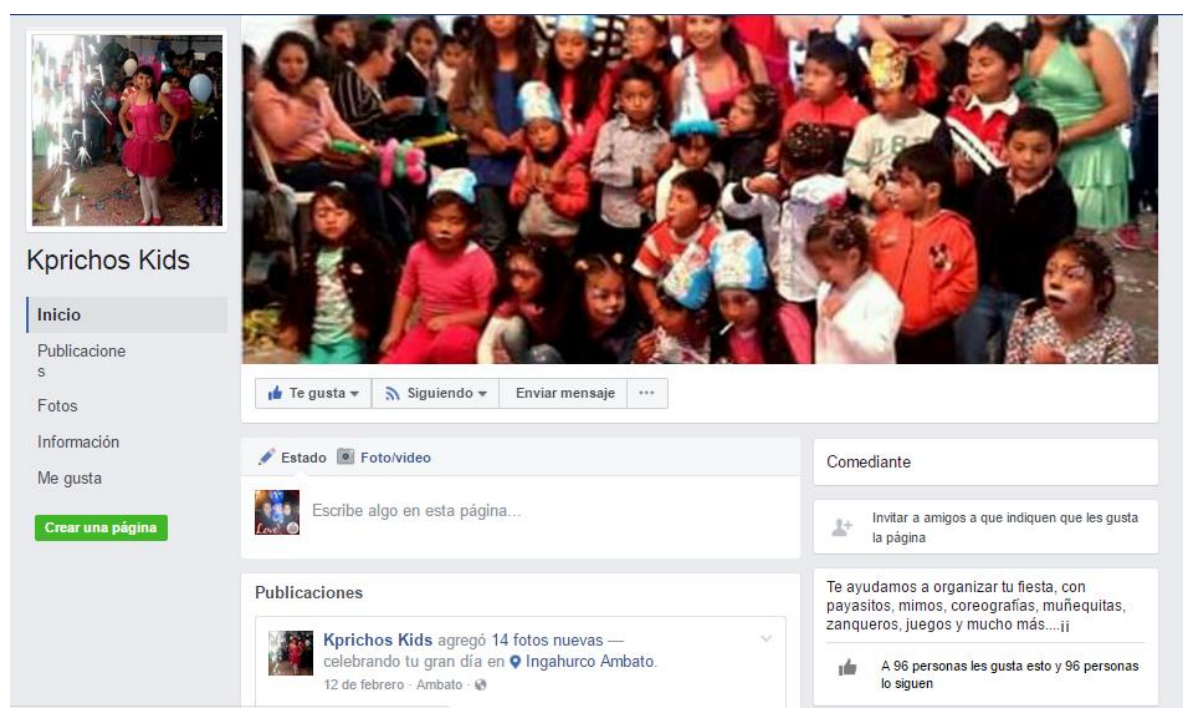

Figura 16. Fan page del emprendimiento Kprichos Kids.

Fuente: elaboración propia. 


\section{CONCLUSIONES}

- Los 74 participantes que aprobaron el evento, adquirieron la habilidad para describir de manera intuitiva un negocio en base al Lienzo de Modelo de Negocios, desglosando el modelo en partes más pequeñas, como son: ubicar el segmento de mercado, generar una propuesta de valor, definir los canales de comunicación, determinar las fuentes de ingreso, actividades y recursos claves, definir la estructura de costos. Es decir, siempre se consideró los factores: cliente, oferta, infraestructura y viabilidad económica.

- Según experiencias anteriores en la modalidad de educación e-learning, el nivel de deserción es alto y fue un reto mantener activos en el evento a las personas con capacidades especiales, por lo que el desarrollo del material bajo las políticas de accesibilidad expuestas, el seguimiento académico (tutorías virtuales) y el soporte a tiempo fueron las claves para lograr que el $68,52 \%$ aprueben la capacitación en esta modalidad de estudios.

- Las ideas de emprendimiento desarrolladas en el lienzo de modelo de negocios fueron puestas en marcha con herramientas de social media en esta caso Facebook y market place con aplicaciones como Mercado Libre y OLX, permitiendo a los participantes adquirir experiencia en el manejo del negocio, convirtiéndose así en personas económicamente activas sin necesidad de depender de un empleador, a través de un seguimiento se determinó que varios de los emprendimientos generados en la capacitación, aún se mantienen activos en Facebook. 


\section{REFERENCIAS BIBLIOGRÁFICAS}

Asís, R. (2015). Sobre discapacidad y derechos. Madrid, España: Dykinson.

Blasco Pérez, M.J. (2015). Nuevas finanzas para nuevos negocios. Barcelona, España: Editorial UOC.

Castro Abancéns, I., \& Rufino Rus, J.I. (2015). Creación de empresas para emprendedores. Madrid, España: Difusora Larousse - Ediciones Pirámide.

Cruz Rubio, M. (2015). Formación de formadores avanzado. Manual teórico. Madrid, España: Editorial CEP, S.L.

Cruz Rubio, M. (2015). Formación de Formadores. Manual teórico. Madrid, España: Editorial CEP,SL.

De Lorenzo, R. (2004). El futuro de los discapacitados en el mundo: el empleo como factor determinante para la inclusión. Revista del ministerio de trabajo y asuntos sociales, 50, 73-89.

Laos Sudea, J.A. (2006). Plan de negocios: una herramienta fundamental para las empresas con miras a exportar. Bogotá, Colombia: Universidad Cooperativa de Colombia.

Ley Orgánica de Discapacidades, 796 (Registro Oficial 25 de septiembre de 2012).

Mendoza, J.M. (2012). Decisiones estratégicas : macroadministración. Barranquilla, Colombia: Universidad del Norte.

Moreno Castro, T. (2016). Emprendimiento y plan de negocio. Santiago de Chile, CHILE: RIL editores. Retrieved from http://www.ebrary.com.

Osorio Tinoco, F., Murillo Vargas, G., \& González Campo, C. (2015). Emprendimiento, redes e innovación. Cali, COLOMBIA: Programa Editorial Universidad del Valle. Retrieved from http://www.ebrary.com.

Osterwalder, A., \& Pigneur, Y. (2013). Generación de modelos de negocio. Barcelona, España: Deusto.

Paz, H.R. (2008). Canales de distribución: gestión comercial y logística. Buenos Aires, Argentina: Ugerman Editor.

SantandreuMascarell, C., CanósDarós, L., \& Marín Roig, J.R. (s.f.). Business Model Canvas y redacción del Plan de Negocio.

Senent, V., \& Ventura, F. (2013). Emprendimiento con perspectiva de género en la economía social. Castellón de la Plana, España: Universitat Jaume I. Servei de Comunicació i Publicacions. Retrieved from http://www.ebrary.com.

Silva, H., Juliao, D., Ortiz, M., Martínez, D., González, J., \& Giraldo, M. (2014). Marketing: conceptos y aplicaciones. Barranquilla, Colombia: Universidad del Norte. 


\section{DECLARACIÓN ÉTICA SOBRE PUBLICACIÓN Y MALAS PRÁCTICAS}

La revista 3C TIC está comprometida con la comunidad académica y científica en garantizar la ética y calidad de los artículos publicados. Nuestra revista tiene como referencia el Código de Conducta y Buenas Prácticas que; para editores de revistas científicas define el COMITÉ DE ÉTICA DE PUBLICACIONES (COPE).

Así nuestra revista garantiza la adecuada respuesta a las necesidades de los lectores y autores; asegurando la calidad de lo publicado; protegiendo y respetando el contenido de los artículos y la integridad de los mismos. El Consejo Editorial se compromete a publicar las correcciones; aclaraciones; retracciones y disculpas cuando sea preciso.

En cumplimiento de estas buenas prácticas; la revista 3C TIC tiene publicado el sistema de arbitraje que sigue para la selección de artículos así como los criterios de evaluación que deben aplicar los evaluadores externos -anónimos y por pares; ajenos al Consejo Editorial-. La revista 3 C TIC mantiene actualizado estos criterios; basados exclusivamente en la relevancia científica del artículo; originalidad; claridad y pertinencia del trabajo presentado.

Nuestra revista garantiza en todo momento la confidencialidad del proceso de evaluación: el anonimato de los evaluadores y de los autores; el contenido evaluado; el informe razonado emitidos por los evaluadores y cualquier otra comunicación emitida por los consejos editorial; asesor y científico si así procediese.

Igualmente queda afectado de la máxima confidencialidad las posibles aclaraciones; reclamaciones o quejas que un autor desee remitir a los comités de la revista o a los evaluadores del artículo.

La revista 3C TIC declara su compromiso por el respecto e integridad de los trabajos ya publicados. Por esta razón; el plagio está estrictamente prohibido y los textos que se identifiquen como plagio o su contenido sea fraudulento; serán eliminados o no publicados de la revista 3 C TIC. La revista actuará en estos casos con la mayor celeridad posible. Al aceptar los términos y acuerdos expresados por nuestra revista; los autores han de garantizar que el artículo y los materiales asociados a él son originales o no infringen derechos de autor. También los autores tienen que justificar que; en caso de una autoría compartida; hubo un consenso pleno de todos los autores afectados y que no ha sido presentado ni publicado con anterioridad en otro medio de difusión. 


\section{DECLARACIÓN SOBRE LA PROPIEDAD INTELECTUAL}

Los autores/as que publiquen en esta revista aceptan las siguientes condiciones:

1. Los autores/as conservan los derechos de autor y ceden a la revista el derecho de la primera publicación; que permite a terceros utilizar lo publicado siempre que mencionen la autoría del trabajo y a la primera publicación en esta revista.

2. Los autores/as pueden realizar otros acuerdos contractuales independientes y adicionales para la distribución no exclusiva de la versión del artículo publicado en esta revista (p. ej.; incluirlo en un repositorio institucional o publicarlo en un libro) siempre que indiquen claramente que el trabajo se publicó por primera vez en esta revista.

\section{POLÍTICA DE ACCESO LIBRE}

Esta revista provee acceso libre inmediato a su contenido bajo el principio de que hacer disponible gratuitamente investigación al público apoya a un mayor intercambio de conocimiento global. 


\section{${ }^{3}$ ciencias}

\section{CONSEJO EDITORIAL}

\begin{tabular}{|ll|}
\hline \multicolumn{2}{|c|}{ COMPONENTES } \\
\hline Director & Víctor Gisbert Soler \\
\hline \multirow{2}{*}{ Editores adjuntos } & $\begin{array}{l}\text { María J. Vilaplana Aparicio } \\
\text { Inés Poveda Pastor } \\
\text { Vicente Sanchís Rico }\end{array}$ \\
\hline Editor asociado & David Juárez Varón \\
\hline
\end{tabular}

\section{COMITÉ CIENTíFICO TÉCNICO}

\begin{tabular}{|l|l|}
\hline ÁREA TEXTIL & $\begin{array}{l}\text { Prof. Dr. Josep Valldeperas Morell } \\
\text { Universidad Politécnica de Cataluña } \\
\text { España }\end{array}$ \\
\hline ÁREA FINANCIERA & $\begin{array}{l}\text { Prof. Dr. Juan Ángel Lafuente Luengo } \\
\text { Universidad Jaume I; Castellón de la Plana } \\
\text { España }\end{array}$ \\
\hline ORGANIZACIÓN DE EMPRESAS Y RRHH & $\begin{array}{l}\text { Prof. Dr. Francisco Llopis Vañó } \\
\text { Universidad de Alicante } \\
\text { España }\end{array}$ \\
\hline \multirow{2}{*}{ ESTADÍSTICA; INVESTIGACIÓN OPERATIVA } & $\begin{array}{l}\text { Prof. Dra. Elena Pérez Bernabéu } \\
\text { Universidad Politécnica de Valencia } \\
\text { España }\end{array}$ \\
\hline DERECHO & $\begin{array}{l}\text { Prof. Dra. María del Carmen Pastor Sempere } \\
\text { Universidad de Alicante } \\
\text { España }\end{array}$ \\
\hline INGENIERÍA Y TECNOLOGÍA & $\begin{array}{l}\text { Prof. Dr. David Juárez Varón } \\
\text { Universidad Politécnica de Valencia } \\
\text { España }\end{array}$ \\
\hline TECNOLOGÍA DE LA INFORMACIÓN Y LA & $\begin{array}{l}\text { Prof. Dr. Manuel Llorca Alcón } \\
\text { Universidad Politécnica de Valencia } \\
\text { España }\end{array}$ \\
\hline
\end{tabular}

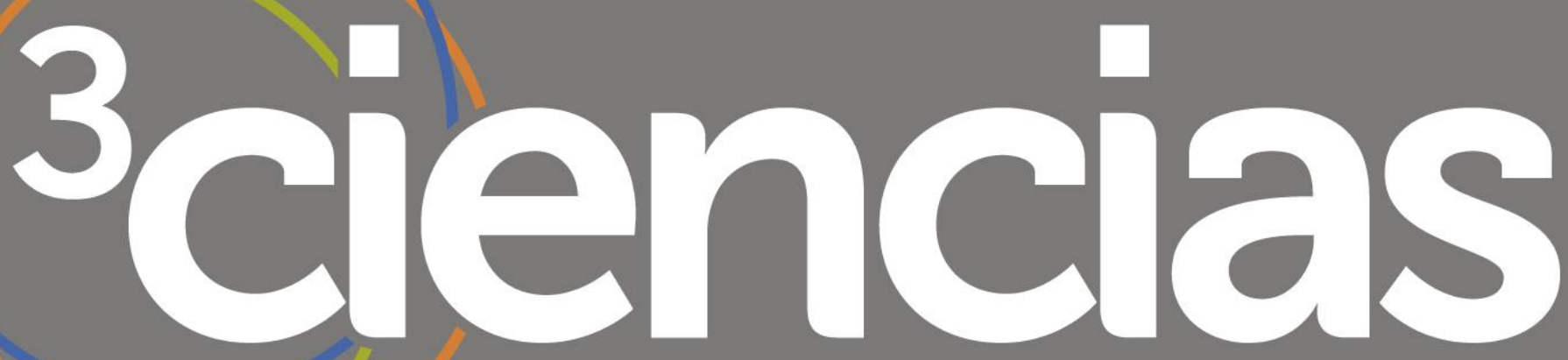


